Universidade de São Paulo

Faculdade de Medicina de Ribeirão Preto

Departamento de Genética

Proteínas do tegumento de abelhas Apis mellifera em metamorfose: identificação por espectrometria de massas

ANDRÉ FERNANDO DITONDO MICAS

Orientadora: Prof. ${ }^{\mathrm{a}} \mathrm{Dr}^{\mathrm{a}}$ Márcia Maria Gentile Bitondi

Ribeirão Preto 
Universidade de São Paulo

Faculdade de Medicina de Ribeirão Preto

Departamento de Genética

\title{
Proteínas do tegumento de abelhas Apis mellifera em metamorfose: identificação por espectrometria de massas
}

\begin{abstract}
Tese de Doutorado apresentada ao Departamento de Genética da Faculdade de Medicina de Ribeirão Preto da Universidade de São Paulo para obtenção de título de Doutor em Ciências.
\end{abstract}

Área de concentração: Genética

Aluno: André Fernando Ditondo Micas

Orientadora: Prof. ${ }^{\mathrm{a}} \mathrm{Dr}^{\mathrm{a}}$ Márcia Maria Gentile Bitondi

Ribeirão Preto 
FICHA CATALOGRÁFICA

Micas, André Fernando Ditondo

"Proteínas do tegumento de abelhas Apis mellifera em metamorfose: identificação por espectrometria de massas" / André Fernando Ditondo Micas; orientadora Márcia Maria Gentile Bitondi -Ribeirão Preto, 2012.

81 p.: il; $30 \mathrm{~cm}$

Tese de Doutorado (Área de Concentração: Genética) - Faculdade de Medicina de Ribeirão Preto da Universidade de São Paulo.

1. Apis mellifera2. Proteínas tegumentares3. Ecdisteróides4. Eletroforese bidimensional4. Maldi-MS5. Múltiplasformas eletroforéticas 


\section{PARECER DA BANCA EXAMINADORA}

André Fernando Ditondo Micas

Título da Tese: Proteínas do tegumento de abelhas Apis mellifera em metamorfose: identificação por espectrometria de massas

Tese de Doutorado apresentada ao Departamento de Genética da Faculdade de Medicina de Ribeirão Preto - USP como parte dos requisitos para título de Doutor em Ciências.

Área de Concentração: Genética

Aprovado em:

\section{Banca examinadora:}

Prof. Dr.

Instituição:

Parecer:

Assinatura:

Prof. Dr.

Instituição:

Parecer:

Assinatura:

Prof. Dr.

Instituição:

Parecer:

Assinatura: 
Prof. Dr.

Instituição:

Parecer:

Assinatura:

Prof. Dr.

Instituição:

Parecer:

Assinatura:

Ribeirão Preto, de de 2012. 


\section{AGRADECIMENTOS}

Este trabalho só foi possível através da participação direta e indireta de muitos colaboradores. O primeiro foi a Prof. a Márcia Maria Gentile Bitondi que aceitou o desafio de iniciar uma nova abordagem de estudo no seu laboratório, agradeço além da confiança, a sua paciência e dedicação. Agradeço também aos amigos do Laboratório de Química de Proteínas, do Hemocentro de Ribeirão Preto, começando pelo Dr. Lewis Greene e o Dr. José César Rosa por disponibilizarem a infraestrutura do seu laboratório. Ao Lucas Oliveira Souza que pacientemente ajudou muito na otimização da extração das proteínas do tegumento e também na focalização dos géis bidimensionais. À Carolina Hassibe Thomé e ao Germano Ferreira Aguiar pelo inestimável apoio durante todo o processo de elaboração, análise e interpretação dos géis bidimensionais e à Helen Julie Laure pela espectrometria de massas das amostras.

Gostaria de agradecer também à atenção e dedicação da equipe do CEMSA - Centro de Espectrometria de Massas Aplicada Ltda, em destaque ao Daniel Temponi Lebre.

Não poderia esquecer a ajuda da Juliana Ramos Martins na quantificação de RNA mensageiro por PCR em tempo real e à Michelle Prioli Soares pela análise dos dados. Este trabalho também só foi possível pelo apoio e dedicação dos técnicos Luiz Roberto Aguiar, Jairo de Souza e a Vera Lucia Castelo Figueiredo, principalmente na obtenção do material biológico.

Aos meus familiares por todo o apoio e paciência, principalmente no período de conclusão deste trabalho. À Pri, por todo o carinho e compreensão durante todo o período de elaboração da tese.

À Dra. Fátima, Dona Antonieta, Dona Elizete, Dona Luzia, Raquel, Mateus e Rafaela pelo inestimável estímulo e apoio neste período de tantas mudanças e desafios. A vocês, toda a minha gratidão.

Agradeço o apoio financeiro do CNPq e da FAPESP 


\section{SUMÁRIO}

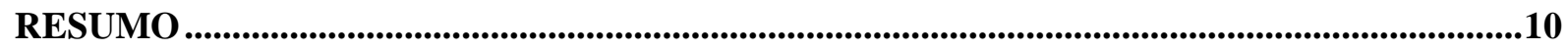

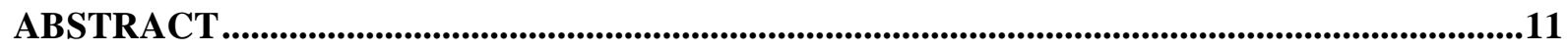

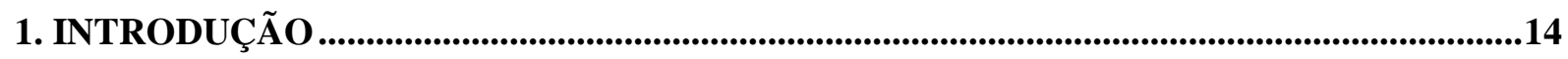

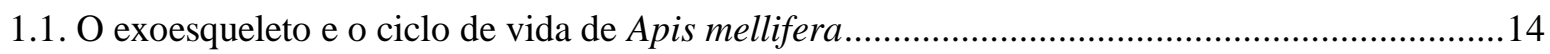

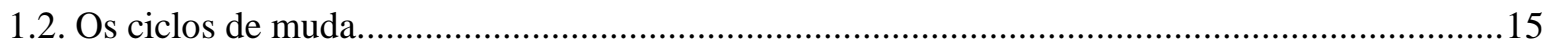

1.3. Os morfotipos da espécie A. melliferae a determinação de castas ...........................................16

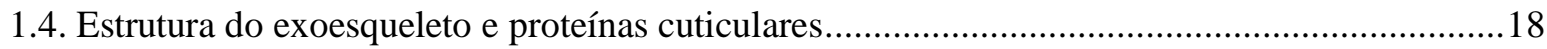

1.5. Estudos sobre a estrutura do tegumento e proteínas cuticulares de Apis mellifera ......................20

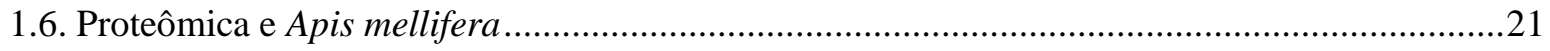



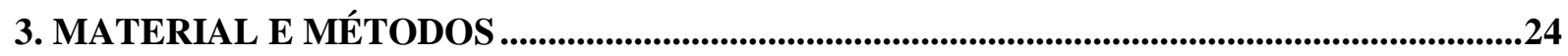

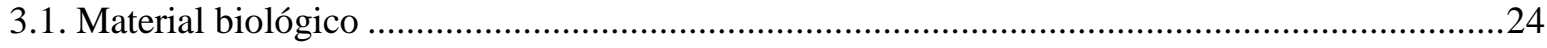

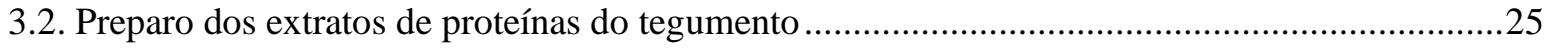

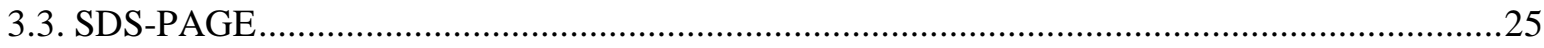

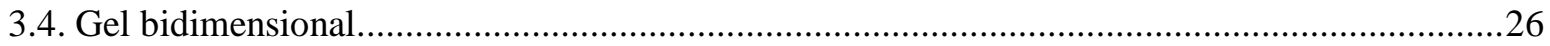

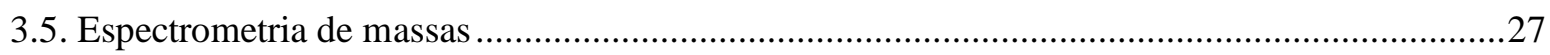



3.7. Extração do RNA totale síntese da primeira fita de cDNA ..........................................................28

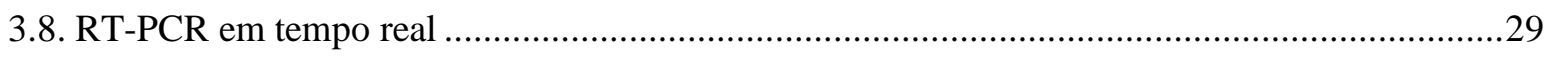



4.1. Avaliação dos métodos de extração das proteínas do tegumento .................................................31

4.2. Otimização da relação entre quantidade de proteína total $(\mu \mathrm{g})$ e número de spots bem definidos

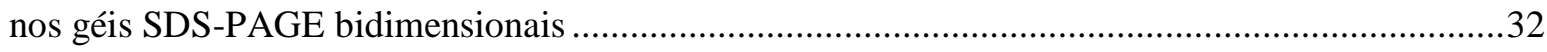

4.3. Caracterização e identificação de proteínas do tegumento de abelhas operárias e zangões em



4.4. Variação de massa molecular e pI das proteínas cuticulares com modificações pós-traducionais

4.5. Relação entre a expressão de proteínas do tegumento e dos genes que as codificam .................70



4.5.2. Larva (L5S) versus pupa $(\mathrm{Pw})$ versus adulta-farata $(\mathrm{Pbl})$.............................................. 72

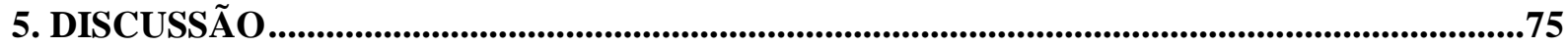

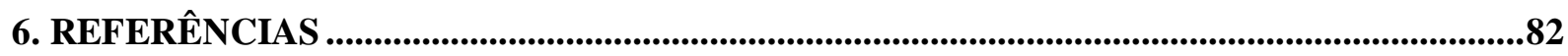




\section{ÍNDICE DE FIGURAS}

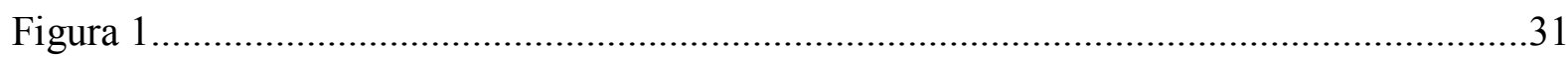

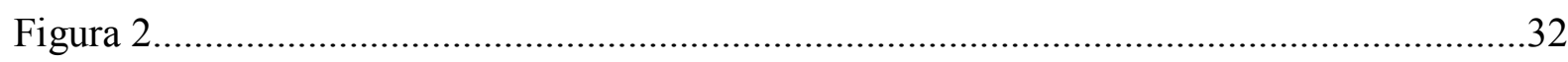



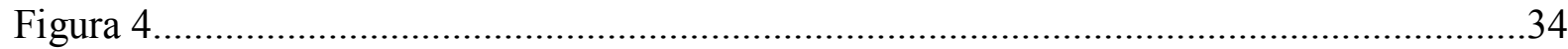







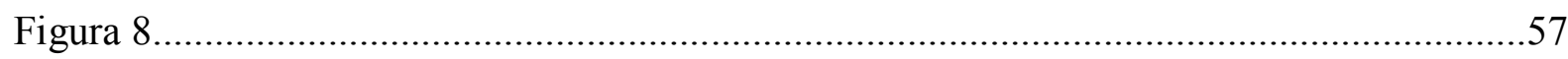

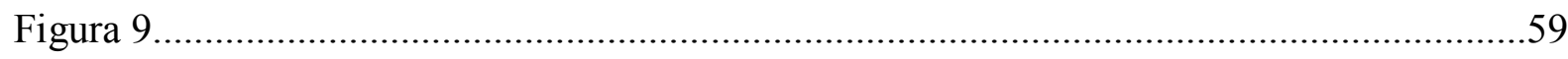



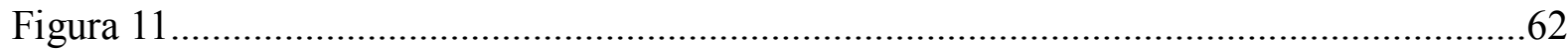



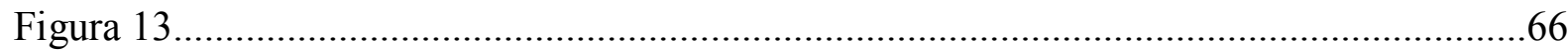

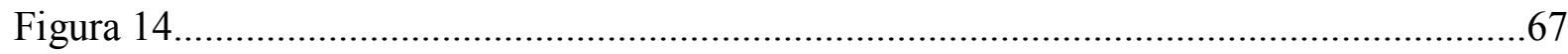

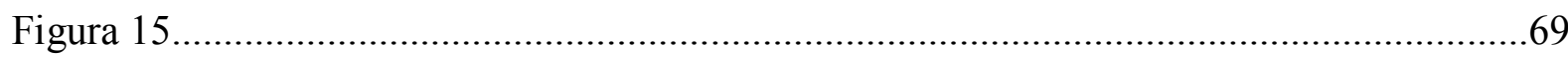

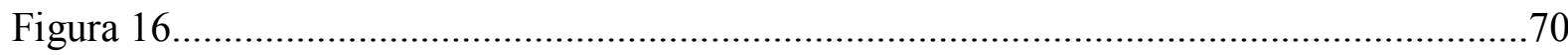

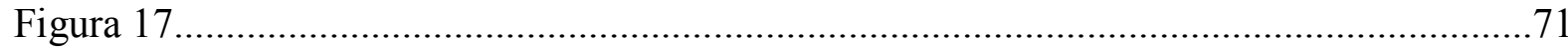

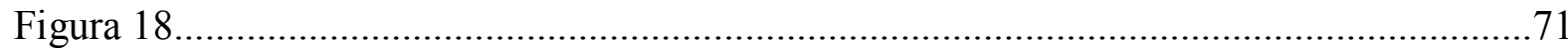

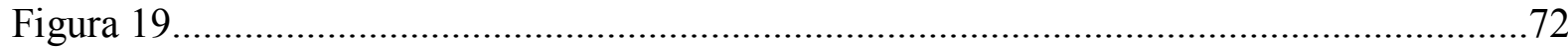

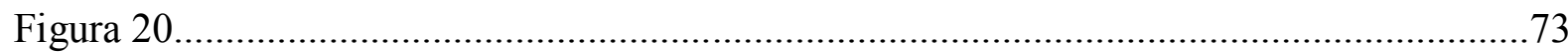

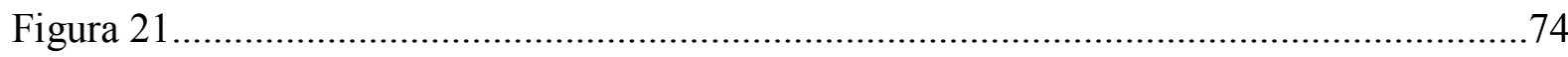

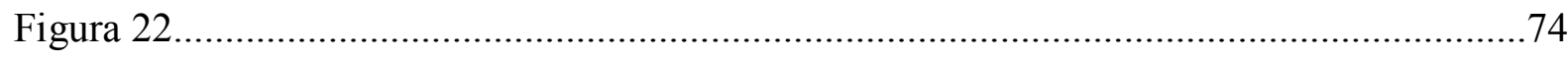

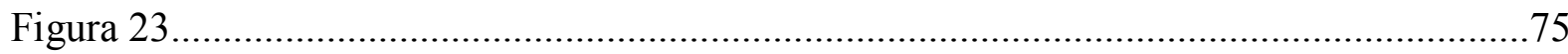

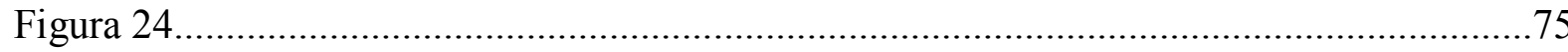




\section{ÍNDICE DE TABELAS}

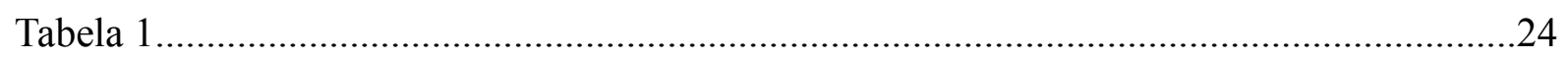



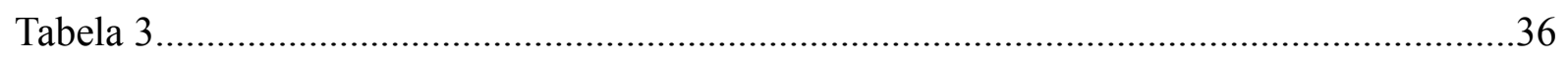

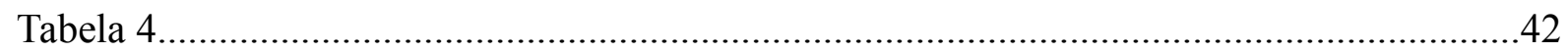

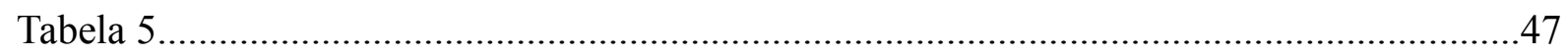

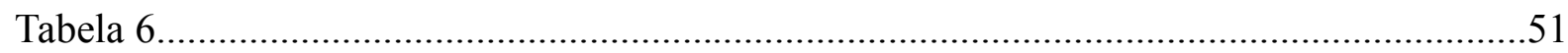

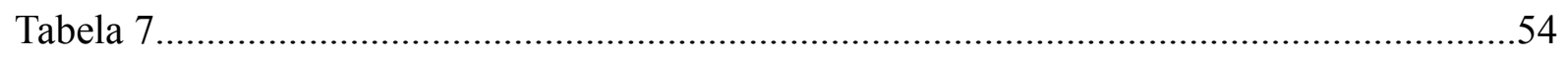

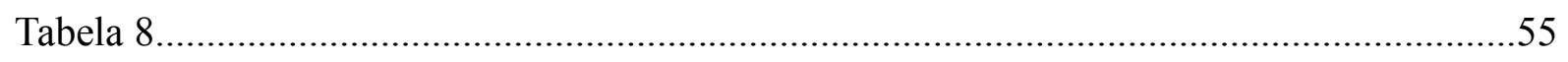

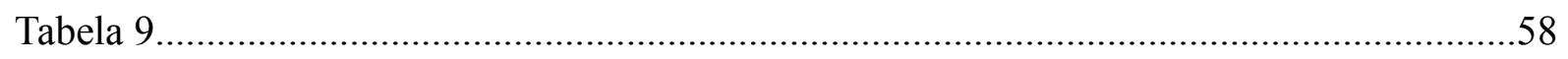

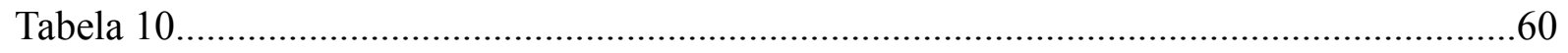



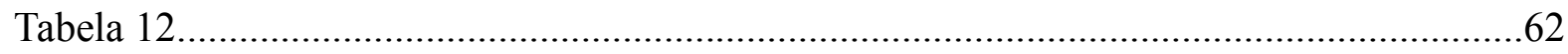



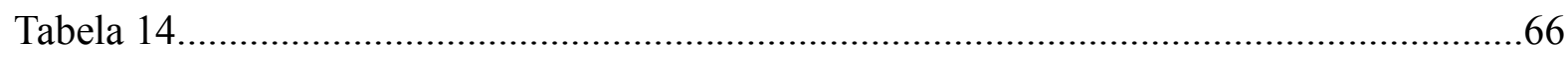






\section{RESUMO}

Micas, A.F.D.

\section{Proteínas do tegumento de abelhas Apis mellifera em metamorfose: identificação por espectrometria de massas}

Como qualquer inseto holometábolo, a abelha Apis mellifera sofre metamorfose completa, apresentando grandes mudanças na forma e fisiologia quando passa do estágio larval para o estágio de pupa (muda metamórfica). Após esta muda, com o prosseguimento do desenvolvimento, o tegumento pupal (cutícula e a epiderme subjacente), extensivamente remodelado, é substituído pelo tegumento adulto, definitivo, que passa por intensa melanização e esclerotização. Eletroforese bidimensional e espectrometria de massas foram utilizadas neste trabalho para caracterizar as mudanças do padrão proteico no tegumento em desenvolvimento de operárias e zangões. No total foram identificadas 51 proteínas diferentes no tegumento torácico extraído de larvas, pupas e adultos (adultos-faratos). Quatorze proteínas foram identificadas como genuinamente cuticulares: Apidermina-3,1-like, Apidermina-2, Cuticular proteins analogous to peritrophins-3C e 3D, AmelCPR3, 12, 16 e 27, Glicoproteína SgAbd-2-like, e cinco outras proteínas homólogas à proteínas cuticulares de outras espécies de insetos contendo um domínio de ligação à quitina. As proteínas diferiram principalmente quantitativamente entre as fases de desenvolvimento e sexo, e poucas diferenças qualitativas foram observadas. Por exemplo, Apidermina-2 é típica de tegumentos fortemente esclerotizados e pigmentados. As diferenças quantitativas foram destacadas pela comparação da abundância de algumas proteínas e seus respectivos RNA mensageiros (utilizando RT-PCR em tempo real) entre as fases de desenvolvimento e entre os sexos. Várias proteínas cuticulares mostraram mais de uma forma molecular, aparentemente derivadas de modificações pós-traducionais. Além de conferir suporte experimental para a validação de genes de $A$. mellifera preditos, ou não-anotados, nossos dados forneceram novas informações sobre as proteínas que atuam no tegumento em desenvolvimento.

Palavras chave: Apis mellifera, tegumento, epiderme, cutícula, proteína cuticular, metamorfose. 


\begin{abstract}
Micas, A.F.D.

Integument protein of honeybee Apis mellifera under metamorphosis: identification by mass spectrometry
\end{abstract}

As a holometabolous insect, the honey bee undergoes complete metamorphosis, displaying a marked change in shape and physiology when passing from the larval to the pupal stage (metamorphic molt). As development progresses, the extensively remodeled pupal integument (cuticle and subjacent epidermis) is replaced by the adult integument, which undergoes intense sclerotization and melanization. Two-dimensional electrophoresis and mass spectrometry were here used to characterize the changing protein patterns in the developing integument of workers and drones. Overall, we identified 51 different proteins in the thoracic integument extracted from larvae, pupae and adults (pharate adults). Fourteen proteins were identified as genuine cuticular proteins: Apidermin-3,1-like protein, Apidermin-2, Cuticular Proteins Analogous to Peritrophins3C and 3D, AmelCPR3, 12, 16 and 27, Glycoprotein SgAbd-2-like, and 5 other proteins homologous to cuticular proteins from other insect species, and containing the chitin-binding domain. Integument proteins mainly differed quantitatively among the developmental stages and sexes, although few qualitative differences have also been detected. For example, Apidermin-2 is typical of the heavily pigmented and sclerotized integument. The quantitative differences were highlighted by comparing the levels of some of these proteins and their respective mRNAs (using RT-qPCR) among the developmental phases and between sexes. It is noteworthy that several cuticle proteins showed more than one molecular form, apparently derived from post-translational modifications. In addition to give experimental support for validation of predicted, or unannotated, honey bee genes, our data provided new information on proteins acting in the metamorphosing integument.

Key words: Apis mellifera, integument, epidermis, cuticle, cuticular proteins, metamorphosis. 


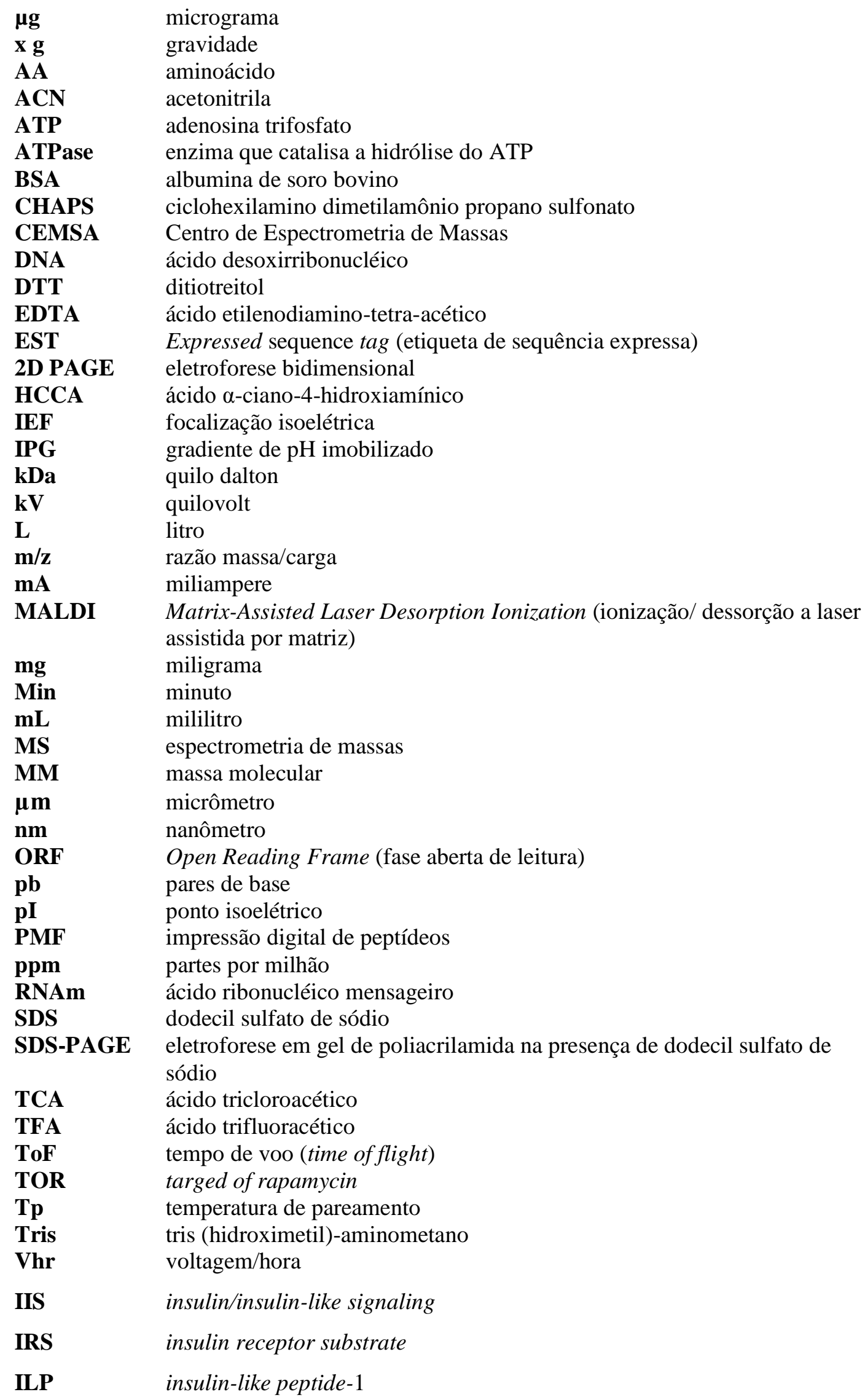


ESI

S

CpG electrospray ionization

segundo

sítios da fita de DNA em que a citosina precede guanina 


\section{INTRODUÇÃO}

\subsection{O exoesqueleto e o ciclo de vida de Apis mellifera}

O exoesqueleto das abelhas, e dos insetos em geral, provê proteção contra predadores, prevenção contra a perda de água, serve como estrutura de suporte à fixação de músculos e permite movimentos rápidos, mas precisos. As funções do exoesqueleto que recobre a cabeça também estão relacionadas à ingestão e digestão mecânica parcial dos alimentos efetivada pelas partes bucais e glândulas associadas, e também à percepção sensorial através dos olhos, ocelos, antenas e cerdas sensitivas. O exoesqueleto torácico é composto de três segmentos bastante modificados e fundidos, cada um com um par de pernas. Além disso, cada um dos dois segmentos torácicos posteriores (mesotórax e metatórax) suporta um par de asas. O tórax das abelhas e de outros himenópteros inclui ainda outro segmento (propodeum), análogo ao primeiro segmento abdominal de outros insetos (Snodgrass, 1956). Assim, o tórax e seus apêndices contêm músculos potentes para o voo, locomoção e para realizar funções especializadas como, por exemplo, aquela realizada pela corbícula das pernas das abelhas operárias que serve para o transporte de pólen de seu local de origem para a colmeia. $\mathrm{O}$ exoesqueleto abdominal consiste de seis segmentos claramente visíveis (segmentos II a VII). Três segmentos adicionais, bastante reduzidos, são associados ao ferrão das operárias e aos órgãos reprodutores das rainhas e zangões. Os segmentos abdominais são recobertos dorsalmente pelos tergitos e ventralmente pelos esternitos, conectados por membranas intersegmentais e laterais (Winston, 2003).

Assim como todos os insetos holometábolos, a abelha Apis mellifera possui um ciclo de vida onde se sucedem os estágios larval, pupal e imaginal ou adulto. O estágio larval é principalmente um período de alimentação e crescimento. A larva de abelha é, essencialmente, uma forma de vida especializada em se alimentar, projetada para crescer rapidamente, despojada de partes externas, e equipada com um enorme sistema digestório. A larva tem a cutícula desprovida de pigmentos, não tem olhos, antenas, asas e ferrão, e possui estruturas bucais simples e necessárias tão somente para se alimentar da grande quantidade de nutrientes depositados continuamente pelas abelhas operárias nos alvéolos de cera onde se desenvolve (Winston, 2003).

O estágio larval compreende cinco instars ou ciclos de muda delimitados pelas sucessivas substituições periódicas da cutícula. Os instars podem ser identificados pelos 
intervalos de aumento do peso corporal e por medidas do diâmetro cefálico (Rembold et al., 1980; Rachinsky et al., 1990; Michelette e Soares, 1993). Em certo momento do $5^{\circ}$ instar larval, o alvéolo do favo onde a larva se desenvolve é hermeticamente selado com um opérculo de cera construído pelas abelhas operárias. A larva, então, deixa de ser alimentada, elimina todo o conteúdo intestinal e começa a tecer seu casulo (Jay, 1963; Winston, 2003). Em seguida, a cutícula pupal começa a ser sintetizada abaixo da cutícula larval. A muda metamórfica termina quando a cutícula larval é descartada expondo assim a cutícula pupal. Inicia-se então o estágio de pupa e a etapa subsequente de desenvolvimento da abelha adulta sob a cutícula pupal. Finalmente, a cutícula pupal é descartada, revelando assim a cutícula definitiva da abelha operária adulta. A última muda, imaginal, transforma a pupa em adulto, com consequente formação do exoesqueleto definitivo.

Ao adulto que está se desenvolvendo, ainda recoberto pela cutícula pupal, dá-se o nome de adulto-farato. À medida que a cutícula adulta se diferencia sob a pupal, torna-se gradualmente mais escura (melanizada) e esclerotizada (endurecida). Estas mudanças podem ser usadas para identificar a idade do adulto-farato. Tanto a pupa quanto o adulto-farato não crescem nem alteram o padrão corporal, apenas os seus tecidos, órgãos e exoesqueleto se diferenciam e paulatinamente adquirem capacidade funcional. Para emergir, o tenro adulto usa suas mandíbulas para abrir pequenas fendas no opérculo do alvéolo e as aumenta o suficiente para sair. Uma vez fora do alvéolo, ocorre o desdobramento das asas e antenas, os pelos do corpo secam e o adulto inicia as suas atividades na colméia (Winston, 2003).

\subsection{Os ciclos de muda}

No início de cada ciclo de muda, a membrana apical lisa da epiderme começa a formar microvilos sobre os quais o novo envelope, ou camada mais externa da cutícula, é montado (Locke, 2001). Esta fina camada de 10-30 nm de espessura não somente protege a epiderme da ação de enzimas que durante a muda digerem a cutícula antiga, como provê também resistência à abrasão, infecção e penetração de alguns compostos químicos, como certos inseticidas. As identidades de suas proteínas constituintes permanecem desconhecidas. A próxima camada cuticular a ser formada é a epicutícula, com aproximadamente $1 \mu \mathrm{m}$ de espessura. É uma camada livre de quitina (longo polímero de $\mathrm{N}$-acetilglicosamina, que é o principal componente do exoesqueleto de artrópodos) e é estabilizada por quinonas (compostos aromáticos modificados pela conversão de um número par de grupos $-\mathrm{CH}=\mathrm{em}-$ 
$\mathrm{C}(=\mathrm{O})-$ ). A procutícula, camada mais interna em relação à epicutícula, contém quitina e proteínas cuticulares em várias combinações e se torna esclerotizada e pigmentada em vários graus (Willis et al. 2005).

A muda é regulada pelos títulos de hormônios chamados coletivamente de ecdisteróides, que coordenam os passos sequenciais das mudas larvais, metamórfica e imaginal (Riddiford et al., 2003). Níveis elevados de ecdisteróides induzem a muda regulando a expressão gênica para o desenvolvimento da cutícula do próximo estágio, e também previnem o início da sequência de ecdise. O declínio nos títulos de ecdisteróides é requerido para a secreção de hormônios peptídicos, tais como PETH (pre-ecdysis triggering hormone), ETH (ecdysis triggering hormone) e EH (eclosion hormone), necessários para a ocorrência da ecdise (Zitnan e Adams, 2005). O período que imediatamente sucede a ecdise adulta é caracterizado pela expansão das asas e término da esclerotização da nova cutícula.

Em resumo, a síntese de DNA e a mitose irão ocorrer nas células da epiderme enquanto os títulos de ecdisteróides estão aumentando. Em seguida, coincidindo com o pico de ecdisteróides, a velha cutícula irá se desprender da epiderme subjacente em um processo denominado apólise. As células epidérmicas, então, secretam o envelope da nova cutícula e o gel de muda contendo enzimas que irão subsequentemente ser ativadas para digerir a cutícula antiga. A epicutícula é então depositada enquanto os níveis de ecdisteróides estão altos. A camada mais espessa da cutícula, a procutícula é depositada enquanto os títulos de ecdisteróides declinam e tornam-se basais. Finalmente a velha cutícula parcialmente digerida é descartada durante a ecdise (Charles, 2010).

\subsection{Os morfotipos da espécie $A$. mellifera e a determinação de castas}

Os himenópteros possuem um sistema haplo-diplóide de determinação sexual. O cariótipo de zangões e fêmeas de A. mellifera foi inicialmente descrito em estudos de gametogênese e embriogênese por Petrunkewitsch (1901) e Nachstein (1913) apud Herrmann et al., 2005. A descoberta de que os zangões se originam de ovos não fertilizados, haplóides, foi realizada por Dziernon (1845) apud Herrmann et al., (2005). As fêmeas se originam de ovos fecundados.

Desta forma, o mecanismo de determinação de sexo e castas pode ser resumido, basicamente, da seguinte maneira: de ovos não fertilizados eclodem zangões, cuja função se limita a fecundar a rainha; enquanto que dos ovos fertilizados eclodem as operárias e a rainha, 
dependendo da qualidade e quantidade de alimento recebido durante o estágio larval (Winston, 2003).

A evolução da organização social da ordem Hymenoptera está intimamente associada à divisão das atividades na colônia. Em abelhas sociais, uma ou poucas fêmeas (rainhas) se especializaram na reprodução, enquanto um grande número de fêmeas, em geral, quase estéreis (operárias) se encarrega de atividades de manutenção e defesa da colônia, e cuidados com as crias. Este polifenismo é determinado por mudanças no desenvolvimento pósembrionário (revisão em Hartfelder e Engels, 1998). A origem das férteis rainhas e das operárias funcionalmente estéreis deve-se à alimentação diferencial recebida durante o estágio larval. Larvas destinadas a serem rainhas são alimentadas com grandes quantidades de geleia real, enquanto aquelas que se desenvolverão como operárias recebem geleia real suplementada com pólen e mel (Haydak, 1970). A dieta diferencial atua sobre o sistema neuroendócrino, no qual são gerados sinais casta-específicos responsáveis por alterações nos títulos do hormônio juvenil e de ecdisteróides (Rachinsky et al., 1990). Um aspecto importante do mecanismo de atuação da dieta-diferencial foi descoberto por Patel et al. (2007), que constataram o papel de TOR (targed of rapamycin), uma quinase componente central de uma via de sinalização eucariótica que regula o crescimento celular e do organismo em resposta ao estado nutricional. A inibição de TOR por rapamicina em larvas destinadas a serem rainhas, induziu o desenvolvimento de características de operárias. Estes efeitos puderam ser revertidos por um antagonista do inibidor (FK506), reforçando o papel de TOR na determinação das castas. Outra via sensível aos nutrientes, IIS (insulin/insulin-like signaling) também está envolvida na determinação de castas em $A$. mellifera. Tanto quanto TOR, a via IIS regula o crescimento celular e metabolismo. Genes que codificam componentes desta via, como ILP-1 (insulin-like peptide-1) e IRS (insulin receptor substrate) (Wheeler et al., 2006) e InR (insulin receptor) (de Azevedo e Hartfelder, 2008) mostraram menor expressão em larvas de operárias que em larvas de rainhas. Além disto, experimentos utilizando RNA de interferência para silenciamento dos genes TOR e IRS (Patel et al., 2007; Wolschin et al., 2011), levaram à redução do título larval de hormônio juvenil e as larvas prospectivas a rainhas se desenvolveram em operárias, demonstrando que estes genes são importantes no processo de diferenciação de castas.

Outros importantes mediadores da diferenciação de castas, capazes de alterar o destino de larvas, são a metilação do DNA (Kucharski et al., 2008) e uma proteína da geleia real denominada royalactin (Kamakura, 2011). Desta forma, foi verificado que a dieta alimentar 
das rainhas resulta em menor taxa de metilação dos dinucleotídeos $\mathrm{CpG}$ que a dieta oferecida às operárias, com consequentes diferenças nos respectivos padrões de expressão gênica. Além disto, o silenciamento do gene codificador da enzima DNA metiltransferase 3 que media a metilação de CpG, causa o desenvolvimento de caracteres de rainhas (Kucharski et al., 2008), assim demonstrando a importância da metilação na diferenciação de castas. Por outro lado, a proteína royalactin é apontada como o indutor primário do desenvolvimento da larva em rainha, sendo sua ação mediada por Egfr (epidermal growth factor receptor), conforme demonstrado por meio do silenciamento de $E g F r$ utilizando RNA de interferência (Kamakura, 2011).

Estas descobertas representam um grande avanço no conhecimento dos aspectos moleculares do processo de diferenciação de castas, ainda não completamente elucidado.

\subsection{Estrutura do exoesqueleto e proteínas cuticulares}

O exoesqueleto mostra-se tipicamente dividido em regiões relativamente rígidas, como os tergitos e esternitos, separados por regiões mais flexíveis e as membranas artropodais, as quais tornam possíveis as várias formas de movimento e locomoção. As diferenças regionais marcantes em suas propriedades mecânicas têm relação direta com as funções e com as forças às quais as diferentes regiões da cutícula são expostas durante a vida do animal. Assim deduzse que as células epidérmicas podem produzir cutícula com propriedades distintas, indicando um controle regional preciso da composição cuticular (Willis et al., 2005).

Proteínas cuticulares de diversas espécies de insetos têm sido bioquimicamente caracterizadas (Willis et al., 2005). Silvert (1985) levantou várias questões a respeito das preparações ou extratos de cutícula utilizados nestes estudos. As proteínas extraídas da cutícula seriam todas proteínas cuticulares autênticas ou haveria também contaminantes oriundos de células aderentes e da hemolinfa? A epiderme é o único sítio de síntese das proteínas cuticulares ou algumas são sintetizadas em outros tecidos e transportadas para a cutícula? Há diferenças entre as proteínas cuticulares dos sucessivos estágios de desenvolvimento do inseto? Embora domínios típicos de proteínas cuticulares tenham sido identificados e experimentos de hibridação com sondas específicas e de imunolocalização possam identificar sua origem e destino final, muito ainda precisa ser feito para a caracterização do proteoma cuticular. Willis et al. (2005) catalogaram cerca de 200 proteínas cuticulares estruturais das ordens: Diptera, Orthoptera, Lepidoptera, Coleoptera, Dictyoptera e 
Hemiptera. Elas foram identificadas através de sequenciamento direto ou por tradução conceitual de cDNAs ou ESTs (Expressed Sequence Tags). Recentemente Willis (2010) publicou um artigo incluindo sequências obtidas da anotação de vários genomas de insetos, assim como novas ESTs, além de proteínas identificadas por análises proteômicas de preparações de cutículas que têm confirmado como autênticas muitas das sequências.

As proteínas cuticulares têm sido consideradas excelentes modelos para estudos da regulação da muda e metamorfose de insetos, e para a compreensão das modificações bioquímicas, físico-químicas e estruturais que ocorrem na cutícula durante o desenvolvimento dos insetos. Atualmente, pergunta-se como a variedade de proteínas cuticulares contribui para a estruturação, propriedades físicas e funções do exoesqueleto dos artrópodes. Uma importante pista foi a descoberta de uma classe destas proteínas que se distingue por possuir o consenso R\&R, identificado por Rebers e Riddiford (1988). Sabe-se que a sequência de aminoácidos deste consenso tem função de estabelecer forte ligação com a quitina cuticular (Rebers e Willis, 2001; Togawa et al., 2004). A descoberta do consenso R\&R permitiu rastrear e identificar genes codificadores de proteínas cuticulares nos genomas de insetos, disponíveis em bancos de dados públicos. Entretanto este consenso está ausente em aproximadamente um terço das 521 sequências de proteínas cuticulares de artrópodes depositadas até fevereiro de 2007 na página da internet CuticleDB- http://bioinformatics2.biol.uoa.gr/cuticleDB/index.jsp (Magkrioti et al., 2004; Karouzou et al., 2007). Tais sequências compartilham outros motivos, a maioria com função ainda desconhecida.

A publicação do genoma completo de A. mellifera (The Honeybee Genome Sequencing Consortium, 2006) revelou que o número de genes codificadores de proteínas cuticulares, contendo o consenso R\&R, era menor do que o descrito para Drosophila ou Anopheles. Foi proposto que a organização social das abelhas, que preserva os imaturos e os jovens adultos (operárias e zangões) no ambiente protetor da colmeia, poderia ter concorrido para a evolução de uma estrutura cuticular menos complexa. No entanto, em seguida a publicação do genoma, foram caracterizados mais três genes que codificam proteínas cuticulares (apiderminas) desprovidas deste consenso (Kucharski et al., 2007), assim como os genes codificadores de duas proteínas da família Tweedle (Soares et al., 2011) que possuem resíduos aromáticos conservados que se ligam à quitina (Tang et al., 2010) .

A identificação das várias proteínas cuticulares que ocorrem durante a ontogênese dos insetos pode elucidar as diferenças que caracterizam as cutículas estágio-específicas (larval, 
pupal e adulto), sexo-específicas ou ainda casta específicas, considerando os insetos sociais, entre eles, as abelhas.

\subsection{Estudos sobre a estrutura do tegumento e proteínas cuticulares de Apis mellifera}

De nosso conhecimento, descrições da estrutura morfológica do tegumento de abelhas são encontradas em Snodgrass (1956), Thompson (1978), Hepburn (1985) e Cruz-Landim (2008). Snodgrass (1956) mostrou um esquema da parede do corpo onde se identifica mais internamente a membrana basal que separa o tegumento da hemolinfa circulante, a epiderme, sobre a membrana basal, e as camadas da cutícula, sobre a epiderme, nomeando-as de procutícula, mais interna, formada pela endocutícula e exocutícula e a epicutícula, mais externa. Em esquemas simplificados, Thompson (1978) ilustrou as mudanças na cutícula durante a muda pupal-adulta, situando neste processo a ocorrência da apólise e da ecdise. Adicionalmente, Cruz-Landim (2008) mostrou por meio de microscopias eletrônica de transmissão e de varredura aspectos do tegumento de $A$. mellifera e de outras abelhas em fases pontuais do desenvolvimento, e também caracterizou a estrutura das glândulas relacionadas ao tegumento. Mais recentemente, a estrutura histológica do tegumento de A. mellifera foi caracterizada por microscopia de luz, em cada passo sequencial da muda pupal-adulta, tornando assim evidentes as modificações das células epidérmicas e da cutícula durante este intervalo de muda (Elias-Neto et al., 2009). As características sub-celulares da epiderme e a progressiva deposição das camadas cuticulares durante este período foram investigadas mais a fundo por meio de microscopia eletrônica de transmissão por Canhos (2010). Utilizando SDSPAGE, Santos et al. (2001) caracterizaram o padrão polipeptídico do tegumento e demonstraram a expressão diferencial de uma variedade de polipeptídios de massas moleculares menores que $66 \mathrm{kDa}$, em estágios distintos da morfogênese da cutícula adulta. Outros trabalhos focalizaram uma enzima cuticular, a fenoloxidase, com função chave na via de síntese de melanina, a qual é imprescindível para a plena diferenciação da cutícula adulta (Zufelato et al., 2004; Lourenço et al., 2005). O gene codificador desta enzima foi isolado, clonado e sequenciado. A própria enzima foi bioquimicamente e físico-quimicamente caracterizada, e sua atividade foi estudada em relação à diferenciação e esclerotização da cutícula adulta. Um gene cuticular de A. mellifera contendo o consenso R\&R, AmelCPR14 foi sequenciado (Soares et al., 2007), e mostrou grande atividade durante a biossíntese da 
cutícula adulta. Dois outros genes codificadores de proteínas cuticulares pertencentes à família Tweedle (AmelTwdll e AmelTwdl2) também foram identificados e clonados. Estudos de expressão mostraram que ambos estão ativos durante a síntese da cutícula adulta, permitindo inferir que seus produtos contribuem para a estruturação do exoesqueleto (Soares et al., 2011). Além disso, os genes codificadores da lacase2 (Elias-Neto et al., 2010) e de uma peroxidase cuticular (Soares et al., 2011), ambas enzimas envolvidas no processo de esclerotização, foram identificados e sequenciados. Em conjunto, estes estudos com foco na biologia molecular do desenvolvimento da cutícula mostraram aspectos da estrutura e expressão de genes codificadores de proteínas e enzimas cuticulares de A. mellifera com participação na construção e diferenciação do exoesqueleto definitivo. O controle da expressão destes genes pelos hormônios da muda, ecdisteróides, também foi pesquisado in vivo e in vitro no contexto dos eventos sequenciais (apólise, síntese da nova cutícula e ecdise) da muda pupal-adulta (Elias-Neto et al., 2010).

\subsection{Proteômica e Apis mellifera}

Os estudos de proteômica de abelha têm apenas poucos anos, com o primeiro artigo publicado em 2005 (Peiren et al., 2005) sobre a composição do veneno de A. mellifera. Outros artigos na mesma data avaliaram o pólen e geleia real (Scarselli et al., 2005) e as glândulas hipofaríngeas (Santos et al., 2005) como material biológico. Mais recentemente, Hernandez et al. (2012) caracterizaram o proteoma do cérebro desta abelha.

Em relação aos organismos vivos em geral, o campo da proteômica diversificou-se rapidamente, utilizando como meios de investigação uma variedade de tecnologias de espectrometria de massas para identificação de proteínas separadas por eletroforese bidimensional (2DE), seguida de MALDI (Matrix-Associated Laser Desorption Ionization). Atualmente, é possível notar um aumento do uso de sistemas livres de géis acoplados com ionização eletrospray (ESI) para separação e identificação de proteínas em amostras de Apis mellifera (Chan e Foster, 2009).

Mesmo que tecnologias alternativas tenham surgido, a técnica de eletroforese bidimensional associada a espectrometria do tipo MALDI é eficiente e pode ser rotineiramente aplicada na identificação de um conjunto heterogêneo de proteínas complexas. Além do mais, ela oferece um mapa das proteínas que reflete as mudanças no nível de 
expressão e informa sobre a existência de isoformas ou modificações pós-traducionais (Chan e Foster, 2009). Assim, a eletroforese bidimensional é um método poderoso e amplamente utilizado para a análise de misturas complexas de proteínas de células e tecidos, ou outras amostras biológicas. A primeira dimensão, a focalização isoelétrica (IEF), separa as proteínas de acordo com o seu ponto isoelétrico (pI), enquanto que a segunda dimensão, SDS-PAGE, separa as proteínas de acordo com suas massas moleculares. Cada spot revelado no gel bidimensional corresponde potencialmente a uma única espécie de proteína na amostra. Milhares de diferentes proteínas podem, assim, ser separadas, e informações como pI, massa molecular aparente e a proporção de cada proteína na amostra podem ser obtidas.

Como se identifica cada uma destas proteínas? Através da técnica analítica denominada Peptide Mass Fingerprint (PMF), que consiste inicialmente da digestão de uma proteína desconhecida em pequenos peptídeos, seguida da medida de suas massas absolutas em espectrômetro de massas MALDI-TOF ou ESI-TOF. As massas obtidas são comparadas in silico frente a bancos de dados contendo sequências de proteínas conhecidas ou, até mesmo, frente aos genomas sequenciados. As sequências de proteínas deduzidas de um genoma específico são "digeridas" teoricamente pelo programa e, através da comparação dos perfis obtidos da proteína de interesse e dos obtidos do genoma, obtém-se a melhor cobertura por análises estatísticas, que corresponderá à proteína desconhecida.

A vantagem deste método é que somente as massas dos peptídeos precisam ser conhecidas. Uma desvantagem é que as sequências de proteínas têm de estar disponíveis em um banco de dados. A maioria dos algoritmos de PMF assume que os peptídeos são originados de uma única proteína. A presença de uma mistura pode complicar significativamente a análise e comprometer potencialmente o resultado.

Desta forma, o presente trabalho enfoca a abordagem comparativa do proteoma do tegumento (cutícula e epiderme subjacente) de A. mellifera. Pretendeu-se identificar as proteínas cuticulares e não-cuticulares de fases pontuais dos ciclos de muda larval, pupal e imaginal, regulados por ecdisteróides, com o intuito de caracterizar a participação destas proteínas na estruturação e diferenciação do exoesqueleto de A. mellifera. 


\section{OBJETIVOS}

\section{Geral:}

Caracterizar o proteoma do tegumento de operárias e zangões de Apis mellifera no contexto da muda e metamorfose regulados por ecdisteróides.

\section{Específicos:}

1. Estabelecer os perfis de proteínas do tegumento de operárias e zangões em etapas críticas da muda e metamorfose por meio de eletroforese bidimensional e espectrometria de massas;

2. Relacionar os perfis diferenciais de proteínas com a variação do título de ecdisteróides que norteia a sucessão de eventos da muda e metamorfose. 


\section{MATERIAL E MÉTODOS}

\subsection{Material biológico}

Operárias e zangões de $A$. mellifera africanizadas nos estágios larval, pupal e adultofarato foram coletados de colmeias do apiário experimental do Departamento de Genética da Faculdade de Medicina de Ribeirão Preto - Universidade de São Paulo, Ribeirão Preto, SP. Larvas em início de $5^{\circ}$ instar com intestino cheio (L5F), as pupas logo após a ecdise pupal e as adultas-faratas, 03 dias após a apólise da cutícula pupal, de operárias e zangões foram identificados de acordo com os critérios de Michelette e Soares (1993), Rembold et al. (1980) e Tozetto et al. (2006) (Tabela 1).

Tabela 1. Aspecto externo das fases de desenvolvimento de abelhas operárias e zangões A. mellifera utilizadas no presente trabalho.

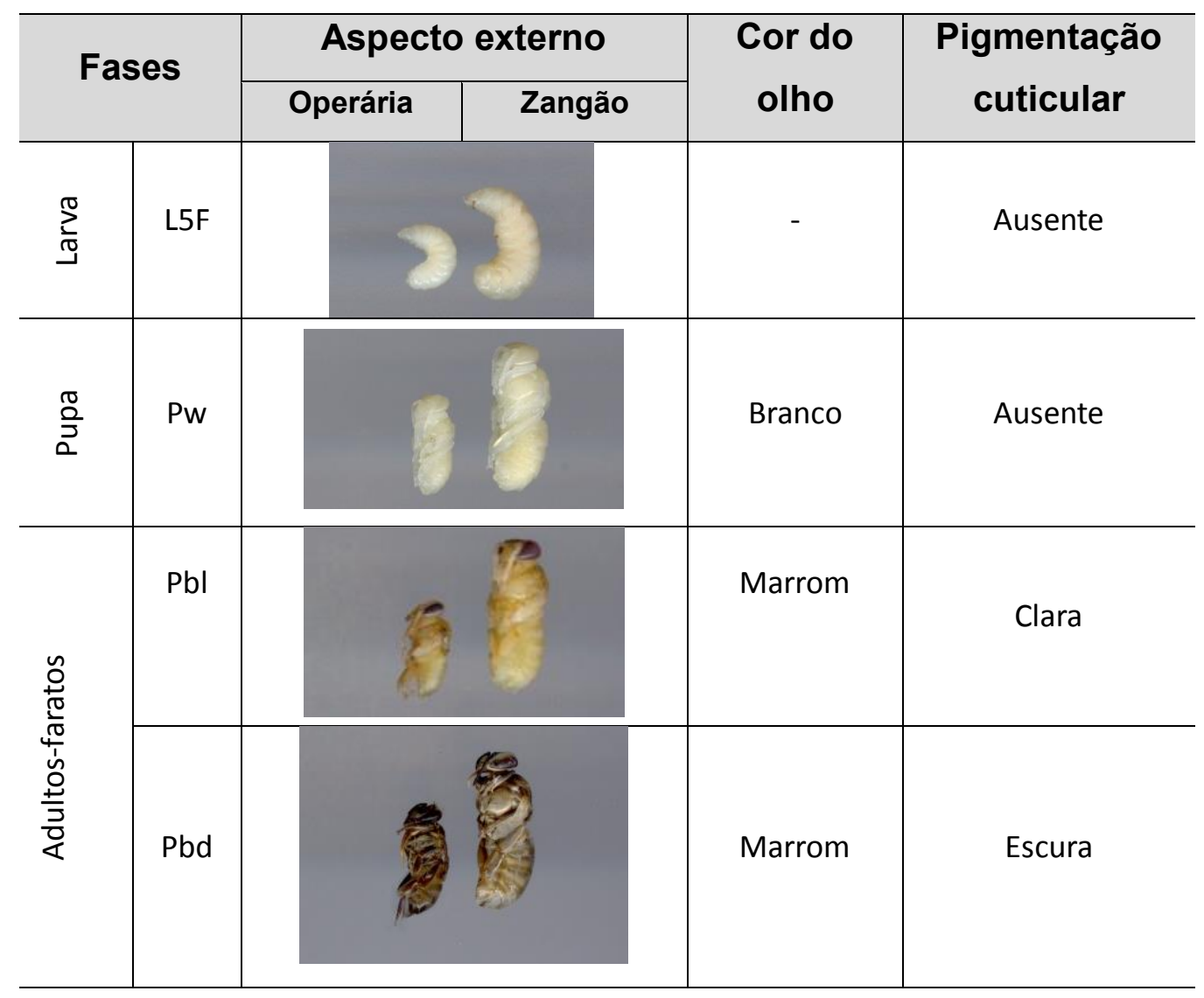

$\mathrm{O}$ tegumento das larvas, retirando as extremidades anterior e posterior, e o tegumento torácico dorsal das pupas e adultas-faratas de operárias e zangões foram utilizados no preparo dos extratos de proteínas e extração de RNA total. Em seguida à dissecação, os tegumentos 
foram lavados rapidamente com solução de Ringer $\left(\mathrm{NaCl} 280 \mathrm{mM} ; \mathrm{KCl} 3,2 \mathrm{mM} ; \mathrm{CaCl}_{2}\right.$ $1,8 \mathrm{mM})$ e estocados a $-70^{\circ} \mathrm{C}$ até a sua utilização.

\subsection{Preparo dos extratos de proteínas do tegumento}

No total foram avaliados três métodos de extração de proteínas do tegumento com intuito de otimizar este processo. Isto se justifica principalmente devido a grande dificuldade de solubilização da cutícula.

O primeiro método consistiu no tratamento dos tegumentos, extraídos e pulverizados em nitrogênio líquido, com uma solução de solubilização composta de ureia $6 \mathrm{M}$ e ácido trifluoracético $0,1 \%$ a $4^{\circ} \mathrm{C}$ por $18 \mathrm{~h}$. No segundo método, extratos pulverizados foram tratados com $600 \mu \mathrm{L}$ de uma solução de $50 \mathrm{mM}$ do agente redutor Ditiotreitol (DTT) (Invitrogen, Life Technologies) e subsequentemente mantidos a $100^{\circ} \mathrm{C}$ por $15 \mathrm{~min}$. No terceiro método, foram utilizados $200 \mu \mathrm{L}$ de solução de lise (Tris-Base $10 \mathrm{mM}$, ureia 7,7M, tioureia 2,2M, CHAPS $4,4 \%)$ e coquetel de inibidores de proteases $(10 \mu \mathrm{L}$ de coquetel Sigma) no material pulverizado, seguido de três ciclos de homogeneização com ultrassom consistindo cada ciclo de $5 \mathrm{~min}$ no ultrassom com gelo, $15 \mathrm{~s}$ no vórtex e $5 \mathrm{~min}$ de descanso no gelo. Terminados os ciclos as amostras foram centrifugadas a $20.000 \mathrm{xg}$ e o sobrenadante foi coletado, descartando o sedimento.

Para estimar a quantidade total de proteínas solubilizadas em todos os métodos, foi utilizado o método de Bradford (1976). Para as curvas padrão, foram utilizadas concentrações conhecidas de BSA (albumina sérica bovina).

\subsection{SDS-PAGE}

Os extratos proteicos do tegumento foram submetidos a eletroforese em gel de poliacrilamida, utilizando-se a técnica de SDS-PAGE para separar as proteínas de acordo com sua massa molecular. O gel de separação foi preparado com $12,5 \%$ de acrilamida. A preparação do gel e do tampão de corrida foi realizada segundo a metodologia descrita por Sambrook e Russel (2001). As bandas proteicas foram visualizadas após coloração com Coomassie Brilliant Blue G coloidal Serva (Sambrook e Russel, 2001; Neuhoff et al., 1988). 


\subsection{Gel bidimensional}

A eletroforese bidimensional foi realizada de acordo com a metodologia descrita por Smolka et al. (2003). Antes da corrida, $150 \mu \mathrm{g}$ de cada extrato proteico foram diluídos em $85 \mu \mathrm{L}$ de tampão de lise (Tris-Base $10 \mathrm{mM}, 7,7 \mathrm{mM}$ ureia, 2,2mM tioureia, 4,4\% CHAPS) acrescido de $0,3 \mathrm{mg}$ de DTT e $0,001 \%$ de azul de bromofenol. Após centrifugação $(800 g$ por 2 min), o sobrenadante foi utilizado para a primeira corrida. As amostras foram aplicadas nas fitas de IPG com a capacidade de separação por ponto isoelétrico (pI) em gradiente de pH 4-7 (GE Healthcare Life Science). Após 12 horas de hidratação, a corrida foi conduzida a $20^{\circ} \mathrm{C}$ com limite de corrente de $50 \mu \mathrm{A}$ por fita com os seguintes passos:

1. Ddp (diferença de potencial elétrico) de $200 \mathrm{~V}$ até acumular $200 \mathrm{Vh}$;

2. Ddp de $500 \mathrm{~V}$ até acumular $1500 \mathrm{Vh}$;

3. Gradiente de $1000 \mathrm{~V}$ até acumular $750 \mathrm{Vh}$;

4. Gradiente de 5000V até acumular 4500Vh;

5. Ddp de $5000 \mathrm{~V}$ até acumular $3000 \mathrm{Vh}$.

Após a focalização, as fitas foram submetidas a um passo final que consiste em um gradiente de $8000 \mathrm{~V}$ por $50 \mathrm{~min}$, com o objetivo de limpar das fitas qualquer proteína que ainda tenha carga, sendo proteínas com pI diferente dos que são contemplados pelo gradiente da fita. O tempo de corrida foi condicionado a cada amostra, cerca de $7 \mathrm{~h}$.

Após a corrida em primeira dimensão, as fitas foram submetidas aos tratamentos de redução e alquilação antes da corrida eletroforética de segunda dimensão, pela imersão das fitas por $15 \mathrm{~min}$ em tampão de equilíbrio (50mM Tris $\mathrm{pH} 8,8,6 \mathrm{M}$ ureia; $30 \%$ glicerol; $2 \%$ SDS) acrescido de 2,5\% DTT, seguido de um tratamento com o mesmo tampão, sem DTT, acrescido de $5 \%$ de iodocetamida por mais $15 \mathrm{~min}$.

Após os passos de equilíbrio, as fitas foram imediatamente submetidas à eletroforese (SDS-PAGE). A visualização dos spots proteicos foi efetuada através do método de coloração por Coomassie coloidal G-250 (Serva) descrito por Neuhoff et al. (1988). Este método consiste de uma etapa de fixação por $1 \mathrm{~h}$ em solução contendo etanol $50 \%$ (v/v) e ácido acético $10 \%(\mathrm{v} / \mathrm{v})$ em água. O tingimento foi realizado overnight em solução contendo Coomassie $0,1 \%(\mathrm{~m} / \mathrm{v})$ em ácido fosfórico $2 \%(\mathrm{v} / \mathrm{v})$, sulfato de amônio $10 \%(\mathrm{~m} / \mathrm{v})$ e metanol $25 \%(\mathrm{v} / \mathrm{v})$. Após uma lavagem com metanol 25\% (v/v), o gel foi estocado em uma solução de azida sódica $0,1 \%(\mathrm{~m} / \mathrm{v})$ em água. 
Este método que utiliza as propriedades iônicas e coloidais do Coomassie G-250 apresenta maior sensibilidade que o método que utiliza o Coomassie R-250, permitindo detectar a partir de 0,5ng de proteínas (Neuhoff et al., 1988).

\subsection{Espectrometria de massas (MALDI -TOF)}

As bandas e spots proteicos oriundos do tegumento, e que mostraram expressão diferencial entre os dois morfotipos da colônia (operárias e zangões) e estágios de desenvolvimento (larval, pupal e farato-adulto), foram extraídas dos géis cortando-se um segmento correspondente à região da banda ou do spot no gel.

Inicialmente os spots foram lavados quatro vezes com $50 \mathrm{mM} \mathrm{NH}_{4} \mathrm{HCO}_{3}$ contendo acetonitrila (ACN) 50\% (v/v) para remoção de SDS e corante, sendo a primeira lavagem realizada overnight a $4^{\circ} \mathrm{C}$ e as demais em intervalos de $15 \mathrm{~min}$ em temperatura ambiente, intercalando-se agitação em vórtex. Após total descoloração, os spots foram lavados com ACN e completamente secos em Speedvac (Savant Instrument) por aproximadamente 40 min. Em seguida, cada spot foi reidratado em um volume reduzido de solução de tripsina, $10 \mu \mathrm{L}$ de $50 \mathrm{mM} \mathrm{NH}_{4} \mathrm{HCO}_{3}$ contendo $0,3 \mu \mathrm{g}$ de tripsina modificada (metilação de resíduos de lisina para redução de autólise e de grau sequencial) (Sigma). Após a reidratação dos spots por cerca de $30 \mathrm{~min}$, foram adicionados $50-100 \mu \mathrm{L}$ de $50 \mathrm{mM} \mathrm{NH}_{4} \mathrm{HCO}_{3}$, considerando o volume suficiente para cobrir o gel do spot. A reação foi mantida a $37^{\circ} \mathrm{C}$ por $24 \mathrm{~h}$ e interrompida pela adição de $1 \mu \mathrm{L}$ de ácido fórmico absoluto.

Os peptídeos foram extraídos do gel com $40 \mu \mathrm{L}$ de solução de ácido trifluoracético (TFA) $2,5 \%(\mathrm{v} / \mathrm{v})$ contendo ACN $50 \%(\mathrm{v} / \mathrm{v})$ por $3 \mathrm{~h}$. Este procedimento foi repetido e os sobrenadantes combinados. Os extratos foram concentrados em Speedvac até atingir o volume aproximado de $5 \mu \mathrm{L}$ e ressuspendidos em $5 \mu \mathrm{L}$ de TFA 2,5\% (v/v) contendo ACN $50 \%(\mathrm{v} / \mathrm{v})$.

Em seguida $1 \mu \mathrm{L}$ de cada extrato de peptídeos, presentes em TFA 2,5\% e ACN 50\%, foi misturado a $1 \mu \mathrm{L}$ de solução de matriz $\alpha$-cyano-4-ácido hidroxicinâmico (concentração de $1 \mathrm{mg}$ de matriz para $50 \mu \mathrm{L}$ de $\mathrm{ACN} 60 \%$ e TFA q.s.p) e aplicados em duplicata nas placas para determinação das massas dos peptídeos, sendo avaliados no espectrômetro de massa MALDITOF/TOF 5800 da AB SCiex, no módulo de operação MS Reflector positive, com faixa de análise de 800 a 4.000Da e foco de massa de 1.500Da. Os peptídeos gerados da autólise da tripsina, de massas correspondentes a $842,51 \mathrm{Da}$ e $2211,10 \mathrm{Da}$, foram utilizados como calibradores internos de massa e a $\beta$-galactosidase (Escherichia coli) e o Cal Mix 1 (mistura de peptídeos padrão para calibração do sistema de MALDI-TOF/TOF) como calibradores 
externos do instrumento. A infraestrutura do Hemocentro, Universidade de São Paulo, Ribeirão Preto - SP, e o serviço de espectrometria oferecido pelo Centro de Espectrometria de Massas Aplicada Ltda CEMSA), São Paulo,SP. Foram disponibilizads para esta análise.

\subsection{Análise dos dados espectrométricos}

Os valores das massas dos peptídeos trípticos obtidos por MALDI-TOF/TOF gerados a partir dos spots selecionados, foram analisados manualmente através do MS-Fit (http://prospector.ucsf.edu) e dos bancos de dados mais recentemente atualizados do NCBI e Swiss-PROT. Os parâmetros utilizados foram: banco de dados NCBInr, permitindo 2 perdas por clivagem, foi aceita a carboximetilação como modificação fixa e a oxidação da metionina como modificação variável, com tolerância de peptídeo de \pm 1 Da.

As informações obtidas dos géis bidimensionais, como massa molecular, ponto isoelétrico e espectros de massas (Fingerprint estrutura primária), forneceram a base para a identificação das proteínas de interesse. Esse processo foi realizado com ferramentas específicas disponíveis em sites especializados, como MASCOT, Protein Prospector, Fasta e BLAST.

\subsection{Extração do RNA total e síntese da primeira fita de cDNA}

O RNA total foi extraído do tegumento torácico dorsal de A. mellifera usando Trizol (Invitrogen) seguindo as instruções do fabricante. $\mathrm{O}$ extrato foi incubado em presença de 3 unidades de DNase (livre de RNAse) (Promega) por $40 \mathrm{~min}$ a $37^{\circ} \mathrm{C}$ para eliminar possível DNA contaminante, seguido por $15 \mathrm{~min}$ a $70^{\circ} \mathrm{C}$ para inativar a enzima. A primeira fita de cDNA foi sintetizada por transcrição reversa usando $2,5 \mu \mathrm{g}$ de RNA total, SuperScript II (transcriptase reversa) e um oligo ( $\left.\mathrm{dT}_{12-18}\right)$ primer (Invitrogen). A quantidade de RNA foi estimada por espectrofotometria $(260 \mathrm{~nm})$ e o grau de pureza foi determinado pela razão entre as leituras de $260 \mathrm{~nm}$ e $280 \mathrm{~nm}$, sendo que a amostra foi considerada pura quando esta razão era maior que 1,9. Reações controle negativas, sem a transcriptase reversa, também foram preparadas e analisadas em paralelo para checar possível contaminação com DNA genômico. Alíquotas de cDNA foram empregadas em reações de PCR em tempo real utilizando PCR Sybr Green Master mix (Promega) e pares de primers (Tabela 2) correspondentes aos genes das proteínas cuticulares identificados por PMF que mostraram expressão diferencial nos 
estágios de desenvolvimento e entre operárias e zangões. Os primers utilizados foram desenhados para amplificar uma região de cada gene que contém um intron, de modo a servir como controle da contaminação por DNA genômico.

Tabela 2. Sequências e temperatura de pareamento (Tp) dos primers utilizados nos experimentos de RT-PCR quantitativa em tempo real.

\begin{tabular}{|c|c|c|c|c|c|}
\hline Gene & Identificador & intron & Primer & Sequência $\left(5^{\prime} \rightarrow 3^{\prime}\right)$ & $\mathbf{T p}$ \\
\hline \multirow{2}{*}{$\begin{array}{l}\text { Yellow like } \\
\text { protein }\end{array}$} & \multirow{2}{*}{ gi|290578556 } & \multirow{2}{*}{$\operatorname{sim}$} & $\begin{array}{l}\text { Yellow like } \\
\text { protein RTF }\end{array}$ & CGACCTGACCAGCGATAAAC & \multirow{2}{*}{$62^{\circ} \mathrm{C}$} \\
\hline & & & $\begin{array}{c}\text { Yellow like } \\
\text { protein RTR }\end{array}$ & TCGTCGGACATGTAGGCGAA & \\
\hline \multirow{2}{*}{ Peritrofina 3-C } & \multirow{2}{*}{ gi|288869506 } & \multirow{2}{*}{ não } & $\begin{array}{c}\text { Peritrophin 3-C } \\
\text { RTF }\end{array}$ & AGGACGTACTACGTGATAGC & \multirow{2}{*}{$60^{\circ} \mathrm{C}$} \\
\hline & & & $\begin{array}{c}\text { Peritrophin } 3-\mathrm{C} \\
\text { RTR }\end{array}$ & CCATTGCCGCAAGTCTTCAA & \\
\hline \multirow{2}{*}{ SgAbd-2-like } & \multirow{2}{*}{ gi|328792988 } & \multirow{2}{*}{ não } & SgAbd-2 RTF & GGAAGCTGATCACCATCCAT & \multirow{2}{*}{$60^{\circ} \mathrm{C}$} \\
\hline & & & SgAbd-2 RTR & ACGTACCTCTTGCTGACGAA & \\
\hline \multirow{2}{*}{ Peroxiredoxina } & \multirow{2}{*}{ gi|328777120 } & \multirow{2}{*}{$\operatorname{sim}$} & Peroxi-2RTF & TCGCACGTGATTATGGCGTA & \multirow{2}{*}{$60^{\circ} \mathrm{C}$} \\
\hline & & & Peroxi-2 RTR & AGCCAGCTGGACATACTTCT & \\
\hline \multirow{2}{*}{ GB13208 } & \multirow{2}{*}{ gi|328782451 } & \multirow{2}{*}{$\operatorname{sim}$} & GB13208 RTF & TCTAGTCCAGTGGATCAGAT & \multirow{2}{*}{$60^{\circ} \mathrm{C}$} \\
\hline & & & GB13208 RTR & CCTCGAAGCTCCATATTCCA & \\
\hline \multirow{2}{*}{ GB14037 } & \multirow{2}{*}{ gi|48097532 } & \multirow{2}{*}{$\operatorname{sim}$} & GB14037 RTF & TGCAGGAGATGCACAGGAA & \multirow{2}{*}{$60^{\circ} \mathrm{C}$} \\
\hline & & & GB14037 RTR & TGCCACCCACTCTGAGGTAA & \\
\hline \multirow{2}{*}{ GB15046 } & \multirow{2}{*}{ gi|328788950 } & \multirow{2}{*}{$\operatorname{sim}$} & GB15046 RTF & GAGGATGGGACTGTAATCG & \multirow{2}{*}{$60^{\circ} \mathrm{C}$} \\
\hline & & & GB15046 RTR & CTGCTGGTGGACTAGCATAA & \\
\hline \multirow{2}{*}{ GB17384 } & \multirow{2}{*}{ gi|110764443 } & \multirow{2}{*}{$\operatorname{sim}$} & GB17384 RTF & ACAATCCAGATTGCGATTCC & \multirow{2}{*}{$60^{\circ} \mathrm{C}$} \\
\hline & & & GB17384 RTR & GGAGTGACAAGAGCTTTCAC & \\
\hline \multirow{2}{*}{ GB18013 } & \multirow{2}{*}{ gi|328781235 } & \multirow{2}{*}{$\operatorname{sim}$} & GB18013 RTF & GGTAACGAGTACTTGTCACC & \multirow{2}{*}{$60^{\circ} \mathrm{C}$} \\
\hline & & & GB18013 RTR & GAGTACCGTAAGAGGTTGG & \\
\hline 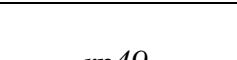 & 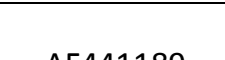 & in & rp49-F & CGTCATATGTTGCCAACTGG & ח \\
\hline rp49 & Af441189 & $\operatorname{sim}$ & rp49-R & TTGAGCACGTTCAACAATGG & 600 \\
\hline
\end{tabular}

\subsection{RT-PCR em tempo real}

Com a finalidade de comparar os níveis de expressão dos genes codificadores das proteínas cuticulares durante os estágios de desenvolvimento, assim como entre as operárias e zangões, ensaios quantitativos em tempo real foram realizados, para os genes das proteínas cuticulares que mostraram diferenças mais marcantes, utilizando-se o equipamento 7500 
Real-time PCR System (Applied Biosystems), submetendo $1 \mu \mathrm{L}$ de cada uma das amostras de cDNA sintetizadas, como descrito no item 3.7. para a reação de PCR. A amplificação foi realizada em placas de 96 poços em volume de reação de $25 \mu \mathrm{L}$, contendo $6,25 \mu \mathrm{L}$ de SYBR Green PCR Master MIX 2x (Applied Biosystems), e 10 $\mu \mathrm{M}$ de cada par de primer específico para os genes analisados, nas seguintes condições: $94^{\circ} \mathrm{C} 2 \mathrm{~min}$, seguido de três ciclos de $94^{\circ} \mathrm{C}$ $30 \mathrm{~s}, 60^{\circ} \mathrm{C} 1 \mathrm{~min}$ e $72^{\circ} \mathrm{C} 1 \mathrm{~min}, 72^{\circ} \mathrm{C} 10 \mathrm{~min}$. Os valores obtidos foram normalizados usando os níveis de mRNA de rp49 de A. mellifera como um controle interno. Para checar a reprodutibilidade, foram realizadas duplicatas experimentais (réplicas técnicas) e triplicatas biológicas (amostras independentes). 


\section{RESULTADOS}

\subsection{Avaliação dos métodos de extração das proteínas do tegumento}

Foram comparados os perfis proteicos de amostras de tegumento homogeneizadas em presença de diferentes reagentes químicos e ultrassom, em três diferentes protocolos. Quanto às concentrações de proteínas solubilizadas, os valores obtidos com o protocolo I (média de $1,1 \mu \mathrm{g} / \mu \mathrm{L}$ ) foram superiores aos obtidos com o protocolo II (média de $0,92 \mu \mathrm{g} / \mu \mathrm{L}$ ) e


Bradford (1976) para a quantificação espectrofotométrica de proteínas. Além do mais, quando os procedimentos de extração foram avaliados quanto à quantidade de bandas, e provavelmente de proteínas diferentes, foi reforçada a maior eficiência do protocolo III (Figura 1). Deve-se levar em conta o fato de que foram obtidos melhores resultados com o protocolo III, mesmo utilizando-se coloração com Coomassie Brilliant Blue G-250, que não é tão sensível quanto a coloração com prata utilizada nos protocolos I e II.

(A)

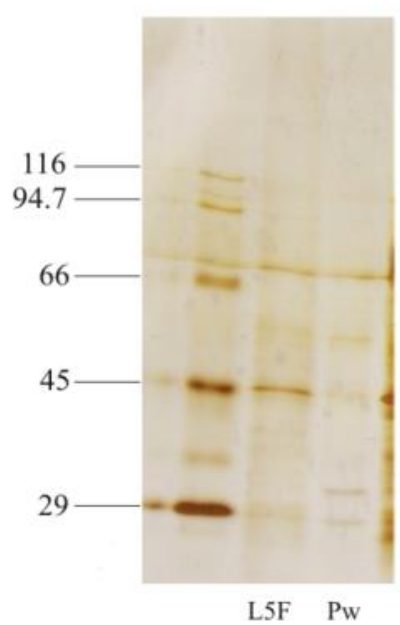

(B)

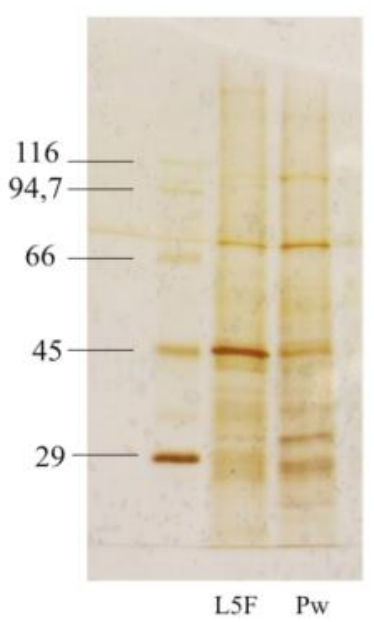

(C)

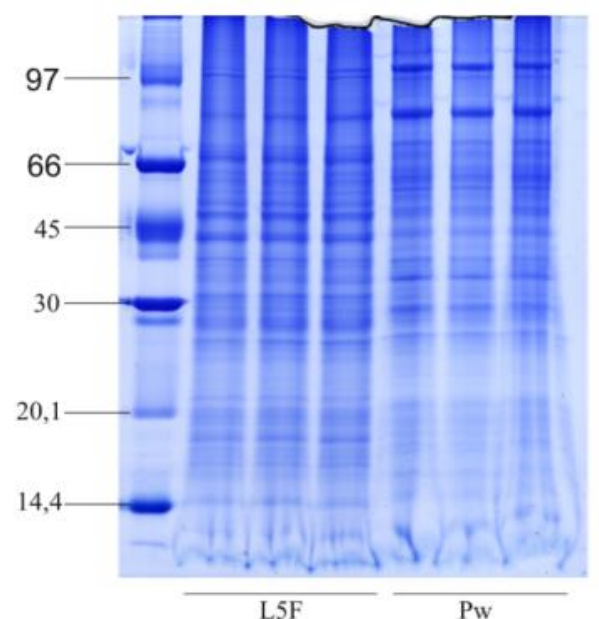

Figura 1. SDS-PAGE de extratos de tegumentos de larvas de $5^{\circ}$ instar L5F e de pupas Pw de abelhas operárias (A) Protocolo I - Utilização de ureia e TFA para extração de proteínas e coloração com prata; (B) Protocolo IIUtilização de SDS e DTT para extração de proteínas e coloração com prata; (C) Protocolo III - Utilização de ureia, tioureia e ultrassom, com coloração com Coomassie Brilliant Blue G-250. Massa total de proteínas de cada amostra: $200 \mathrm{ug} / \mathrm{mL}$. Marcadores moleculares na pista esquerda de cada gel. 


\subsection{Otimização da relação entre quantidade de proteína total $(\mu g)$ e número de}

spots bem definidos nos géis SDS-PAGE bidimensionais

Foi estabelecida a melhor relação entre a quantidade de proteína adicionada na fita de IPG e o número de spots obtidos. Foram comparados extratos de tegumentos de pupas (Pw) contendo 100,150 e $200 \mu \mathrm{g}$ de proteína total em cada fita. A melhor resolução e o maior número de spots foram obtidos com a amostra de $150 \mu \mathrm{g}$ (Figura 2).

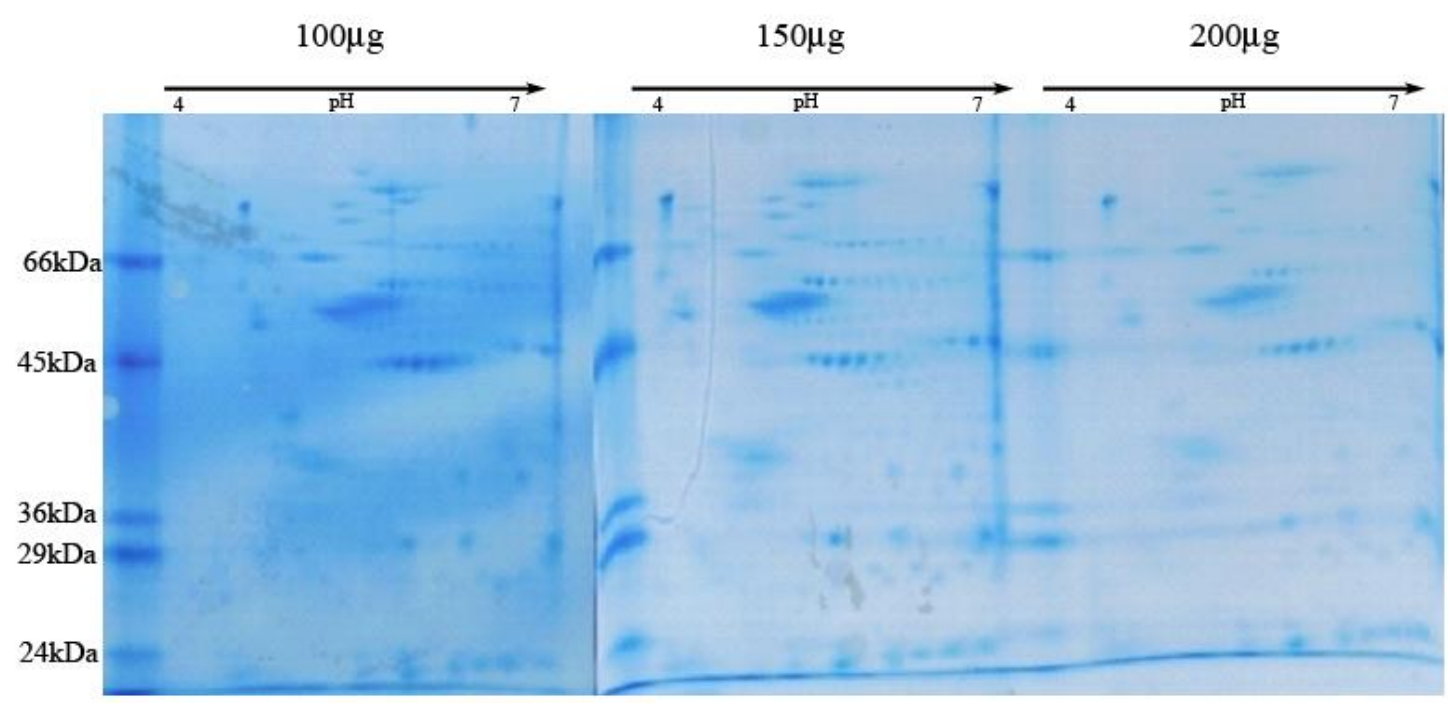

Figura 2. SDS-PAGE 12,5\% bidimensional de extratos de proteínas do tegumento de pupas (Pw) de operárias contendo diferentes quantidades de proteína total. Marcadores de massa molecular são mostrados à esquerda da figura. Coloração: Coomassie Brilliant Blue G-250.

A Figura 3 mostra os perfis proteicos do tegumento de abelhas operárias em diferentes fases de desenvolvimento (larval, pupal e adulto-farato). É possível notar que os tegumentos das diferentes fases de desenvolvimento resultaram em perfis característicos, contendo proteínas que são compartilhadas, assim como próprias. (Na Figura 15 observa-se algumas proteínas compartilhadas entre todas as fases analisadas, como a Flexible protein 12 (Amel CPR12) e a Cuticular protein analogous to Peritrophin 3-C, assim como foram encontradas proteínas fase específicas como a Cuticular protein analogous to Peritrophin 3-D). Notam-se spots "em linhas", que podem ser interpretados como possíveis alterações pós-traducionais, uma vez que não há alteração significativa das respectivas massas moleculares, mas apenas do ponto isoelétrico. Tais modificações oferecem uma grande flexibilidade de regulação e possivelmente possuem implicações nas propriedades estruturais da cutícula. 


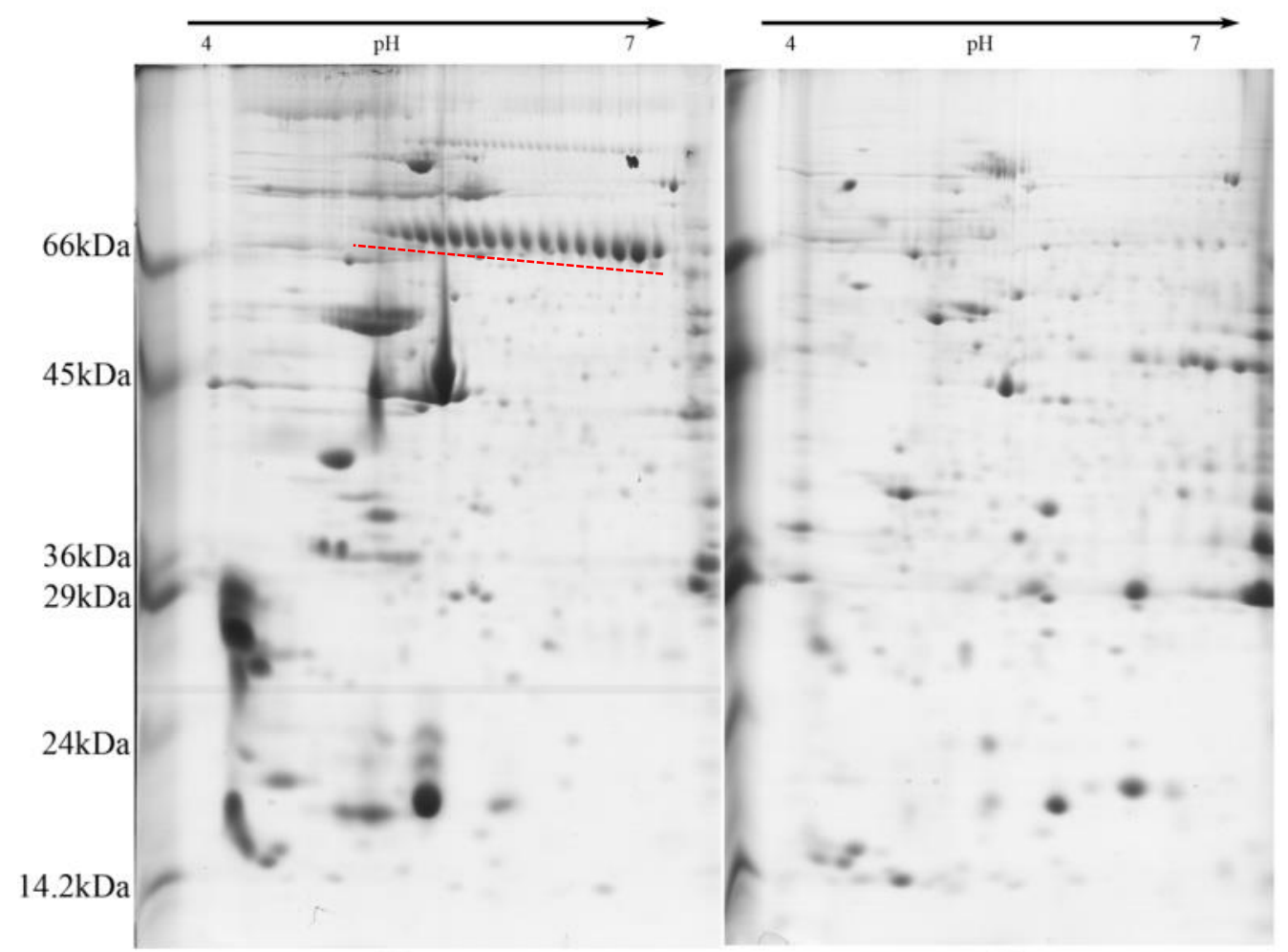

(A)

(B)

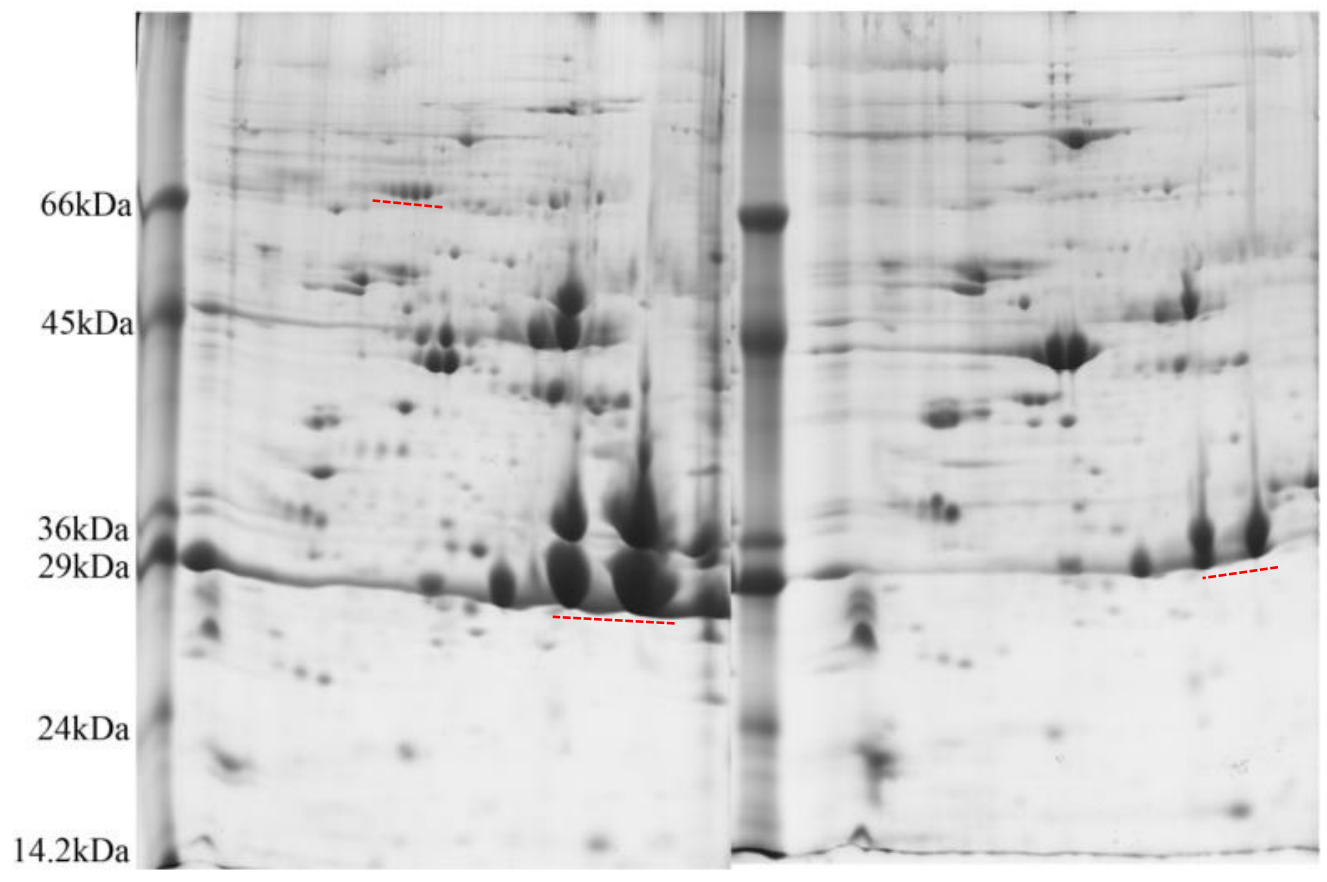

(C)

(D)

Figura 3- SDS PAGE 12,5\% bidimensional de proteínas do tegumento de abelhas operárias em estágio larval L5F (A), pupal Pw (B) e adulto-farato Pbl (C) e Pbd (D). As amostras foram preparadas com 150ug de proteínas. As linhas tracejadas indicam múltiplas formas de algumas proteínas, possivelmente resultantes de modificações pós-traducionais. Marcadores moleculares foram colocados à esquerda de cada gel. Coloração com Coomassie Brilliant Blue G-250. 


\subsection{Caracterização e identificação de proteínas do tegumento de abelhas operárias e zangões em desenvolvimento}

Na Figura 4, observam-se as eletroforeses bidimensionais dos tegumentos referentes à fase larval (L5F) de operárias (A) e zangões (B), notando-se uma grande abundância de spots e uma grande semelhança entre os morfotipos. As proteínas identificadas por espectrometria de massas estão numeradas e as destacadas em vermelho são aquelas com características moleculares de proteínas cuticulares. Ao total foram identificados 40 spots, que correspondem a 20 proteínas diferentes, cinco com múltiplas formas eletroforéticas (variação de massa molecular e/ou ponto isoelétrico) e oito proteínas cuticulares (Tabela 3 ).

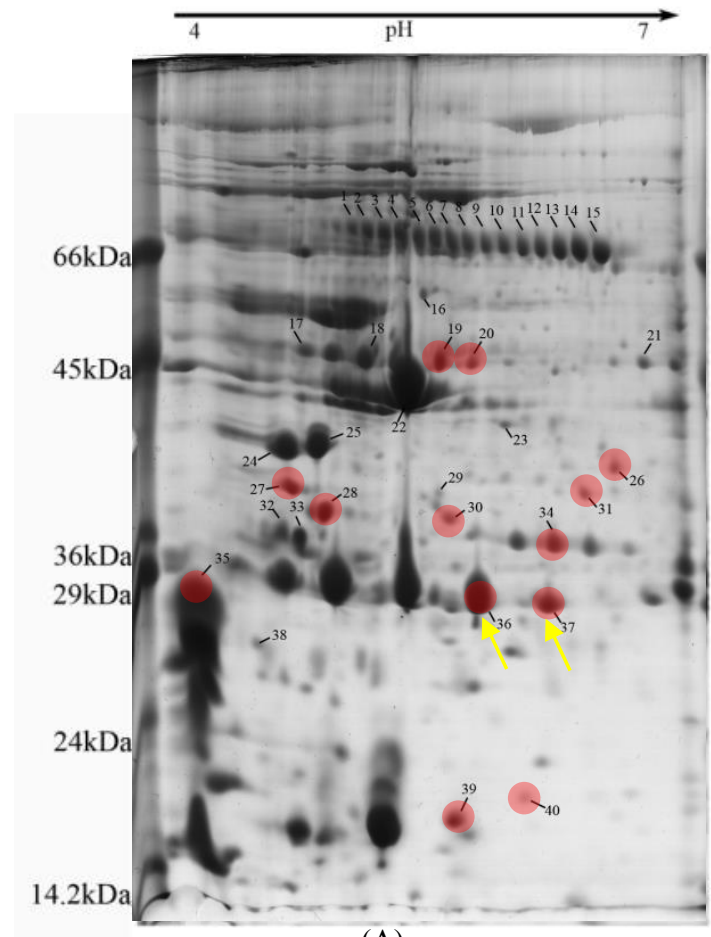

(A)

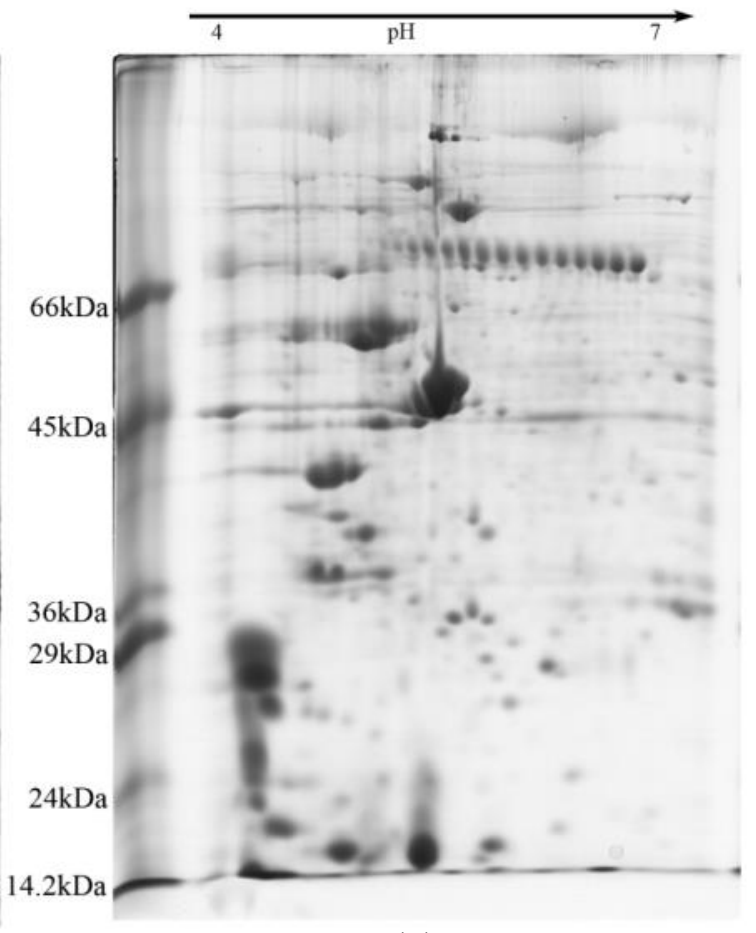

(B)

Figura 4. SDS-PAGE bidimensional de proteínas do tegumento de larvas (L5F) de operárias (A) e zangões (B). Os números correspondem às proteínas que foram identificadas por espectrometria de massa, em destaque (vermelho) estão as proteínas cuticulares. Massa total de proteínas em cada amostra: 150ug. Marcadores moleculares são mostrados à esquerda de cada gel. $\mathrm{O}$ intervalo de $\mathrm{pH}$ está indicado acima da figura. As setas amarelas indicam múltiplas formas de Apidermin-3-like APD-3 like.

A Tabela 3 mostra a lista de proteínas identificadas com as proteínas cuticulares destacadas em cinza. 
Tabela 3. Relação das proteínas de tegumento de larvas L5F identificadas por meio de SDS-PAGE bidimensional e espectrometria de massas.

\begin{tabular}{|c|c|c|c|c|c|c|c|c|}
\hline Spot & Protein Name & $\begin{array}{l}\text { GenBank } \\
\text { Acession } \\
\text { Number }\end{array}$ & $\begin{array}{c}\text { Theoretical } \\
\text { MW(KdA)/pI }\end{array}$ & $\begin{array}{l}\text { Experimental } \\
\mathrm{MW}(\mathbf{k D a}) / \mathbf{p I}\end{array}$ & $\begin{array}{l}\text { Peptide } \\
\text { hits }\end{array}$ & Score & Coverage & PeptideSequences \\
\hline 1 & LOC724664 & gi|32781235 & $58,42 / 6,6$ & $68,69 / 5,1$ & 34 & 503 & 17 & $\begin{array}{l}\text { K.SVPVVHISDQQDK.Q } \\
\text { R.YDHHLDNVVQVK.S } \\
\text { R.VHEGSPSTVNIVER.G } \\
\text { K.TSSPVQHAVHAVPTVVK.S } \\
\text { R.AVNFNVPLPLSSSTQLNK.N } \\
\text { K.SVGIVSHQPVETQHSVTEVLK.T }\end{array}$ \\
\hline 2 & LOC724664 & gi|32781235 & $58,42 / 6,6$ & $68,69 / 5,2$ & 34 & 503 & 17 & $\begin{array}{l}\text { K.SVPVVHISDQQDK.Q } \\
\text { R.YDHHLDNVVQVK.S } \\
\text { R.VHEGSPSTVNIVER.G } \\
\text { K.TSSPVQHAVHAVPTVVK.S } \\
\text { R.AVNFNVPLPLSSSTQLNK.N } \\
\text { K.SVGIVSHQPVETQHSVTEVLK.T }\end{array}$ \\
\hline 3 & LOC724664 & gi|32781235 & $58,42 / 6,6$ & $68,41 / 5,3$ & 34 & 584 & 18 & $\begin{array}{l}\text { R.DVLPGDPR.Y } \\
\text { K.SVPVVHISDQQDK.Q } \\
\text { R.YDHHLDNVVQVK.S } \\
\text { R.VHEGSPSTVNIVER.G } \\
\text { K.TSSPVQHAVHAVPTVVK.S } \\
\text { R.AVNFNVPLPLSSSTQLNK.N } \\
\text { K.SVGIVSHQPVETQHSVTEVLK.T }\end{array}$ \\
\hline 4 & LOC724664 & gi|32781235 & $58,42 / 6,6$ & $68,41 / 5,4$ & 34 & 450 & 15 & $\begin{array}{l}\text { R.YDHHLDNVVQVK.S } \\
\text { R.VHEGSPSTVNIVER.G } \\
\text { K.TSSPVQHAVHAVPTVVK.S } \\
\text { R.AVNFNVPLPLSSSTQLNK.N } \\
\text { K.SVGIVSHQPVETQHSVTEVLK.T }\end{array}$ \\
\hline 5 & LOC724664 & gi|32781235 & $58,42 / 6,6$ & $68,41 / 5,5$ & 34 & 369 & 15 & $\begin{array}{l}\text { R.YDHHLDNVVQVK.S } \\
\text { R.VHEGSPSTVNIVER.G } \\
\text { K.TSSPVQHAVHAVPTVVK.S } \\
\text { R.AVNFNVPLPLSSSTQLNK.N } \\
\text { K.SVGIVSHQPVETQHSVTEVLK.T }\end{array}$ \\
\hline 6 & LOC724664 & gi|32781235 & $58,42 / 6,6$ & $68,41 / 5,6$ & 34 & 492 & 17 & $\begin{array}{l}\text { K.SVPVVHISDQQDK.Q } \\
\text { R.YDHHLDNVVQVK.S } \\
\text { R.VHEGSPSTVNIVER.G } \\
\text { K.TSSPVQHAVHAVPTVVK.S } \\
\text { R.AVNFNVPLPLSSSTQLNK.N } \\
\text { K.SVGIVSHQPVETQHSVTEVLK.T }\end{array}$ \\
\hline 7 & LOC724664 & gi|32781235 & $58,42 / 6,6$ & $67,33 / 5,7$ & 34 & 496 & 17 & $\begin{array}{l}\text { K.SVPVVHISDQQDK.Q } \\
\text { R.YDHHLDNVVQVK.S } \\
\text { R.VHEGSPSTVNIVER.G } \\
\text { K.TSSPVQHAVHAVPTVVK.S } \\
\text { R.AVNFNVPLPLSSSTQLNK.N } \\
\text { K.SVGIVSHQPVETQHSVTEVLK.T }\end{array}$ \\
\hline 8 & LOC724664 & gi|32781235 & $58,42 / 6,6$ & $67,33 / 5,8$ & 34 & 527 & 17 & $\begin{array}{l}\text { K.SVPVVHISDQQDK.Q } \\
\text { R.YDHHLDNVVQVK.S } \\
\text { R.VHEGSPSTVNIVER.G }\end{array}$ \\
\hline
\end{tabular}




\begin{tabular}{|c|c|c|c|c|c|c|c|c|}
\hline & & & & & & & & $\begin{array}{l}\text { K.TSSPVQHAVHAVPTVVK.S } \\
\text { R.AVNFNVPLPLSSSTQLNK.N } \\
\text { K.SVGIVSHQPVETQHSVTEVLK.T }\end{array}$ \\
\hline 9 & LOC724664 & gi|32781235 & $58,42 / 6,6$ & $67,33 / 5,9$ & 34 & 411 & 17 & $\begin{array}{l}\text { K.SVPVVHISDQQDK.Q } \\
\text { R.YDHHLDNVVQVK.S } \\
\text { R.VHEGSPSTVNIVER.G } \\
\text { K.TSSPVQHAVHAVPTVVK.S } \\
\text { R.AVNFNVPLPLSSSTQLNK.N } \\
\text { K.SVGIVSHQPVETQHSVTEVLK.T }\end{array}$ \\
\hline 10 & LOC724664 & gi|32781235 & $58,42 / 6,6$ & $67,33 / 6,0$ & 34 & 286 & 10 & $\begin{array}{l}\text { K.SVPVVHISDQQDK.Q } \\
\text { R.YDHHLDNVVQVK.S } \\
\text { R.VHEGSPSTVNIVER.G } \\
\text { K.SVGIVSHQPVETQHSVTEVLK.T }\end{array}$ \\
\hline 11 & LOC724664 & gi|32781235 & $58,42 / 6,6$ & $67,06 / 6,1$ & 34 & 559 & 17 & $\begin{array}{l}\text { K.SVPVVHISDQQDK.Q } \\
\text { R.YDHHLDNVVQVK.S } \\
\text { R.VHEGSPSTVNIVER.G } \\
\text { K.TSSPVQHAVHAVPTVVK.S } \\
\text { R.AVNFNVPLPLSSSTQLNK.N } \\
\text { K.SVGIVSHQPVETQHSVTEVLK.T }\end{array}$ \\
\hline 12 & LOC724664 & gi|32781235 & $58,42 / 6,6$ & $66,80 / 6,2$ & 34 & 594 & 17 & $\begin{array}{l}\text { K.SVPVVHISDQQDK.Q } \\
\text { R.YDHHLDNVVQVK.S } \\
\text { R.VHEGSPSTVNIVER.G } \\
\text { K.TSSPVQHAVHAVPTVVK. } \\
\text { R.AVNFNVPLPLSSSTQLNK.N } \\
\text { K.SVGIVSHQPVETQHSVTEVLK.T }\end{array}$ \\
\hline 13 & LOC724664 & gi|32781235 & $58,42 / 6,6$ & $66,53 / 6,3$ & 34 & 620 & 18 & $\begin{array}{l}\text { R.DVLPGDPR.Y } \\
\text { K.SVPVVHISDQQDK.Q } \\
\text { R.YDHHLDNVVQVK.S } \\
\text { R.VHEGSPSTVNIVER.G } \\
\text { K.TSSPVQHAVHAVPTVVK.S } \\
\text { R.AVNFNVPLPLSSSTQLNK.N } \\
\text { K.SVGIVSHQPVETQHSVTEVLK.T }\end{array}$ \\
\hline 14 & LOC724664 & gi|32781235 & $58,42 / 6,6$ & $66,0 / 6,4$ & 34 & 353 & 17 & $\begin{array}{l}\text { R.VHEGSPSTVNIVER.G } \\
\text { K.TSSPVQHAVHAVPTVVK.S } \\
\text { R.AVNFNVPLPLSSSTQLNK.N } \\
\text { K.SVGIVSHQPVETQHSVTEVLK.T }\end{array}$ \\
\hline 15 & LOC724664 & gi|32781235 & $58,42 / 6,6$ & $65,74 / 6,5$ & 34 & 588 & 17 & $\begin{array}{l}\text { K.SVPVVHISDQQDK.Q } \\
\text { R.YDHHLDNVVQVK.S } \\
\text { R.VHEGSPSTVNIVER.G } \\
\text { K.TSSPVQHAVHAVPTVVK.S } \\
\text { R.AVNFNVPLPLSSSTQLNK.N } \\
\text { K.SVGIVSHQPVETQHSVTEVLK.T } \\
\end{array}$ \\
\hline 16 & $\begin{array}{l}60 \mathrm{kDa} \\
\text { Heat shock } \\
\text { protein }\end{array}$ & gi|66547450 & $60,41 / 5,6$ & $56,94 / 5,5$ & 70 & 227 & 16 & $\begin{array}{l}\text { R.NVILEQSWGSPK.I } \\
\text { R.AAVEEGIVPGGGTALLR.C } \\
\text { K.ISSVQSIIPALELANSQR.K } \\
\text { R.KPLVIIAEDIDGEALSTLVVNR.L } \\
\text { K.LVQDVANNTNEEAGDGTTTATVLAR. } \\
\text { A }\end{array}$ \\
\hline
\end{tabular}




\begin{tabular}{|c|c|c|c|c|c|c|c|c|}
\hline 17 & LOC725960 & gi|110755329 & $52 / 4,6$ & $46,83 / 4,8$ & 55 & 74 & 2 & K.SYELPDGQVITIGNER.F \\
\hline 18 & ATP synthase & gi|328785025 & $55,35 / 5,3$ & $49,52 / 5,3$ & 50 & 83 & 7 & $\begin{array}{l}\text { R.GQSVLDSGYPIR.I } \\
\text { R.IINVIGEPIDER.G } \\
\text { R.LVLEVAQHLGENTVR.T }\end{array}$ \\
\hline 19 & APD-3-like & gi|290578564 & $23,59 / 6,5$ & $45,36 / 5,6$ & 8 & 116 & 7 & K.ANVGPQSGPSDSVGPQEGAK.N \\
\hline 20 & APD-3-like & gi|290578564 & $23,59 / 6,5$ & $44,93 / 5,8$ & 8 & 116 & 7 & K.ANVGPQSGPSDSVGPQEGAK.N \\
\hline 21 & LOC100577680 & gi|328777526 & $41,3 / 6,4$ & $44,93 / 6,8$ & 29 & 593 & 32 & $\begin{array}{l}\text { R.LIELLTAR.G } \\
\text { R.VSVQQPTFIK.T } \\
\text { K.TISPAYEYYH.- } \\
\text { K.ALAPTIAHAAVPVYQK.T } \\
\text { R.VISATPAPESAEPADER.V } \\
\text { R.VVVRPAGSAVVELDQPTSK.T } \\
\text { R.VVISRPIETLQEVNVVEPATK.I } \\
\text { R.GNVAEVGFGHSSPSQSAIGDAGQVR.G }\end{array}$ \\
\hline 22 & $\begin{array}{l}\text { Actin-clone } \\
\text { 205-like isoform }\end{array}$ & gi|328790806 & $41,78 / 5,3$ & $44,24 / 5,6$ & 37 & 693 & 22 & $\begin{array}{l}\text { K.AGFAGDDAPR.A } \\
\text { R.GYSFTTTAER.E } \\
\text { K.IWHHTFYNELR.V } \\
\text { K.SYELPDGQVITIGNER.F } \\
\text { R.VAPEEHPVLLTEAPLNPK.A } \\
\text { K.DLYANNVLSGGTTMYPGIADR.M }\end{array}$ \\
\hline 23 & Silkfibroin3 & gi|209969888 & $33,53 / 5,8$ & $41,41 / 6,0$ & 37 & 186 & 13 & $\begin{array}{l}\text { K.ASALALAEAYLR.A } \\
\text { R.LATVAQNVASDLQK.R } \\
\text { K.IESVAAAEGSANSASEDSR.A }\end{array}$ \\
\hline 24 & $\begin{array}{l}\text { Tropomyosin-1- } \\
\text { like }\end{array}$ & gi|66522386 & $32,16 / 4,7$ & $40,28 / 4,7$ & 51 & 602 & 18 & $\begin{array}{l}\text { K.VQLIEEDLER.S } \\
\text { R.KVQLIEEDLER.S } \\
\text { K.ALTNAESEVAALNR.K } \\
\text { K.EVDRLEDELGINK.D } \\
\text { K.LAFVEDELEVAEDR.V } \\
\text { R.KLAFVEDELEVAEDR.V } \\
\end{array}$ \\
\hline 25 & $\begin{array}{l}\text { Tropomyosin } 1 \text { is } \\
\text { oform B }\end{array}$ & gi|229577296 & $32,8 / 4,7$ & $40,34 / 4,9$ & 51 & 558 & 25 & $\begin{array}{l}\text { K.IVELEEELR.V } \\
\text { K.LAMVEADLER.A } \\
\text { R.IQLLEEDLER.S } \\
\text { R.KLAMVEADLER.A } \\
\text { K.LAEASQAADESER.A } \\
\text { R.RIQLLEEDLER.S } \\
\text { K.ALQNAESEVAALNR.R } \\
\text { K.EVDRLEDELVHEK.E } \\
\end{array}$ \\
\hline 26 & LOC100577363 & gi|328790553 & $39,79 / 7,0$ & $39,12 / 6,6$ & 33 & 152 & 11 & $\begin{array}{l}\text { R.YPLYISGTR.D } \\
\text { R.FEIPEDSER.K } \\
\text { R.SQVCVPTPLYR.R } \\
\text { R.FEMYLCPNNNPR.N } \\
\end{array}$ \\
\hline 27 & $\begin{array}{l}\text { Peritrophins } 3-\mathrm{C} \\
\text { analogous }\end{array}$ & gi|288869506 & $29,53 / 4,9$ & $38,11 / 4,8$ & 24 & 47 & 3 & R.LYGIFPDEK.K \\
\hline 28 & LOC413679 & gi|328787428 & $29,11 / 4,9$ & $36,90 / 4,9$ & 23 & 72 & 4 & K.SPNAIQHLLVGK.R \\
\hline
\end{tabular}







Peptide hits: Peptídeos com similaridade com o banco de dados

Score: é uma medida de probabilidade baseada no número de correspondências entre a sequência submetida e o banco de dados.

Coverage: Porcentagem de cobertura da proteína pelos peptídeos identificados. 
Devido à similaridade entre os perfis eletroforéticos dos tegumentos de operárias e zangões, tanto em estágio larval (L5F), como pupal ( $\mathrm{Pw}$ ) e adulto-farato ( $\mathrm{Pbl}$ e $\mathrm{Pbd}$ ), foram submetidas à identificação pela espectrometria de massas apenas as amostras de operárias. A única diferença notada entre os morfotipos foi a presença nas operárias de uma série de spots da proteína APD-3 like (Figura 4) com possíveis modificações pós-traducionais, de aproximadamente $24 \mathrm{kDa}$. Esta série não foi frequente mesmo entre as amostras do tegumento de larvas de L5F operárias. Assim, pode ser considerada apenas como uma flutuação amostral. A Figura 5 mostra as eletroforeses bidimensionais de tegumentos de pupas Pw de operárias (A) e zangões (B). É possível notar, novamente, a grande semelhança dos perfis entre os morfotipos.

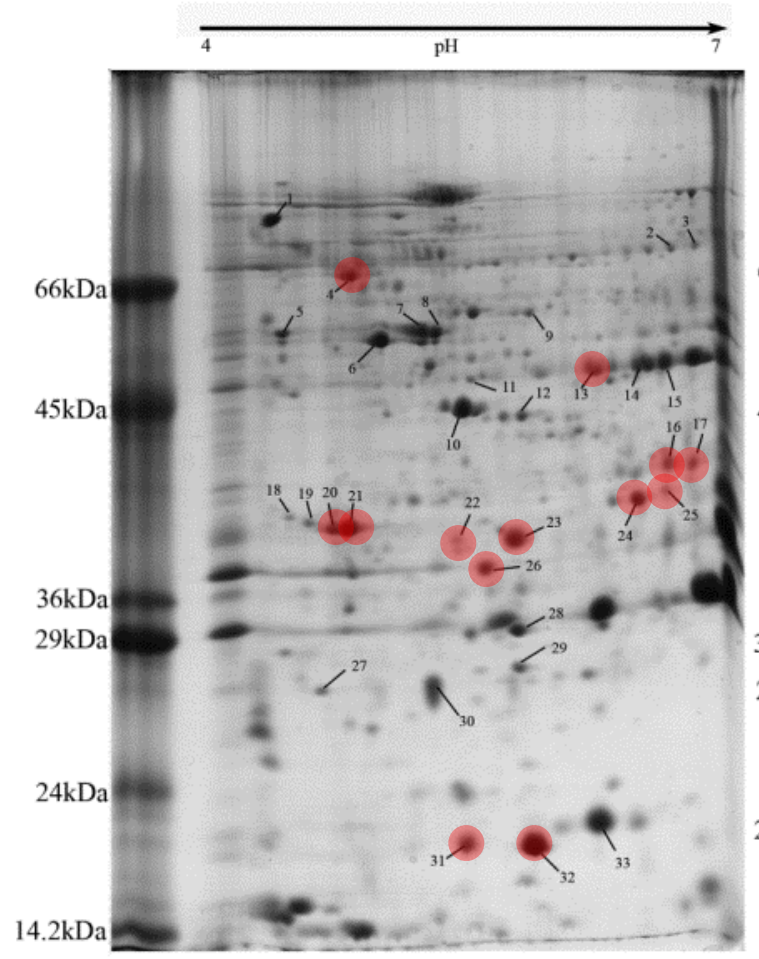

(A)



(B)

Figura 5. SDS-PAGE bidimensional de amostras de tegumento pupal (Pw) de operárias (A) e zangões (B). Os números correspondem às proteínas que foram identificadas por espectrometria de massas, em destaque (vermelho) estão as proteínas cuticulares. Cada amostra contem 150ug de proteína. Marcadores de massa molecular são mostrados à esquerda de cada gel. O intervalo de pH está indicado acima da figura.

Foram identificados 33 spots correspondentes a 23 proteínas diferentes, sete delas com múltiplas formas eletroforéticas, e oito proteínas cuticulares. Na Tabela 4, temos a relação das proteínas identificadas no tegumento pupal $(\mathrm{Pw})$. Destacadas em cinza estão as proteínas com domínios estruturais cuticulares. 
Tabela 4. Relação de proteínas do tegumento de pupas $(\mathrm{Pw})$ identificadas por meio de SDS-PAGE bidimensional e espectrometria de massas.

\begin{tabular}{|c|c|c|c|c|c|c|c|c|}
\hline Spot & ProteinName & $\begin{array}{l}\text { GenBank } \\
\text { Acession } \\
\text { Number }\end{array}$ & $\begin{array}{c}\text { Theoretical } \\
\text { MW(KdA)/pI }\end{array}$ & $\begin{array}{l}\text { Experimental } \\
\mathrm{MW}(\mathbf{k D a}) / \mathbf{p I}\end{array}$ & $\begin{array}{l}\text { Peptide } \\
\text { hits }\end{array}$ & Score & Coverage & PeptideSequences \\
\hline 1 & LOC725960 & gi|110755329 & $52 / 4,6$ & $82,92 / 4,4$ & 55 & 227 & 10 & $\begin{array}{l}\text { K.KPEQPAVQQDQAK.A } \\
\text { K.AGDESKPELLPKPQELKV.- } \\
\text { K.AQQPAAVEQPALSSEESSSK.S }\end{array}$ \\
\hline 2 & LOC100577680 & gi|328777526 & $41,3 / 6,4$ & $77,34 / 6,7$ & 29 & 159 & 15 & $\begin{array}{l}\text { R.VISATPAPESAEPADER.V } \\
\text { R.VVVRPAGSAVVELDQPTSK.T } \\
\text { R.GNVAEVGFGHSSPSQSAIGDAGQVR.G }\end{array}$ \\
\hline 3 & LOC100577680 & gi|328777526 & $41,3 / 6,4$ & $78,25 / 6,8$ & 29 & 46 & 11 & $\begin{array}{l}\text { R.VVVRPAGSAVVELDQPTSK.T } \\
\text { R.GNVAEVGFGHSSPSQSAIGDAGQVR.G }\end{array}$ \\
\hline 4 & LOC408365 & gi|48097532 & $60,6 / 4,9$ & $69,40 / 4,9$ & 52 & 157 & 4 & $\begin{array}{l}\text { K.DAGEWFR.L } \\
\text { K.DKDAGEWFR.L } \\
\text { R.APLGLYFHAAWLK.N }\end{array}$ \\
\hline 5 & Calreticulin isoform1 & gi|66545506 & $47,17 / 4,4$ & $57,42 / 4,5$ & 44 & 181 & 11 & $\begin{array}{l}\text { K.NWVYSEHPGK.E } \\
\text { R.SGTIFDNVLITDDPEVAR.K } \\
\text { K.FWNDPENDKGIQTSQDAR.F }\end{array}$ \\
\hline 6 & Tubulin beta-1 chain & gi|408782 & $49,84 / 5,0$ & $56,32 / 5,0$ & 37 & 476 & 15 & $\begin{array}{l}\text { R.YLTVAAIFR.G } \\
\text { R.FPGQLNADLR.K } \\
\text { K.LAVNMVPFP.L } \\
\text { R.ISEQFTAMFR.R } \\
\text { R.ISEQFTAMFR.R + Oxidation (M) } \\
\text { R.LHFFMPGFAPLTSR.G } \\
\text { K.GHYTEGAELVDSVLDVVR.K }\end{array}$ \\
\hline 7 & Tubulin beta- 1 chain & gi|408782 & $49,84 / 5,0$ & $58,54 / 5,3$ & 40 & 342 & 16 & $\begin{array}{l}\text { K.EIVDLVLDR.I } \\
\text { R.LIGQIVSSITASLR.F } \\
\text { R.AVFIDLEPTVVDEVR.T } \\
\text { R.IHFPLVTYAPVISAEK.A } \\
\text { R.AFVHWYVGEGMEEGEFSEAR.E }\end{array}$ \\
\hline 8 & Tubulin beta-1 chain & gi|408782 & $49,84 / 5,0$ & $58,54 / 5,4$ & 40 & 285 & 13 & $\begin{array}{l}\text { K.EIVDLVLDR.I } \\
\text { R.AVFIDLEPTVVDEVR.T } \\
\text { R.IHFPLVTYAPVISAEK.A } \\
\text { R.AFVHWYVGEGMEEGEFSEAR.E }\end{array}$ \\
\hline 9 & $\begin{array}{l}\text { Protein disulfide- } \\
\text { isomerase A3 }\end{array}$ & gi|66546657 & $55,86 / 5,6$ & $62,28 / 5,9$ & 65 & 118 & 7 & $\begin{array}{l}\text { R.GFPTLYWAPK.N } \\
\text { K.GDFVSDYNGPR.E } \\
\text { K.FDATANDVPGPYEVR.G }\end{array}$ \\
\hline 10 & $\begin{array}{l}\text { Actin, clone } 205 \text {-like } \\
\text { isoform } 2\end{array}$ & gi|328790806 & $37,16 / 5,4$ & $45,35 / 5,5$ & 37 & 566 & 28 & $\begin{array}{l}\text { K.AGFAGDDAPR.A } \\
\text { R.AVFPSIVGRPR.H } \\
\text { K.IWHHTFYNELR.V } \\
\text { K.SYELPDGQVITIGNER.F } \\
\text { R.VAPEEHPVLLTEAPLNPK.A } \\
\text { K.DLYANTVLSGGTTMYPGIADR.M }\end{array}$ \\
\hline 11 & $\begin{array}{l}\text { Protein disulfide- } \\
\text { isomerase A6-like }\end{array}$ & gi|66551889 & $47,2 / 5,1$ & $49,96 / 5,6$ & 45 & 118 & 9 & $\begin{array}{l}\text { K.STDFVQEYDGGR.T } \\
\text { K.GSFSYDGINEFLR.D } \\
\text { K.IFGIDNKPEDYNGPR.T } \\
\end{array}$ \\
\hline 12 & Beta- & gi|328778710 & $43,43 / 5,6$ & $44,81 / 5,9$ & 34 & 54 & 4 & R.VGLIQHSIVLPTTEPLQK.Q \\
\hline
\end{tabular}




\begin{tabular}{|c|c|c|c|c|c|c|c|c|}
\hline & ureidopropionase-like & & & & & & & \\
\hline 13 & $\begin{array}{l}\text { LOC409345 } \\
\text { (Amel CPR3) }\end{array}$ & gi|110764443 & $34,35 / 5,5$ & $51,92 / 6,3$ & 24 & 159 & 5 & R.NGDLVQGSYSLIEADGTR.R \\
\hline 14 & LOC100577680 & gi|328777526 & $41,3 / 6,4$ & $52,94 / 6,5$ & 29 & 317 & 21 & $\begin{array}{l}\text { R.VISATPAPESAEPADER.V } \\
\text { R.VVVRPAGSAVVELDQPTSK.T } \\
\text { R.VVISRPIETLQEVNVVEPATK.I } \\
\text { R.GNVAEVGFGHSSPSQSAIGDAGQVR.G }\end{array}$ \\
\hline 15 & LOC100577680 & gi|328777526 & $41,3 / 6,4$ & $53,35 / 6,7$ & 29 & 498 & 30 & $\begin{array}{l}\text { R.LIELLTAR.G } \\
\text { R.VSVQQPTFIK.T } \\
\text { K.ALAPTIAHAAVPVYQK.T } \\
\text { R.VISATPAPESAEPADER.V } \\
\text { R.VVVRPAGSAVVELDQPTSK.T } \\
\text { R.VVISRPIETLQEVNVVEPATK.I } \\
\text { R.GNVAEVGFGHSSPSQSAIGDAGQVR.G }\end{array}$ \\
\hline 16 & LOC100577363 & gi|328790553 & $39,79 / 6,7$ & $42,53 / 6,7$ & 33 & 96 & 5 & $\begin{array}{l}\text { R.YPLYISGTR.D } \\
\text { R.FEIPEDSER.K }\end{array}$ \\
\hline 17 & $\begin{array}{l}\text { LOC409345 } \\
\text { (Amel CPR3) }\end{array}$ & gi|110764443 & $34,35 / 5,5$ & $42,59 / 6,8$ & 24 & 90 & 5 & R.NGDLVQGSYSLIEADGTR.R \\
\hline 18 & Annexin-B9-like & gi|66530530 & $35,94 / 4,6$ & $39,43 / 4,7$ & 36 & 214 & 13 & $\begin{array}{l}\text { R.LAGHSLEDAIK.R } \\
\text { K.GFGTDEQTIIDVLAHR.G } \\
\text { R.DENPDVDGEAAIQDAER.L }\end{array}$ \\
\hline 19 & LOC412543 & gi|328788413 & $49 / 5,2$ & $39,70 / 4,5$ & 40 & 52 & 2 & K.DIDGNDLYVGR.A \\
\hline 20 & Peritrofinas 3-C & gi|288869506 & $29,53 / 4,9$ & $39,16 / 4,8$ & 24 & 47 & 3 & R.LYGIFPDEK.K \\
\hline 21 & Peritrofinas 3-C & gi|288869506 & $29,53 / 4,9$ & $39,16 / 4,7$ & 17 & 126 & 11 & $\begin{array}{l}\text { R.LYGIFPDEK.K } \\
\text { K.YYICLEGIAR.E } \\
\text { K.YQCSPGLAYDR.E }\end{array}$ \\
\hline 22 & LOC725838 & gi|328788950 & $27,82 / 6,1$ & $38,83 / 5,8$ & 18 & 142 & 15 & \\
\hline 23 & LOC725838 & gi|328788950 & $27,82 / 6,1$ & $38,83 / 5,9$ & 14 & 397 & 37 & $\begin{array}{l}\text { K.AAHFAEFAR.A } \\
\text { R.LAELAEAEAR.A } \\
\text { R.FAPPAPVGQDGNVIDTPEVAQAK.A } \\
\text { K.NQPQSVEYNPQSQPYNFPSPQPPAYVR.Q } \\
\text { K.FAQEYKPEVQGQAYASPPAAPVQYNSPA } \\
\text { AR.V }\end{array}$ \\
\hline 24 & $\begin{array}{l}\text { LOC100576341 } \\
\text { (Amel CPR16) }\end{array}$ & gi|328779296 & $34,92 / 6,4$ & $40,81 / 6,5$ & 25 & 69 & 8 & $\begin{array}{l}\text { K.ILPSYFSFAQLTK.D } \\
\text { R.LLHSSLHHTQDSLGR.Y }\end{array}$ \\
\hline 25 & LOC100577363 & gi|328790553 & $39,79 / 6,7$ & $39,12 / 6,6$ & 33 & 96 & 11 & $\begin{array}{l}\text { R.YPLYISGTR.D } \\
\text { R.FEIPEDSER.K }\end{array}$ \\
\hline 26 & $\begin{array}{l}\text { LOC725509 } \\
(\text { Amel CPR27) }\end{array}$ & gi|328782451 & $26,07 / 7,7$ & $37,57 / 5,7$ & 18 & 122 & 15 & $\begin{array}{l}\text { K.YGFVDDTGNIR.E } \\
\text { K.AQYQPQYQPQYR.S } \\
\text { R.SQYQPQYQEQQQR.A }\end{array}$ \\
\hline
\end{tabular}




\begin{tabular}{|c|c|c|c|c|c|c|c|c|}
\hline 27 & $\begin{array}{l}\text { Tumor protein } \\
\text { homolog }\end{array}$ & gi|66515987 & $19,84 / 4,6$ & $24 / 4,8$ & 23 & 255 & 25 & $\begin{array}{l}\text { K.HGLEEQKF.- } \\
\text { R.LQETFAFGDK.K } \\
\text { R.LQETFAFGDKK.S } \\
\text { K.LVDDVLYEVYGK.V } \\
\text { K.LEEQAPDQVEVFK.K }\end{array}$ \\
\hline 28 & $\begin{array}{l}\text { Short-chain } \\
\text { dehydrogenase } \\
\text { reductase }\end{array}$ & gi|58585184 & $27,19 / 5,2$ & $31,62 / 5,9$ & 25 & 156 & 13 & $\begin{array}{l}\text { K.VIEWVEK.N } \\
\text { K.ELVVTPNR.E } \\
\text { K.VISISPDLVETDMTAQWLK. }\end{array}$ \\
\hline 29 & $\begin{array}{l}\text { Glutathione S- } \\
\text { transferase-like }\end{array}$ & gi|328793353 & $23,68 / 6,1$ & $26,76 / 5,9$ & 30 & 192 & 21 & $\begin{array}{l}\text { K.IADEVVPYYLER.L } \\
\text { R.LAAFHYEENEEIK.A } \\
\text { K.DDWEALEIDSIVDTIHDVR.A }\end{array}$ \\
\hline 30 & LOC725273 & gi|328792562 & $47,62 / 4,5$ & $24,46 / 5,4$ & 34 & 297 & 12 & $\begin{array}{l}\text { K.YDFWTSGNK.L } \\
\text { R.SLGLQLASFETK.E } \\
\text { R.ITTIQLDGVQYFVSR.M } \\
\text { R.RPGNRPADVPPGTEPQR.V }\end{array}$ \\
\hline 31 & LOC725454 & gi|110759098 & $17,65 / 6,1$ & $17,76 / 5,3$ & 13 & 119 & 12 & $\begin{array}{l}\text { R.INLAQETLK.S } \\
\text { K.LVPGAPIGLDGR.V } \\
\text { K.AEHAAAHINER.I } \\
\end{array}$ \\
\hline 32 & LOC725454 & gi|110759098 & $17,26 / 6,0$ & $18,45 / 6,0$ & 13 & 173 & 18 & $\begin{array}{l}\text { R.INLAQETLK.S } \\
\text { K.LVPGAPIGLDGR.V } \\
\text { K.AEHAAAHINER.I }\end{array}$ \\
\hline 33 & LOC100576916 & gi|328788947 & $17,26 / 6,0$ & $12,36 / 6,3$ & 11 & 344 & 39 & $\begin{array}{l}\text { R.FGYGAPIGPDGR.V } \\
\text { K.AAHLATQAYEAAR.N } \\
\text { K.NLGLHPYGALAFASLPYAYR.F } \\
\text { R.SVIPYSYLEVLDTPEVAQAK.A }\end{array}$ \\
\hline
\end{tabular}

Legenda: $\quad$ Peptide hits: Peptídeos com similaridade com o banco de dados

Score: é uma medida de probabilidade baseada no número de correspondências entre a sequência submetida e o banco de dados.

Coverage: Porcentagem de cobertura da proteína pelos peptídeos identificados. 
Os perfis eletroforéticos das amostras de tegumentos de adultas-faratas $(\mathrm{Pbl})$ estão apresentados na Figura 6, em que se nota a grande semelhança entre os perfis de operárias (A) e zangões (B), fato este que justifica a identificação apenas das amostras de operárias.

Ao total foram caracterizados 34 spots e identificadas 19 proteínas diferentes, seis destas com diferentes formas eletroforéticas e cinco proteínas cuticulares.

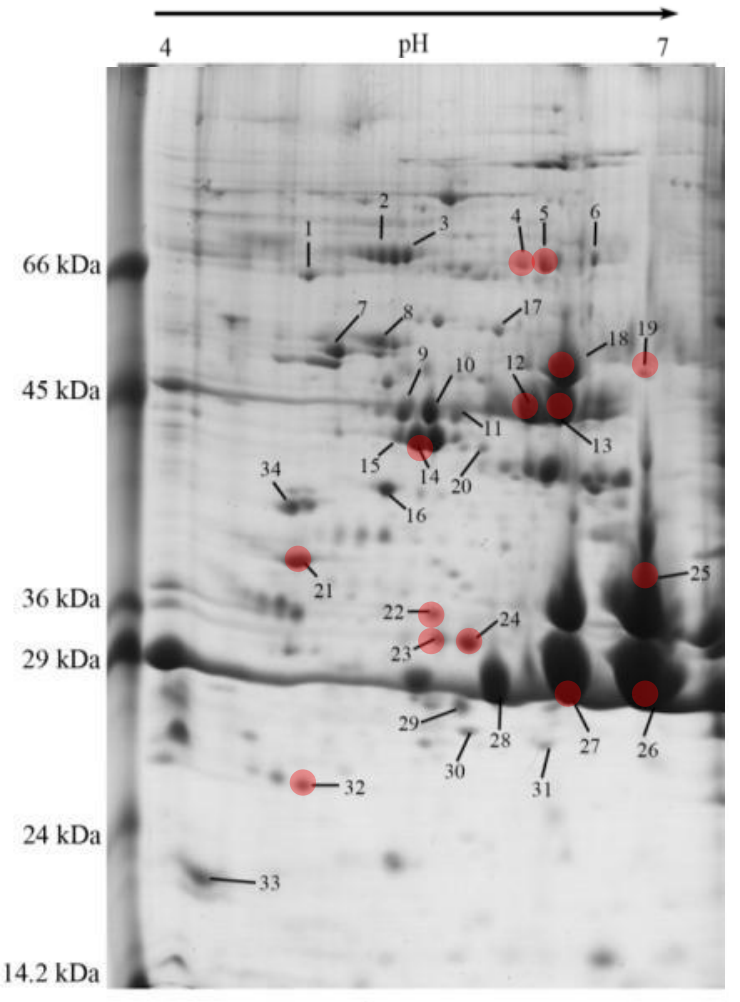

A

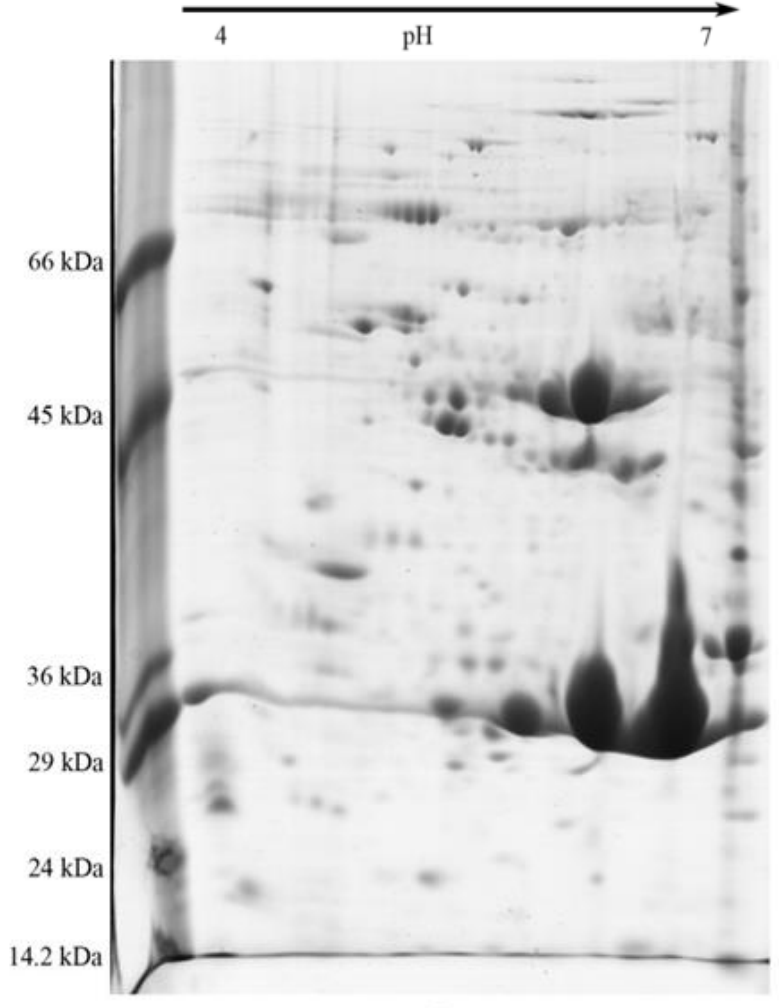

B

Figura 6. SDS-PAGE bidimensional das amostras de tegumento de adultas-faratas (Pbl) de abelhas operárias (A) e zangões (B). Os números correspondem às proteínas que foram identificadas por espectrometria de massa, em destaque (vermelho) estão as proteínas cuticulares. Cada amostra contem 150ug de proteína. Marcadores de massa molecular são mostrados à esquerda de cada gel. $\mathrm{O}$ intervalo de $\mathrm{pH}$ está indicado acima da figura.

A Tabela 5 relaciona as proteínas identificadas nos tegumentos das adultas-faratas $\mathrm{Pbl}$, em destaque as proteínas cuticulares, entre as quais, pode-se notar uma grande série da proteína APD-3 like, com modificações pós-traducionais. 
Tabela 5. Proteínas do tegumento de adultas-faratas Pbl identificadas por meio de SDS-PAGE bidimensional e espectrometria de massas. Em destaque as proteínas cuticulares.

\begin{tabular}{|c|c|c|c|c|c|c|c|c|}
\hline Spot & ProteinName & $\begin{array}{l}\text { GenBank } \\
\text { Acession } \\
\text { Number }\end{array}$ & $\begin{array}{c}\text { Theoretical } \\
\text { MW(KdA)/pI }\end{array}$ & $\begin{array}{l}\text { Experimental } \\
\mathrm{MW}(\mathrm{kDa}) / \mathbf{p I}\end{array}$ & $\begin{array}{l}\text { Peptide } \\
\text { hits }\end{array}$ & Score & $\begin{array}{c}\text { Cover } \\
\text { age }\end{array}$ & PeptideSequences \\
\hline 1 & DENN domain-containing & gi|328778716 & $149,6 / 7,1$ & $63,08 / 4,8$ & 145 & 32 & 1 & R.KGSARLEPLPYGNGR.T \\
\hline 2 & LOC410975 & gi|66546405 & $78,54 / 5,2$ & $66,56 / 5,2$ & 71 & 65 & 2 & R.IEIPEDTPYGIFAR.S \\
\hline 3 & LOC410975 & gi|66546405 & $78,54 / 5,2$ & $66,55 / 5,3$ & 71 & 81 & 2 & R.IEIPEDTPYGIFAR.S \\
\hline 4 & Proteína APD-3-like & gi|290578564 & $23,59 / 6,5$ & $64,12 / 5,9$ & 8 & 116 & 7 & K.ANVGPQSGPSDSVGPQEGAK.N \\
\hline 5 & Proteína APD-3-like & gi|290578564 & $23,59 / 6,5$ & $63,60 / 6,0$ & 8 & 179 & 11 & $\begin{array}{l}\text { R.ADIGPAEGPK.A } \\
\text { K.ANVGPQSGPSDSVGPQEGAK.N }\end{array}$ \\
\hline 6 & Peroxidase & gi|328776817 & $80,56 / 5,9$ & $64,65 / 6,3$ & 66 & 80 & 4 & $\begin{array}{l}\text { R.ELAFTIEQLNEIR.K } \\
\text { K.ASDQYFDPEITHFLFR.N }\end{array}$ \\
\hline 7 & Tubulin beta- 1 chain & gi|408782 & $50,18 / 4,8$ & $49,47 / 4,9$ & 37 & 525 & 20 & $\begin{array}{l}\text { R.YLTVAAIFR.G } \\
\text { K.IREEYPDR.I } \\
\text { R.FPGQLNADLR.K } \\
\text { K.LAVNMVPFPR.L } \\
\text { R.ISEQFTAMFR.R } \\
\text { R.INVYYNEASGGK.Y } \\
\text { R.AILVDLEPGTMDSVR.S } \\
\text { K.GHYTEGAELVDSVLDVVR.K }\end{array}$ \\
\hline 8 & Tubulin beta- 1 chain & gi|408782 & $50,18 / 4,8$ & $50,92 / 5,1$ & 40 & 205 & 11 & $\begin{array}{l}\text { K.EIVDLVLDR.I } \\
\text { R.QLFHPEQLITGK.E } \\
\text { R.LIGQIVSSITASLR.F } \\
\text { R.AVFIDLEPTVVDEVR.T }\end{array}$ \\
\hline 9 & Proteína Yellow-like & gi|290578556 & $48,71 / 5,5$ & $43,47 / 5,3$ & 36 & 397 & 17 & $\begin{array}{l}\text { K.LFVTVPR.W } \\
\text { R.GLLWIISDR.M } \\
\text { R.TLFFHPLSSR.R } \\
\text { R.WGTQFGQAPLLER.F } \\
\text { K.GEYIPENALPVGIEIWR.N } \\
\text { R.DENLSQNSYHEFQILPER.G }\end{array}$ \\
\hline 10 & Proteína Yellow-like & gi|290578556 & $48,71 / 5,5$ & $43,42 / 5,4$ & 36 & 42 & 4 & $\begin{array}{l}\text { R.GLLWIISDR.M } \\
\text { R.TLFFHPLSSR.R }\end{array}$ \\
\hline 11 & Proteína Yellow-like & gi|290578556 & $48,71 / 5,5$ & $43,42 / 5,5$ & 36 & 47 & 3 & $\begin{array}{l}\text { K.LFVTVPR.W } \\
\text { R.GLLWIISDR.M }\end{array}$ \\
\hline 12 & Proteína APD-3-like & gi|290578564 & $23,59 / 6,5$ & $43,36 / 5,9$ & 8 & 170 & 11 & $\begin{array}{l}\text { R.ADIGPAEGPK.A } \\
\text { K.ANVGPQSGPSDSVGPQEGAK.N }\end{array}$ \\
\hline 13 & Proteína APD-3-like & gi|290578564 & $23,59 / 6,5$ & $44,70 / 6,1$ & 8 & 170 & 11 & $\begin{array}{l}\text { R.ADIGPAEGPK.A } \\
\text { K.ANVGPQSGPSDSVGPQEGAK.N }\end{array}$ \\
\hline 14 & Actin, clone 205 -like & gi|66509780 & $48,71 / 5,5$ & $43,42 / 5,4$ & 37 & 579 & 22 & $\begin{array}{l}\text { K.AGFAGDDAPR.A } \\
\text { R.GYSFTTTAER.E } \\
\text { K.IWHHTFYNELR.V } \\
\text { K.SYELPDGQVITIGNER.F } \\
\text { R.VAPEEHPVLLTEAPLNPK.A } \\
\text { K.DLYANNVLSGGTTMYPGIADR. }\end{array}$ \\
\hline
\end{tabular}




\begin{tabular}{|c|c|c|c|c|c|c|c|c|}
\hline & & & & & & & & M \\
\hline 15 & Actin, clone 205-like & gi|66509780 & $48,71 / 5,5$ & $43,42 / 5,3$ & & & & \\
\hline 16 & Tropomyosin-2-like & gi $\mid 48129583$ & $32,9 / 5,1$ & $40,20 / 5,2$ & 61 & 246 & 10 & $\begin{array}{l}\text { K.LALVEEELEGGAEER.V } \\
\text { K.KLALVEEELEGAEER.V } \\
\text { K.IIEREDELFIVQNIVK.S }\end{array}$ \\
\hline 17 & $\begin{array}{l}\text { Proteindisulfide-isomerase } \\
\text { A3 }\end{array}$ & gi|66546657 & $55,86 / 5,6$ & $51,98 / 5,8$ & 65 & 59 & 3 & K.FDATANDVPGPYEVR.G \\
\hline 18 & Proteína APD-3-like & gi|290578564 & $23,59 / 6,5$ & $44,88 / 6,1$ & 8 & 229 & 11 & $\begin{array}{l}\text { R.ADIGPAEGPK.A } \\
\text { K.ANVGPQSGPSDSVGPQEGAK.N }\end{array}$ \\
\hline 19 & Proteína APD-3-like & gi|290578564 & $23,59 / 6,5$ & $44,88 / 6,5$ & 8 & 116 & 11 & K.ANVGPQSGPSDSVGPQEGAK.N \\
\hline 21 & $\begin{array}{l}\text { Cuticular protein } \\
\text { analogous to peritrophins } \\
\text { 3-D }\end{array}$ & gi|288869485 & $20,42 / 4,7$ & $39,21 / 4,9$ & 15 & 46 & 2 & R.FWPYPR.Y \\
\hline 22 & $\begin{array}{l}\text { LOC725509 } \\
\text { (Amel CPR27) }\end{array}$ & gi|328782451 & $26,07 / 7,7$ & $32,81 / 5,4$ & 18 & 223 & 15 & $\begin{array}{l}\text { K.YPTGEVYGK.Y } \\
\text { K.YGFVDDTGNIR.E } \\
\text { K.AQYQPQYQPQYR.S } \\
\text { R.SQYQPQYQEQQR.A }\end{array}$ \\
\hline 23 & $\begin{array}{l}\text { Cuticular protein } \\
\text { analogous to peritrophins } \\
3-\mathrm{C}\end{array}$ & gi|288869506 & $29,53 / 4,9$ & $29,18 / 5,4$ & 24 & 105 & 38 & \\
\hline 25 & Proteína APD-3-like & gi|290578564 & $23,59 / 6,5$ & $39,21 / 6,5$ & 8 & 211 & 11 & $\begin{array}{l}\text { R.ADIGPAEGPK.A } \\
\text { K.ANVGPQSGPSDVGPQEGAK.N }\end{array}$ \\
\hline 26 & Proteína APD-3-like & gi|290578564 & $23,59 / 6,5$ & $35,12 / 6,5$ & 8 & 117 & 7 & K.ANVGPQSGPSDSVGPQEGAK.N \\
\hline 27 & Proteína APD-3-like & gi|290578564 & $23,59 / 6,5$ & $28,64 / 6,1$ & 8 & 168 & 11 & $\begin{array}{l}\text { R.ADIGPAEGPK.A } \\
\text { K.ANVGPQSGPSDSVGPQEGAK.N }\end{array}$ \\
\hline 28 & Proteína APD-3-like & gi|290578564 & $23,59 / 6,5$ & $24,82 / 5,7$ & 8 & 175 & 11 & $\begin{array}{l}\text { R.ADIGPAEGPK.A } \\
\text { K.ANVGPQSGPSDVGPQEGAK.N }\end{array}$ \\
\hline 29 & $\begin{array}{l}\text { Apolipoprotein D-like } \\
\text { isoform } 2\end{array}$ & gi|328786624 & $31,48 / 5,6$ & $22,84 / 5,5$ & 37 & 255 & 13 & $\begin{array}{l}\text { R.LAPGTVLQK.A } \\
\text { K.YTIPLTPETK.Y } \\
\text { R.YFQLTEVVRR.C } \\
\text { K.FLGVWYEAER.Y }\end{array}$ \\
\hline 30 & $\begin{array}{l}\text { Glutathione S-transferase- } \\
\text { like }\end{array}$ & gi|328793353 & $23,68 / 6,1$ & $20,32 / 5,5$ & 30 & 205 & 16 & $\begin{array}{l}\text { K.VLNLPAIK.S } \\
\text { K.IADEVVPYYLER.L } \\
\text { R.LAAFHYEENEEIK.A }\end{array}$ \\
\hline
\end{tabular}




\begin{tabular}{|c|c|c|c|c|c|c|c|c|}
\hline 31 & Peroxiredoxinal & gi|328777120 & $21,79 / 5,6$ & $18,75 / 5,9$ & 23 & 112 & 23 & R.DYGVLDEESGVPFR.G \\
\hline 32 & $\begin{array}{l}\text { Glicoproteína SgAbd-2- } \\
\text { like }\end{array}$ & gi|328792988 & $20,69 / 5,2$ & $16,17 / 4,7$ & 20 & 39 & 5 & K.GLDLIFAGIR.Q \\
\hline 33 & $\begin{array}{l}\text { Translation initiation } \\
\text { factor 5A-like }\end{array}$ & gi|110767655 & $17,59 / 5,2$ & $10,69 / 4,1$ & 18 & 40 & 6 & K.IPDGELGAQLR.A \\
\hline 34 & $\begin{array}{l}\text { Tropomyosin, exon 9B - } \\
\text { fruit fly }\end{array}$ & gi| 85165 & $32,89 / 4,7$ & $40,25 / 4,7$ & 48 & 206 & 11 & $\begin{array}{l}\text { K.IVELEEELR.L } \\
\text { R.IQLLEEDLER.S } \\
\text { K.ALQNAESEVAALNR.R }\end{array}$ \\
\hline
\end{tabular}

Legenda: Peptide hits: Peptídeos com similaridade com o banco de dados

Score: é uma medida de probabilidade baseada no número de correspondências entre a sequência submetida e o banco de dados.

Coverage: Porcentagem de cobertura da proteína pelos peptídeos identificados. 
A Figura 7 apresenta o perfil eletroforético do tegumento de adultas-faratas $\mathrm{Pbd}$ de operárias (A) e zangões (B). Como o perfil entre as adultas-faratas ( $\mathrm{Pbl}$ e $\mathrm{Pbd}$ ) mostrou-se extremamente semelhante, foram identificadas principalmente as proteínas de $\mathrm{Pbl}$, por possuir spots mais fortes (escuros) que foram complementados com spots de Pbd. Provavelmente a diferença de intensidade dos spots entre estas fases de desenvolvimento é decorrente do processo de esclerotização, que aumenta a interação das proteínas cuticulares com a matriz de quitina, o que dificulta a sua extração.

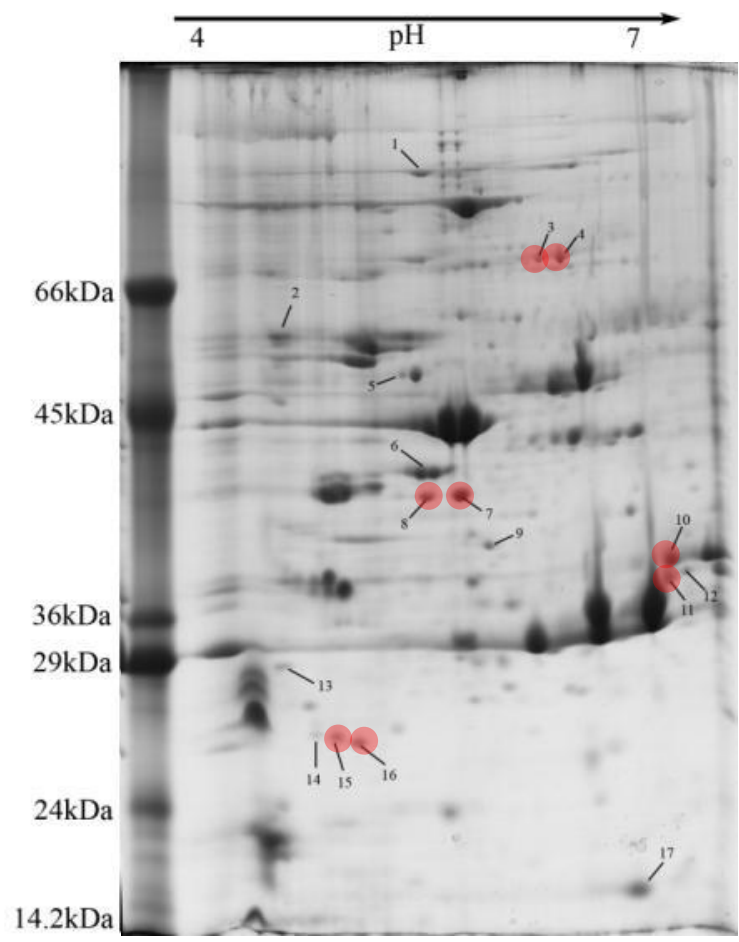

A

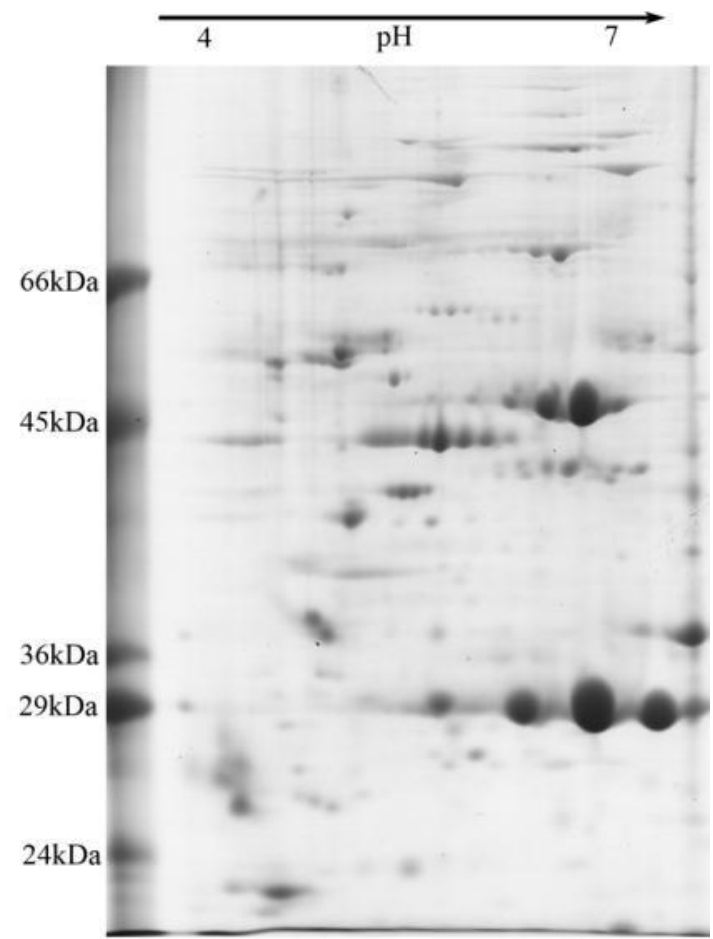

B

Figura 7. SDS-PAGE bidimensional de amostras de tegumentos de adultas-faratas Pbd de operárias (A) e zangões (B). Os números correspondem às proteínas que foram identificadas por espectrometria de massa, em destaque (vermelho) estão as proteínas cuticulares. Marcadores de massa molecular são mostrados à esquerda de cada gel. Cada amostra contem 150 ug de proteína. O intervalo de $\mathrm{pH}$ está indicado acima da figura.

A Tabela 6 relaciona as proteínas identificadas nas amostras de tegumentos de adultasfaratas $\mathrm{Pbd}$. Foram identificadas 13 proteínas, três delas em múltiplas formas eletroforéticas e quatro proteínas cuticulares. 
Tabela 6. Proteínas do tegumento de adultas faratas Pbd identificadas por meio de SDS-PAGE bidimensional e espectrometria de massas.

\begin{tabular}{|c|c|c|c|c|c|c|c|c|}
\hline Spot & ProteinName & $\begin{array}{l}\text { GenBank } \\
\text { Acession } \\
\text { Number }\end{array}$ & $\begin{array}{c}\text { Theoretical } \\
\text { MW(KdA)/pI }\end{array}$ & $\begin{array}{l}\text { Experimental } \\
\mathrm{MW}(\mathbf{k D a}) / \mathbf{p I}\end{array}$ & $\begin{array}{l}\text { Peptide } \\
\text { hits }\end{array}$ & Score & Coverage & PeptideSequences \\
\hline 1 & $\begin{array}{l}\text { Myosin heavy } \\
\text { chain }\end{array}$ & gi|328790595 & $250,15 / 5,6$ & $87,37 / 5,4$ & 336 & 246 & 3 & $\begin{array}{l}\text { K.ANAEAQLWR.T } \\
\text { K.DLLDQIGEGGR.N } \\
\text { R.IEELEEEIEAER.G } \\
\text { K.ADLESQLQDLNDR.F } \\
\text { R.GAYEEGQEQLEAVR.R } \\
\text { R.DLEEANIQHETTLANLR.K } \\
\end{array}$ \\
\hline 2 & $\begin{array}{l}\text { Calreticulin } \\
\text { isoform } 1\end{array}$ & gi|66545506 & $47,17 / 4,4$ & $55,80 / 4,4$ & 44 & 165 & 6 & $\begin{array}{l}\text { K.NWVYSEHPGK.E } \\
\text { R.SGTIFDNVLITDDPEVAR }\end{array}$ \\
\hline 3 & $\begin{array}{l}\text { Proteína APD-3- } \\
\text { like }\end{array}$ & gi|290578564 & $23,59 / 6,5$ & $69,71 / 5,9$ & 8 & 91 & 7 & K.ANVGPQSGPSDSVGPQEGAK.N \\
\hline 4 & $\begin{array}{l}\text { Proteína APD-3- } \\
\text { like }\end{array}$ & gi|290578564 & $23,59 / 6,5$ & $69,71 / 6,1$ & 8 & 118 & 7 & $\begin{array}{l}\text { R.GFPTLYWAPK.N } \\
\text { K.GDFVSDYNGPR.E } \\
\text { K.FDATANDVPGPYEVR.G }\end{array}$ \\
\hline 5 & $\begin{array}{l}\text { ATP synthase } \\
\text { subunit beta }\end{array}$ & gi|328785025 & $55,35 / 5,3$ & $49,12 / 5,1$ & 50 & 313 & 18 & $\begin{array}{l}\text { R.IPVGAETLGR.I } \\
\text { R.GQSVLDSGYPIR.I } \\
\text { R.IINVIGEPIDER.G } \\
\text { K.AHGGYSVFAGVGER.T } \\
\text { R.VALTGLTVAEYFR.D } \\
\text { R.LVLEVAQHLGENTVR.T } \\
\text { R.AIAELGIYPAVDPLDSTSR.I } \\
\end{array}$ \\
\hline 6 & $\begin{array}{l}\text { Tropomyosin-2- } \\
\text { like }\end{array}$ & gi|48129583 & $32,9 / 5,1$ & $41,63 / 5,2$ & 61 & 228 & 9 & $\begin{array}{l}\text { R.EDELFIVQNIVK.S } \\
\text { K.LALVEEELEGAEER.V } \\
\text { K.KLALVEEELEGAEER.V }\end{array}$ \\
\hline 7 & $\begin{array}{l}\text { LOC409345 } \\
\text { (Amel CPR3) }\end{array}$ & gi|110764443 & $34,35 / 5,5$ & $40,58 / 5,4$ & 24 & 550 & 34 & $\begin{array}{l}\text { K.ALVTPVQLPEK.V } \\
\text { R.SGPLIASNGPIAR.D } \\
\text { R.FQQQIQQQQR.I } \\
\text { K.QLQQLQQQQQSR.L } \\
\text { R.NGDLVQGSYLIEADGTR.R } \\
\text { R.IVEYTADPINGFNAVVSR.E } \\
\text { K.LEELEAAPHYSFAYDVQDAVTGDSK.A }\end{array}$ \\
\hline 8 & $\begin{array}{l}\text { LOC409345 } \\
\text { (Amel CPR3) }\end{array}$ & gi|110764443 & $34,35 / 5,5$ & $40,53 / 5,3$ & 24 & 406 & 26 & $\begin{array}{l}\text { K.ALVTPVQLPEK.V } \\
\text { R.SGPLIASNGPIAR.D } \\
\text { R.FQQQIQQQQR.I } \\
\text { K.QLQQLQQLQQQSR.L } \\
\text { R.NGDLVQGSYSLIEADGTR.R } \\
\text { R.IVEYTADPINGFNAVVSR.E } \\
\end{array}$ \\
\hline 9 & Annexin-B9-like & gi|328790767 & $35,94 / 4,6$ & $38,37 / 5,6$ & 38 & 135 & 9 & $\begin{array}{l}\text { K.TIIDVLTR.R } \\
\text { R.LLVSLVQANR.D } \\
\text { R.TIAAFYENLYGK.S }\end{array}$ \\
\hline 10 & $\begin{array}{l}\text { Proteína APD-3- } \\
\text { like }\end{array}$ & gi|290578564 & $23,59 / 6,5$ & $37,55 / 6,6$ & 8 & 174 & 11 & $\begin{array}{l}\text { R.ADIGPAEGPK.A } \\
\text { K.ANVGPQSGPSDSVGPQEGAK.N }\end{array}$ \\
\hline
\end{tabular}




\begin{tabular}{|c|c|c|c|c|c|c|c|c|}
\hline 11 & Apidermin2 & gi||145386569 & $7,75 / 10,4$ & $36,79 / 6,6$ & 28 & 162 & 35 & $\begin{array}{l}\text { K.VAPAIALAPAPK.L } \\
\text { K.LLAAPAVVAAPGPWK.A }\end{array}$ \\
\hline 12 & $\begin{array}{l}\text { Proteína } \\
\text { 1(2)37Cc-like }\end{array}$ & gi|48097857 & $30,01 / 6,5$ & $37,02 / 6,7$ & 28 & 218 & 18 & $\begin{array}{l}\text { K.DLQNVNITLR.I } \\
\text { K.IYTVLGIDYAER.V } \\
\text { R.IEAAEDIAHNLSR.S } \\
\text { K.AVVAQFDAGELITQR.E }\end{array}$ \\
\hline 13 & $\begin{array}{l}\text { Complement } \\
\text { component } 1 \mathrm{Q}\end{array}$ & gi|66508940 & $29,90 / 4,89$ & $27,63 / 4,4$ & 24 & 70 & 5,2 & \\
\hline 14 & $\begin{array}{l}\text { Tumor protein } \\
\text { homolog }\end{array}$ & gi|66515987 & $19,84 / 4,6$ & $20,07 / 4,6$ & 23 & 251 & 22,7 & \\
\hline 15 & $\begin{array}{l}\text { Endocuticle } \\
\text { structural } \\
\text { glicoproteína } \\
\text { SgAbd-2-like }\end{array}$ & gi|328792988 & $20,69 / 5,2$ & $24,7 / 4,7$ & 20 & 53 & 5,5 & \\
\hline 16 & $\begin{array}{l}\text { Endocuticle } \\
\text { structural } \\
\text { glycoprotein } \\
\text { SgAbd-2-like }\end{array}$ & gi|328792988 & $20,69 / 5,2$ & $24,6 / 4,8$ & 20 & 46 & 5,5 & \\
\hline 17 & LOC552685 & gi|66514755 & $16,67 / 6,63$ & $16 / 6,40$ & 8 & 111 & 8,1 & \\
\hline
\end{tabular}

Legenda: $\quad$ Peptide hits: Peptídeos com similaridade com o banco de dados

Score: é uma medida de probabilidade baseada no número de correspondências entre a sequência submetida e o banco de dados.

Coverage: Porcentagem de cobertura da proteína pelos peptídeos identificados. 
No total foram identificadas 51 proteínas diferentes, das quais 14 são proteínas cuticulares. A Tabela 7 compila todas as proteínas cuticulares identificadas. Foram encontradas quatro proteínas da classe CPR (nomeadas no banco de dados de proteínas cuticulares (Cuticle DB- http://bioinformatics2.biol.uoa.gr/cuticleDB/index.jsp), como a Amel CPR3, Amel CPR12, Amel CPR16 e Amel CPR27, duas proteínas portadoras do domínio R\&R (Glicoproteina SgAbd-2-like e LOC100577363), mas não mencionadas neste banco de dados, duas apiderminas (APD-3-like e Apidermina 2), quatro peritrofinas (Cuticular protein analogous to peritrophins 3-C, Cuticular protein analogous to peritrophins 3-D, LOC408365 e LOC413679) e duas proteínas que possuem similaridade com proteínas cuticulares de outras espécies de insetos (LOC725454 e LOC725838).

Tabela 7. Proteínas cuticulares identificadas por meio de SDS-PAGE bidimensional e espectrometria de massas.

\begin{tabular}{|c|c|c|c|}
\hline Proteína & $\begin{array}{l}\text { Access } \\
\text { Number }\end{array}$ & GB & Domínio/Similaridade \\
\hline APD-3-like & gi|290578564 & GB12636-PA & Protein Apidermina 3, 1-like \\
\hline Apidermina 2 & gi|145386569 & GB18647-PA & \\
\hline $\begin{array}{l}\text { Cuticular protein } \\
\text { analogous to } \\
\text { peritrophins } 3-\mathrm{C}\end{array}$ & gi|288869506 & GB13298-PA & $\begin{array}{l}\text { Chitin-binding domain type } 2 \text {, } \\
\text { Chitin-binding Peritrophin-A } \\
\text { domain }\end{array}$ \\
\hline $\begin{array}{l}\text { Cuticular protein } \\
\text { analogous to } \\
\text { peritrophins 3-D }\end{array}$ & gi|288869485 & GB13470-PA & $\begin{array}{l}\text { Chitin-binding domain type } 2 \text {, } \\
\text { chitin-binding Peritrophin-A } \\
\text { domain }\end{array}$ \\
\hline $\begin{array}{l}\text { Flexible cuticle protein } \\
12 \text { (Amel CPR12) }\end{array}$ & gi|399220308 & & $\begin{array}{l}\text { pupal cuticle protein precursor } \\
{[\text { Bombyx mori }]} \\
\text { NP_001119729.1 }\end{array}$ \\
\hline $\begin{array}{l}\text { Glicoproteina SgAbd-2- } \\
\text { like }\end{array}$ & gi|328792988 & GB11134-PA & $\begin{array}{l}\text { Chitin-binding } 4 \text { superfamily, } \\
\text { chitin-binding type } R \& R\end{array}$ \\
\hline $\begin{array}{l}\text { LOC100576341 } \\
\text { (Amel CPR16) }\end{array}$ & gi|328779296 & GB15705-PA & chitin binding 4 superfamily \\
\hline LOC100577363 & gi|328790553 & GB17094-PA & Chitin binding 3 superfamily \\
\hline LOC408365 & gi|48097532 & GB14037-PA & $\begin{array}{l}\text { Chitin-binding domain type } \\
2 ; \text { Chitin binding Peritrophin-A } \\
\text { domain }\end{array}$ \\
\hline $\begin{array}{l}\text { LOC409345 } \\
\text { (Amel CPR3) }\end{array}$ & gi|110764443 & GB17384-PA & Chitin-binding 4 superfamily \\
\hline LOC725454 & gi|110759098 & GB15046-PA & $\begin{array}{l}\text { Similaridade putative cuticle } \\
\text { protein [Manduca } \\
\text { sexta]AAF16706.1 }\end{array}$ \\
\hline $\begin{array}{l}\text { LOC725509 } \\
\text { (Amel CPR27) }\end{array}$ & gi|328782451 & GB13208-PA & Chitin binding 4 superfamily \\
\hline LOC725838 & gi|328788950 & & $\begin{array}{l}\text { pupal cuticle protein precursor } \\
{[\text { Bombyx mori] }} \\
\text { NP_001119729.1 }\end{array}$ \\
\hline LOC413679 & gi|328787428 & GB20072 & $\begin{array}{l}\text { Chitin binding Peritrophin-A } \\
\text { domain }\end{array}$ \\
\hline
\end{tabular}


Durante a identificação de proteínas observou-se a presença de múltiplas formas eletroforéticas da mesma proteína (Tabela 8). Estas modificações ampliam a diversidade das proteínas sem necessidade de nova transcrição, possibilitando maior flexibilidade de adaptação a diferentes condições. Estas modificações pós-traducionais são efetuadas por enzimas. Destacadas em cinza as proteínas cuticulares.

Tabela 8. Proteínas identificadas em múltiplas formas eletroforéticas. Em destaque estão as proteínas cuticulares

\begin{tabular}{|c|c|c|c|}
\hline Proteína & $\begin{array}{l}\text { Access } \\
\text { Number }\end{array}$ & GB & Domínio/Similaridade \\
\hline Actin, clone 205-like & gi $\mid 66509780$ & GB18527-PA & ATP binding \\
\hline APD-3-like & gi|290578564 & GB12636-PA & Protein Apidermina 3, 1-like \\
\hline $\begin{array}{l}\text { Cuticular protein } \\
\text { analogous to } \\
\text { peritrophins 3-C }\end{array}$ & gi|288869506 & GB13298-PA & $\begin{array}{l}\text { Chitin-binding domain type } 2 \text {, } \\
\text { Chitin-binding Peritrophin-A } \\
\text { domain }\end{array}$ \\
\hline $\begin{array}{l}\text { Glicoproteína SgAbd-2- } \\
\text { like }\end{array}$ & gi|328792988 & GB11134-PA & $\begin{array}{l}\text { Chitin-binding } 4 \text { superfamily, } \\
\text { Chitin-binding type R\&R }\end{array}$ \\
\hline LOC100577363 & gi|328790553 & GB17094-PA & Chitin binding 3 superfamily \\
\hline LOC100577680 & gi|328777526 & GB14189-PA & $\begin{array}{l}\text { Similaridade com proteínas } \\
\text { preditas }\end{array}$ \\
\hline $\begin{array}{l}\text { LOC409345 } \\
\text { (Amel CPR3) }\end{array}$ & gi|110764443 & GB17384-PA & Chitin-binding 4 superfamily \\
\hline LOC410975 & gi|66546405 & GB15794-PA & $\begin{array}{l}\text { PAN/Apple domain profile, ZP } \\
\text { domain profile }\end{array}$ \\
\hline LOC724664 & gi|32781235 & GB18013-PA & $\begin{array}{l}\text { Similaridade com proteínas } \\
\text { preditas }\end{array}$ \\
\hline LOC725454 & gi|110759098 & GB15046-PA & $\begin{array}{l}\text { Similaridade com putative } \\
\text { cuticle protein [Manduca } \\
\text { sexta] AAF16706.1 }\end{array}$ \\
\hline $\begin{array}{l}\text { LOC725509 } \\
\text { (Amel CPR27) }\end{array}$ & gi|328782451 & GB13208-PA & Chitin binding 4 superfamily \\
\hline $\begin{array}{l}\text { Myosin regulatory light } \\
\text { chain } 2\end{array}$ & gi|328777082 & GB13399-PA & $\begin{array}{l}\text { Myosin regulatory light chain } \\
\text { P Calmodulin }\end{array}$ \\
\hline Tubulin beta-1 chain & gi|408782 & GB10275-PA & $\begin{array}{l}\text { Tubulin-beta mRNA } \\
\text { autoregulation signal }\end{array}$ \\
\hline Proteína Yellow-like & gi|290578556 & GB19464-PA & Major royal jelly protein; \\
\hline
\end{tabular}

\subsection{Variação de massa molecular e pI das proteínas cuticulares com modificações} pós-traducionais

A Figura 8 mostra as variações pós-traducionais da proteína APD-3-like no tegumento das fases de desenvolvimento estudadas. A massa molecular predita é $23,59 \mathrm{kDa}$ e o pI é 6,5 . No entanto, nas larvas (L5F) e nas pupas ( $\mathrm{Pw}$ ) foram identificadas quatro formas de proteína APD-3-like, enquanto que nas adultas-faratas ( $\mathrm{Pbl} \mathrm{e} \mathrm{Pbd}$ ) foram encontradas nove e oito formas desta proteína, respectivamente. As massas moleculares e pIs destas diferentes formas 
estão relacionados na Tabela 9. Nas pupas (Pw), as isoformas APD-3 like foram identificadas pela posição dos respectivos spots nos géis 2-DE em comparação com os marcadores de massa molecular e com as eletroforeses 2-DE de larvas (L5F) e adultas faratas (Pbl e Pbd). 


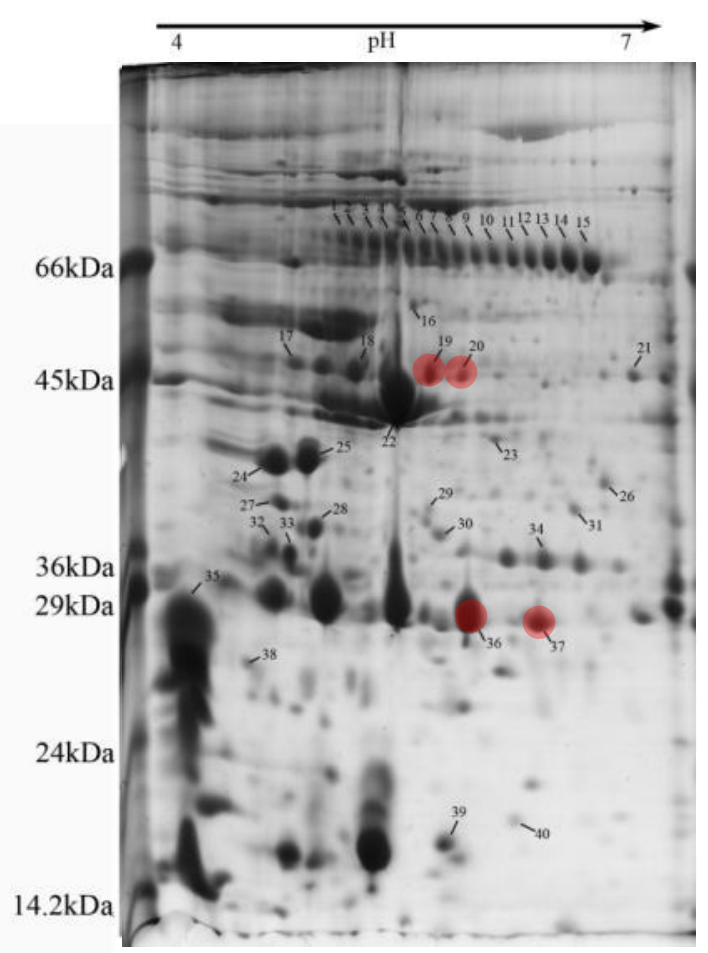

(A)

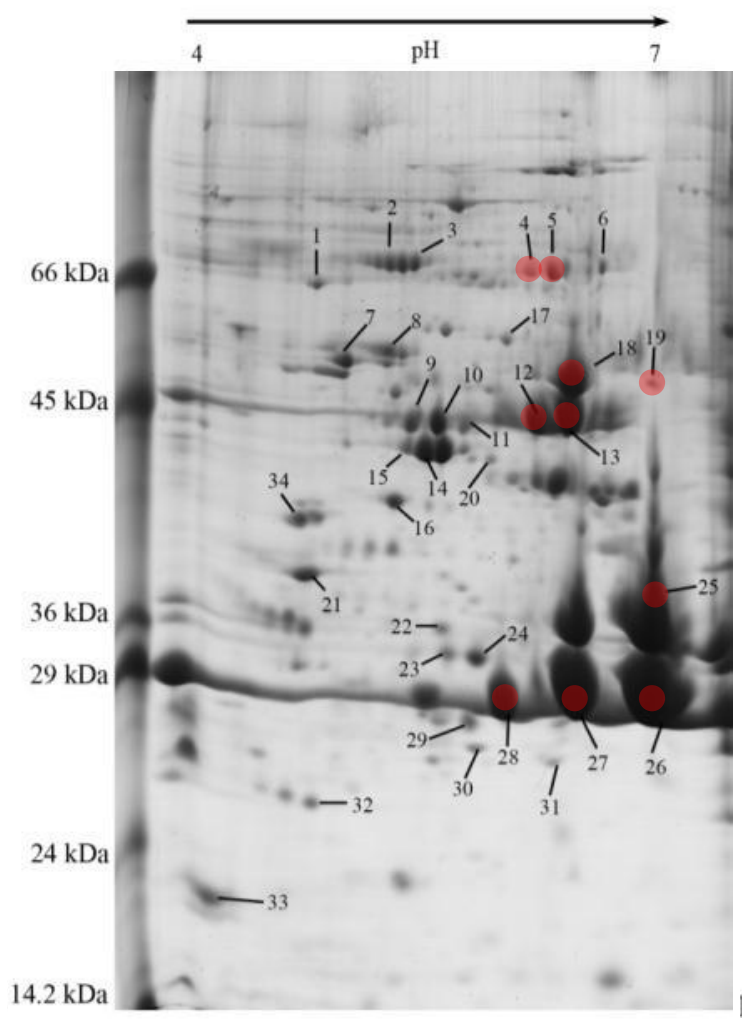

(C)

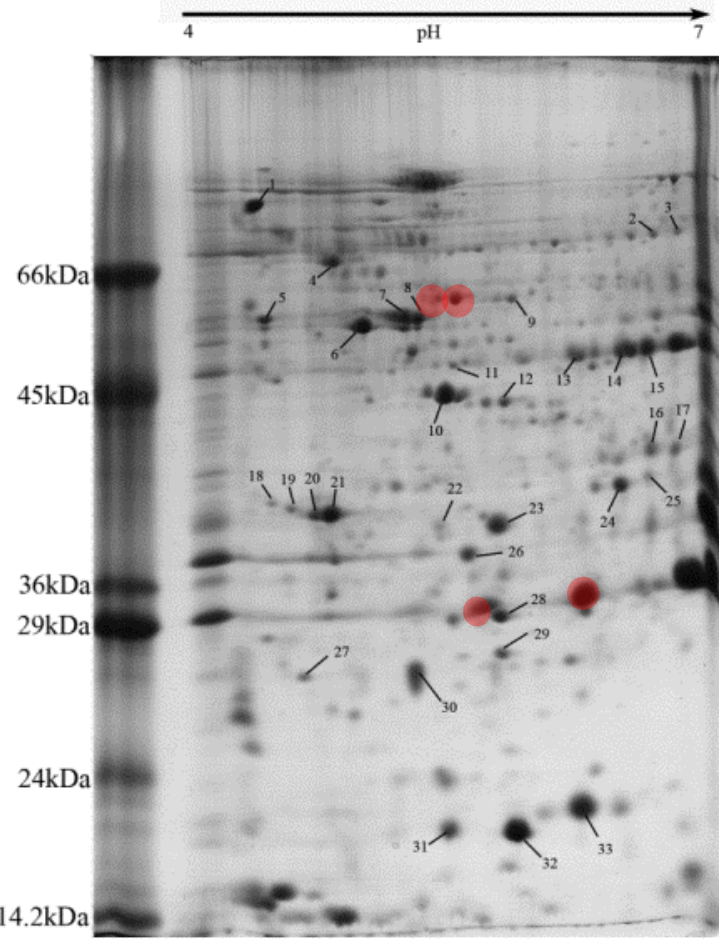

(B)

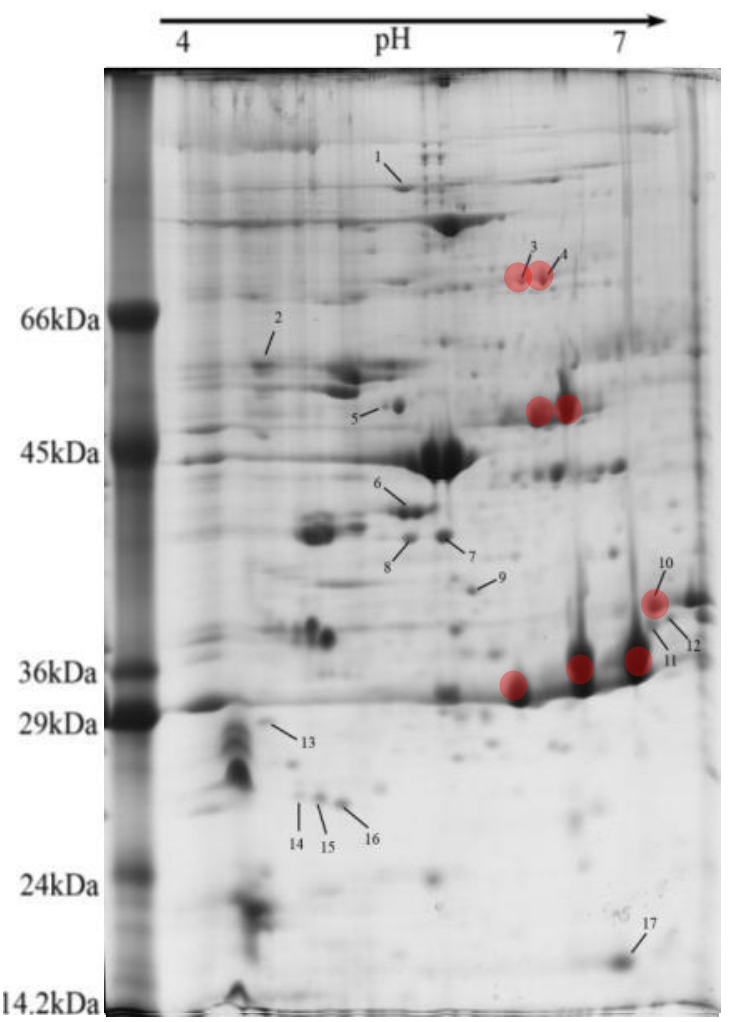

(D)

Figura 8. SDS-PAGE bidimensional mostrando modificações pós-traducionais de APD-3 like no tegumento larval (L5F) (A), pupal ( $\mathrm{Pw})(\mathrm{B})$, e adultos-faratos $\mathrm{Pbl}(\mathrm{C})$ e $\mathrm{Pbd}(\mathrm{D})$ de abelhas operárias. Os números correspondem às proteínas que foram identificadas por espectrometria de massas. Marcadores de massa molecular são mostrados à esquerda de cada gel. Cada amostra contem 150ug de proteína. O intervalo de pH está indicado acima da figura. As marcas em vermelho mostram as diferentes massas moleculares e pIs das formas de proteína APD-3-like. 
Tabela 9. Massas moleculares e pIs das formas eletroforéticas observadas da proteína ADP-3-like nos tegumentos de larvas (L5F), pupas $(\mathrm{Pw})$ e adultas-faratas ( $\mathrm{Pbl}$ e $\mathrm{Pbd}$ ) em comparação com os valores preditos.

\begin{tabular}{|c|c|c|c|}
\hline \multirow{2}{*}{ L5F } & \multirow{2}{*}{$\begin{array}{l}\text { Massa Molecular } \\
(\mathrm{kDa})\end{array}$} & \multicolumn{2}{|c|}{ Ponto Isoelétrico } \\
\hline & & \multicolumn{2}{|c|}{ pI (1) } \\
\hline Predito & 23,59 & \multicolumn{2}{|c|}{6,5} \\
\hline Observado & 45,36 & \multicolumn{2}{|c|}{5,6} \\
\hline Observado & 44,93 & \multicolumn{2}{|c|}{5,8} \\
\hline Observado & 26,21 & \multicolumn{2}{|c|}{5,8} \\
\hline Observado & 25,52 & \multicolumn{2}{|c|}{6,2} \\
\hline \multirow[t]{2}{*}{$\mathbf{P w}$} & \multirow{2}{*}{$\begin{array}{c}\text { Massa Molecular } \\
(\mathrm{kDa})\end{array}$} & \multicolumn{2}{|c|}{ Ponto Isoelétrico } \\
\hline & & $\mathrm{pI}(1)$ & pI (2) \\
\hline Predito & 23,59 & 6,5 & \\
\hline Observado & 45,36 & 5,6 & 5,8 \\
\hline Observado & 26 & 6,2 & \\
\hline
\end{tabular}

\begin{tabular}{l|c|c|c}
\hline \multirow{2}{*}{ Pbl } & $\begin{array}{c}\text { Massa Molecular } \\
(\mathrm{kDa})\end{array}$ & \multicolumn{2}{c}{ Ponto Isoelétrico } \\
\cline { 3 - 4 } & & pI (1) & pI (2) \\
\hline Predito & 23,59 & 6,5 & \\
\hline Observado & 64,12 & 5,9 & \\
\hline Observado & 63,60 & 6,0 & 6,5 \\
\hline Observado & 44,88 & 6,1 & \\
\hline Observado & 44,70 & 6,1 & \\
\hline Observado & 43,36 & 5,9 & \\
\hline Observado & 39,21 & 6,5 & \\
\hline Observado & 35,12 & 6,5 & \\
\hline
\end{tabular}

\begin{tabular}{l|c|c|c|c}
\hline \multirow{2}{*}{ Pbd } & $\begin{array}{c}\text { Massa Molecular } \\
(\mathrm{kDa})\end{array}$ & \multicolumn{3}{|c}{ Ponto Isoelétrico } \\
\cline { 3 - 5 } & & $\mathrm{pI}(1)$ & $\mathrm{pI}(2)$ & $\mathrm{pI}(3)$ \\
\hline Predito & 23,59 & 6,5 & 6,16 & \\
\hline Observado & 69,71 & 5,9 & 6,0 & \\
\hline Observado & 50 & 6,28 & 6,68 & \\
\hline Observado & 43,36 & 5,9 & & \\
\hline Observado & 29 & 5,85 & 6,28 & 6,68 \\
\hline
\end{tabular}

A Figura 9 mostra as variações de massa molecular e ponto isoelétrico observadas para a Peritrophin 3-C-like, com massa molecular predita de 29,53kDa e ponto isoelétrico de 4,9. Verificam-se duas formas moleculares mais pesadas (maiores que $36 \mathrm{kDa}$ ) em larvas (L5F) e pupas ( $\mathrm{Pw}$ ) e duas formas mais leves nas adultas-faratas ( $\mathrm{Pbl}$ e $\mathrm{Pbd}$ ). As massas moleculares e pIs destas diferentes formas de peritrophin-3C-like estão relacionados na Tabela 10. 
Nos géis 2-DE de tegumentos de adultas-faratas $\mathrm{Pbd}$, as isoformas de peritrophin 3Clike foram identificadas pela posição dos spots em comparação com os marcadores de massa molecular e com os géis 2-DE de larvas, pupas e adultas-faratas Pbl.



(A)

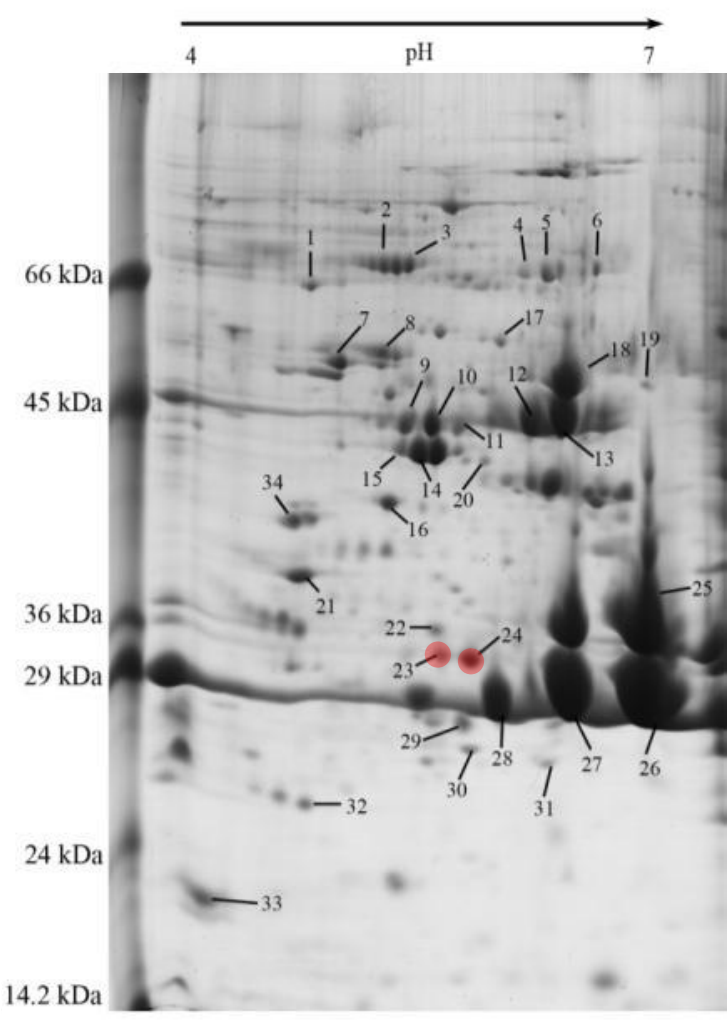

(C)

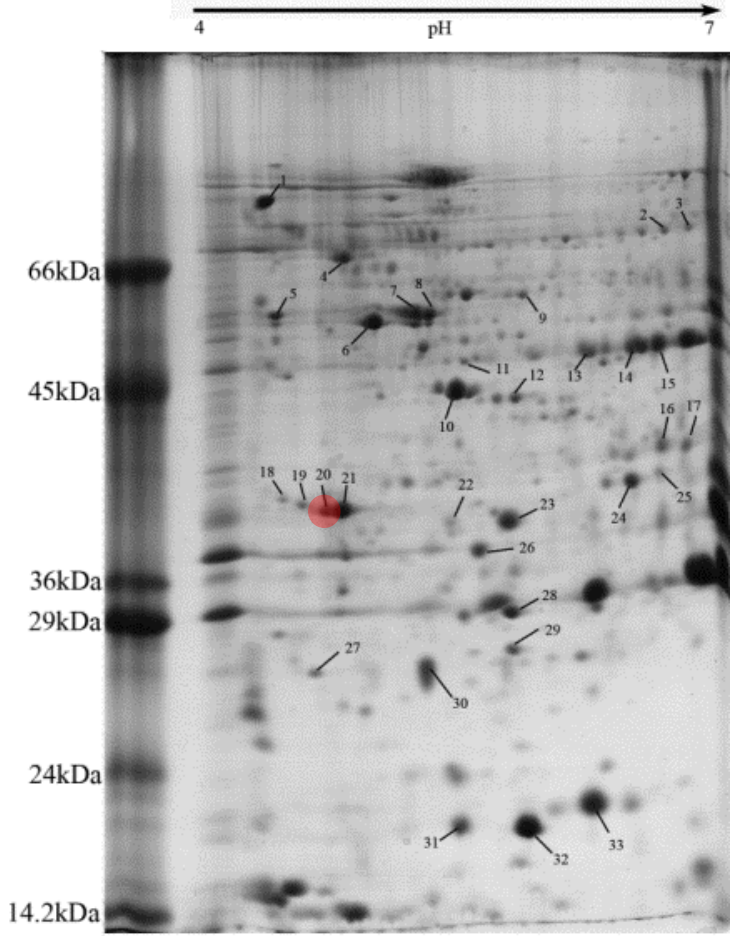

(B)

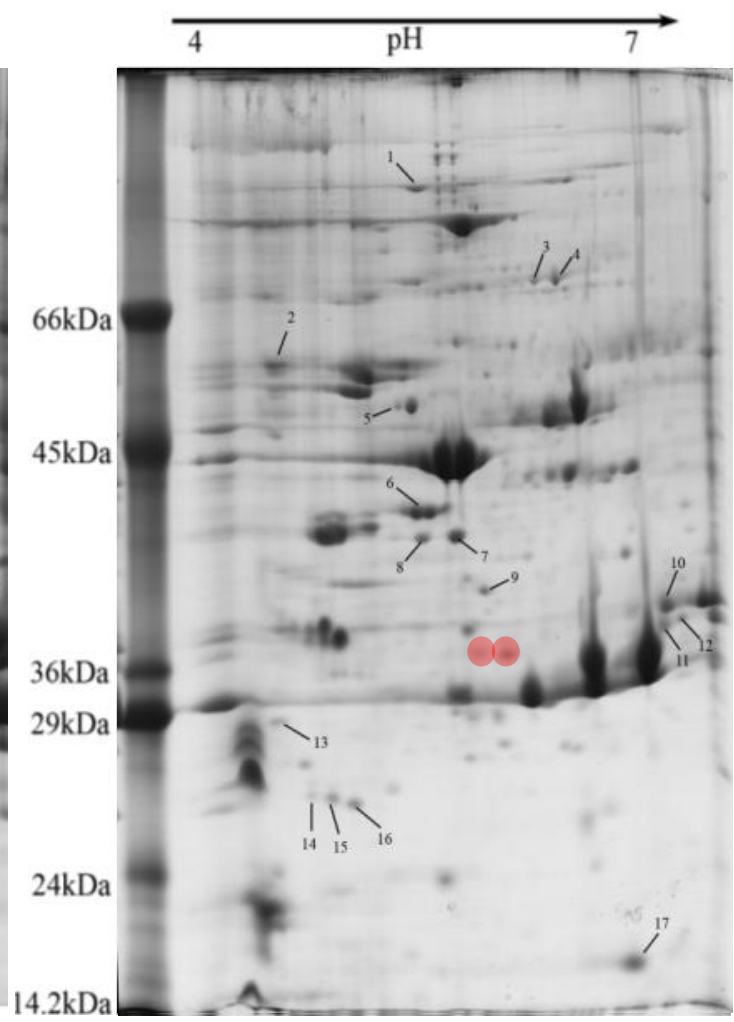

(D) 
Figura 9. SDS-PAGE bidimensionais mostrando modificações pós-traducionais da proteína Peritrophin 3C-like no tegumento larval (L5F) (A), pupal (Pw) (B) e adulto-farato Pbl (C) e Pbd (D) de abelhas operárias. Os números correspondem às proteínas que foram identificadas por espectrometria de massas. Marcadores de massa molecular são mostrados à esquerda de cada gel. Cada amostra contem 150ug de proteína. O intervalo de pH está indicado acima da figura. As marcas em vermelho mostram as diferentes massas moleculares e pIs das formas de Peritrophin 3C like.

Tabela 10. Massas moleculares e pIs das formas eletroforéticas de Peritrophin-3-C like nos tegumentos de larvas (L5F), pupas $(\mathrm{Pw})$ e adultas-faratas ( $\mathrm{Pbl} \mathrm{e} \mathrm{Pbd}$ ) em comparação com os valores preditos.

\begin{tabular}{l|c|c|c}
\hline & $\begin{array}{c}\text { Massa Molecular } \\
(\mathrm{kDa})\end{array}$ & \multicolumn{2}{|c}{ Ponto Isoelétrico } \\
\cline { 3 - 4 } & & $\mathrm{pI}(1)$ & $\mathrm{pI}(2)$ \\
\hline Predito & 29,53 & 4,9 & \\
\hline L5F Observado & 38,11 & 4,8 & 4,8 \\
\hline \multirow{2}{*}{ Pw Observado } & 39,16 & 4,7 & \\
\hline \multirow{2}{*}{ Pbl Observado } & 29,18 & 5,4 & \\
\cline { 2 - 4 } & 28,64 & 5,8 & \\
\hline \multirow{2}{*}{ Pbd Observado } & 29,18 & 5,4 & \\
\cline { 2 - 4 } & 28,64 & 5,8 & \\
\hline
\end{tabular}

A Figura 10 apresenta as modificações pós-traducionais observadas na proteína Endocuticle Structural Glycoprotein SgAbd-2-like. As mesmas duas formas moleculares foram observadas no tegumento das quatro fases do desenvolvimento analisadas: larvas (L5F), pupas ( $\mathrm{Pw})$ e adultas-faratas (Pbl e Pbd). Nos géis 2-DE de larvas L5F e pupas Pw as isoformas de SgABD-2-like foram identificadas pela posição dos spots em comparação com os marcadores de massa molecular e com os géis 2-DE de adultas-faratas. As massas moleculares e pIs destas diferentes formas de proteína SgAbd-2-like estão relacionadas na Tabela 11 .

Tabela 11. Massas moleculares e pIs das formas eletroforéticas de Sg-Abd-2-like nos tegumentos de larvas (L5F), pupas $(\mathrm{Pw})$ e adultas-faratas ( $\mathrm{Pbl} \mathrm{e} \mathrm{Pbd})$ em comparação com os valores preditos.

\begin{tabular}{l|c|c}
\hline \multirow{2}{*}{$\begin{array}{c}\text { L5F, Pw, } \\
\text { Pbl e Pbd }\end{array}$} & $\begin{array}{c}\text { Massa Molecular } \\
(\mathrm{kDa})\end{array}$ & Ponto Isoelétrico \\
\cline { 3 - 3 } & & $\mathrm{pI}$ \\
\hline Predito & 20,69 & 5,2 \\
\hline Observado & 24,7 & 4,7 \\
\hline Observado & 24,6 & 4,8 \\
\hline
\end{tabular}




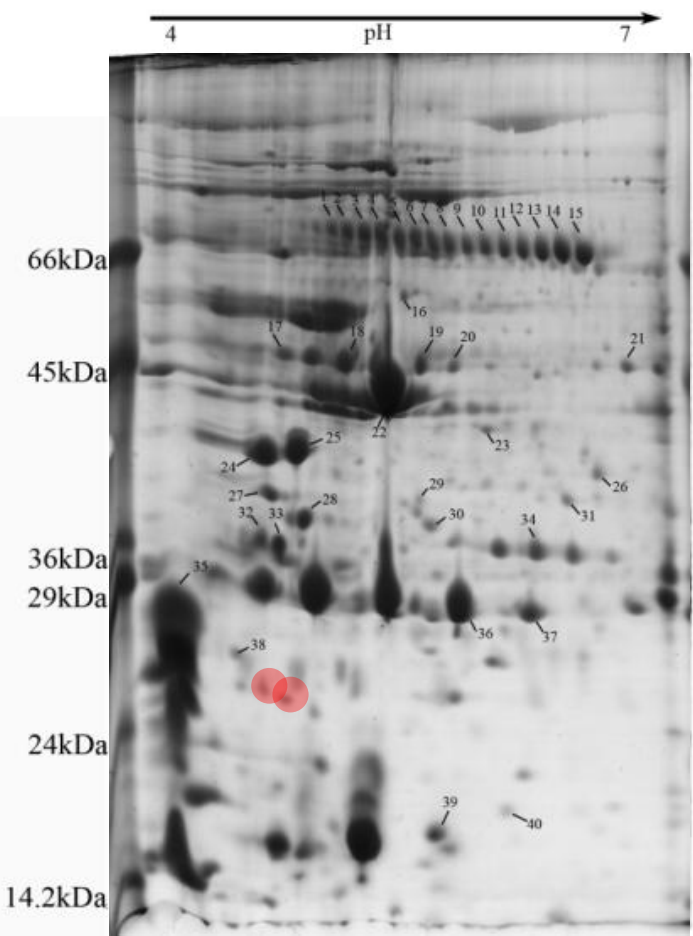

(A)

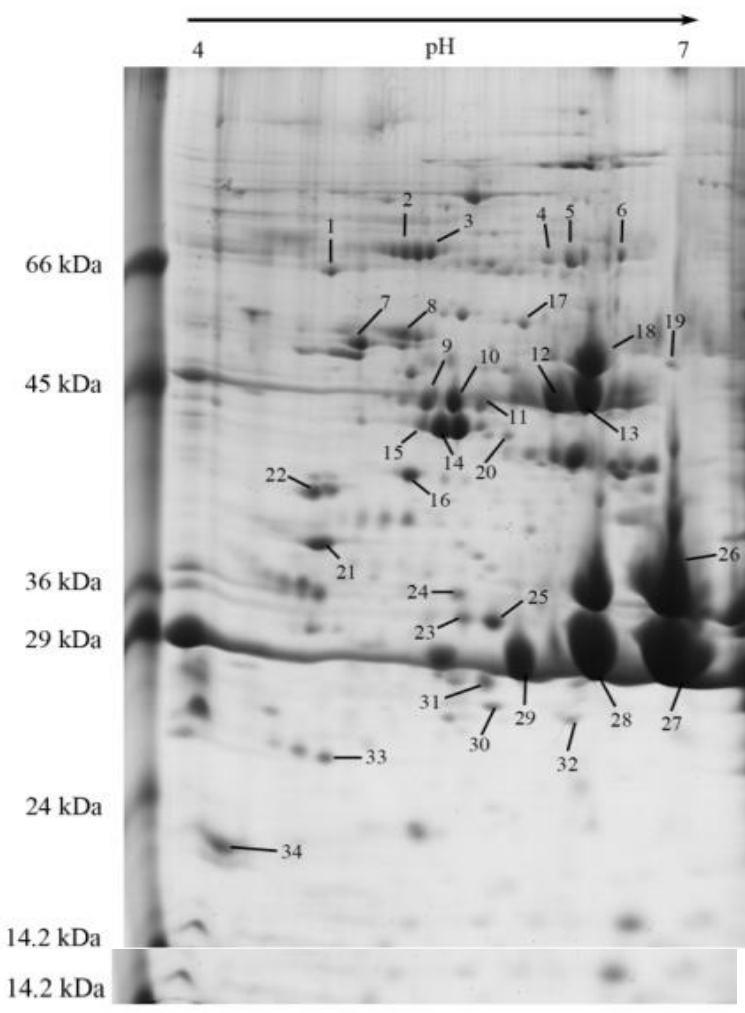

(C)

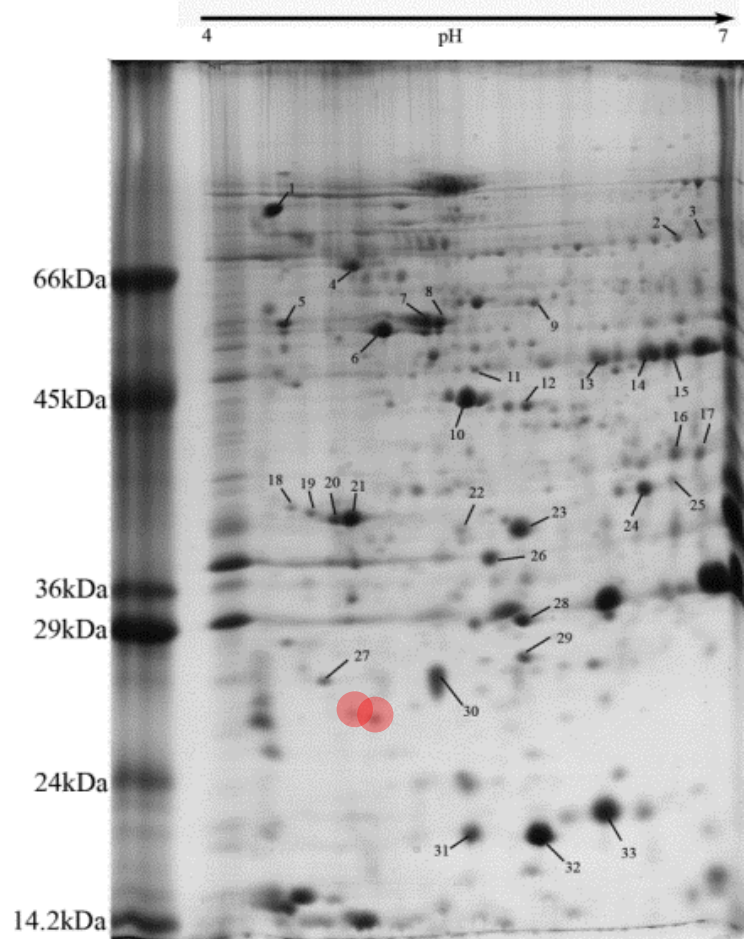

(B)

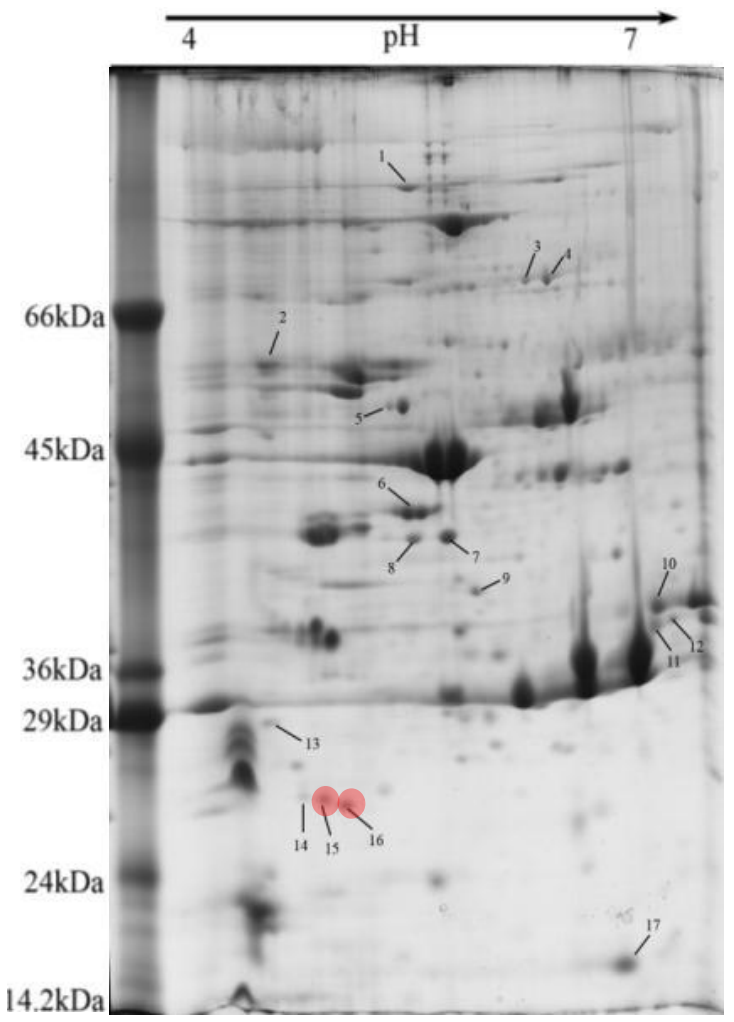

(D)

Figura 10. SDS-PAGE bidimensional mostrando modificações pós-traducionais da proteína Sg-Abd-2-like no tegumento larval (L5F) (A), pupal (Pw) (B) e adulto farato $\mathrm{Pbl}(\mathrm{C})$ e $\mathrm{Pbd}(\mathrm{D})$ de abelhas operárias. Os números correspondem às proteínas que foram identificados por espectrometria de massas. Marcadores de massa 
molecular são mostrados à esquerda de cada gel. Cada amostra contem 150ug de proteína. O intervalo de pH está indicado acima da figura. As marcas em vermelho mostram as diferentes massas moleculares e pIs das formas das proteína SgAbd-2-like.

A Figura 11 mostra as variantes eletroforéticas da proteína cuticular LOC725454. As massas moleculares e o pIs destas diferentes formas da proteína LOC725454 estão relacionadas na Tabela 12 .



(A)

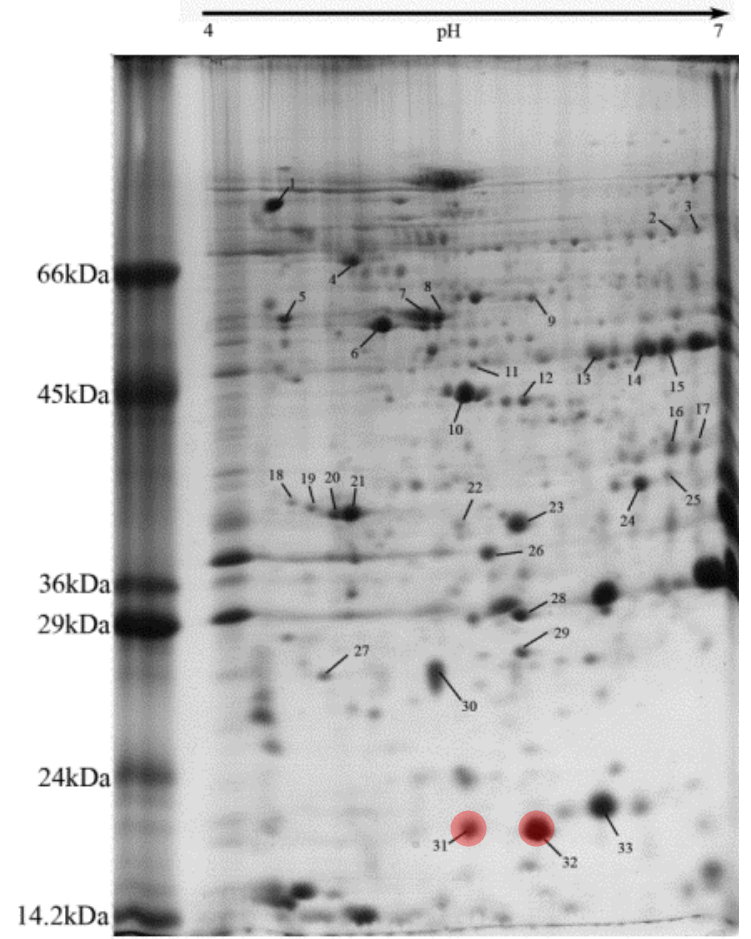

(B)

Figura 11. SDS-PAGE bidimensional mostrando modificações pós-traducionais da proteína LOC725454 no tegumento larval $(\mathrm{L} 5 \mathrm{~F})(\mathrm{A})$ e pupal $(\mathrm{Pw})(\mathrm{B})$ de abelhas operárias. Os números correspondem às proteínas que foram identificadas por espectrometria de massas. Marcadores de massa molecular são mostrados à esquerda de cada gel. Cada amostra contem $150 \mathrm{ug}$ de proteína. O intervalo de $\mathrm{pH}$ está indicado acima da figura. As marcas em vermelho mostram as diferentes massas moleculares e pIs das formas da proteína LOC725454.

Tabela 12. Massas moleculares e pIs das formas eletroforéticas da proteína LOC725454 nos tegumentos de larvas (L5F) e pupas (Pw) em comparação com os valores preditos.

\begin{tabular}{l|c|c}
\hline & $\begin{array}{c}\text { Massa Molecular } \\
(\mathrm{kDa})\end{array}$ & Ponto Isoelétrico \\
\cline { 2 - 3 } & & $\mathrm{pI}(1)$ \\
\hline Predito & 29,53 & 4,9 \\
\hline \multirow{2}{*}{\begin{tabular}{l} 
Obs \\
\multirow{2}{*}{ Pw Observado }
\end{tabular}} & 18,45 & 6,1 \\
\cline { 2 - 3 } & 17,76 & 6,3 \\
\cline { 2 - 3 } & 18,45 & 5,3 \\
\hline
\end{tabular}


A Figura 12 mostra as variações de massa molecular e pI da proteína LOC725509 (AmelCPR27). As massas moleculares e o pIs destas diferentes formas da proteína LOC725509 estão relacionadas na Tabela 13. Nos géis 2-DE de adultas-faratas Pbd as isoformas da proteína LOC 725509 foram identificadas pela posição dos respectivos spots em comparação com os marcadores de massa molecular e os géis 2-DE de pupas Pw e adultasfaratas $\mathrm{Pbl}$. 


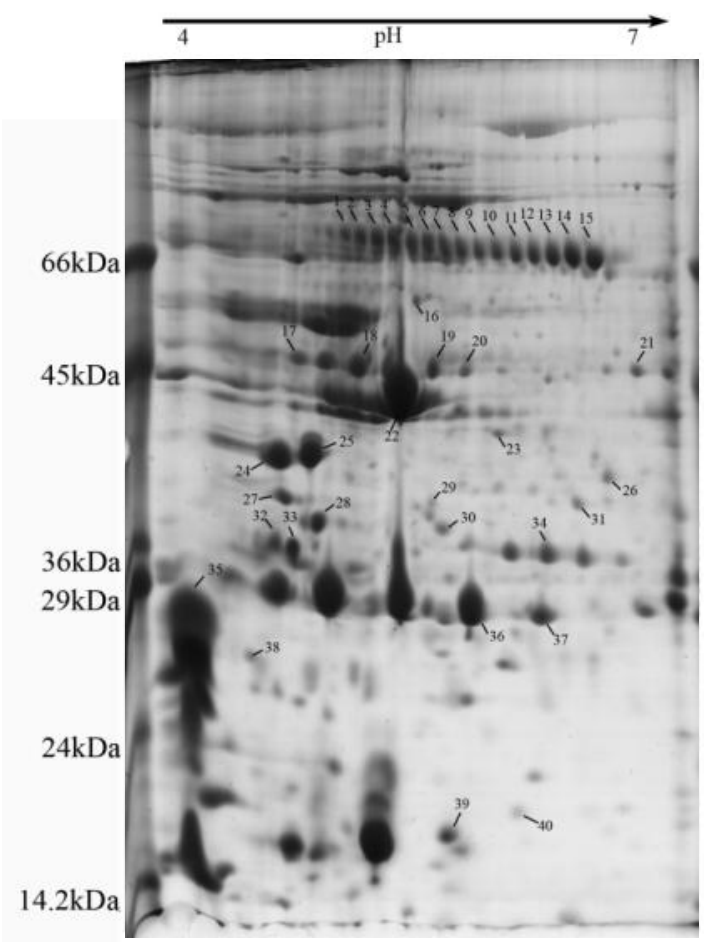

(A)

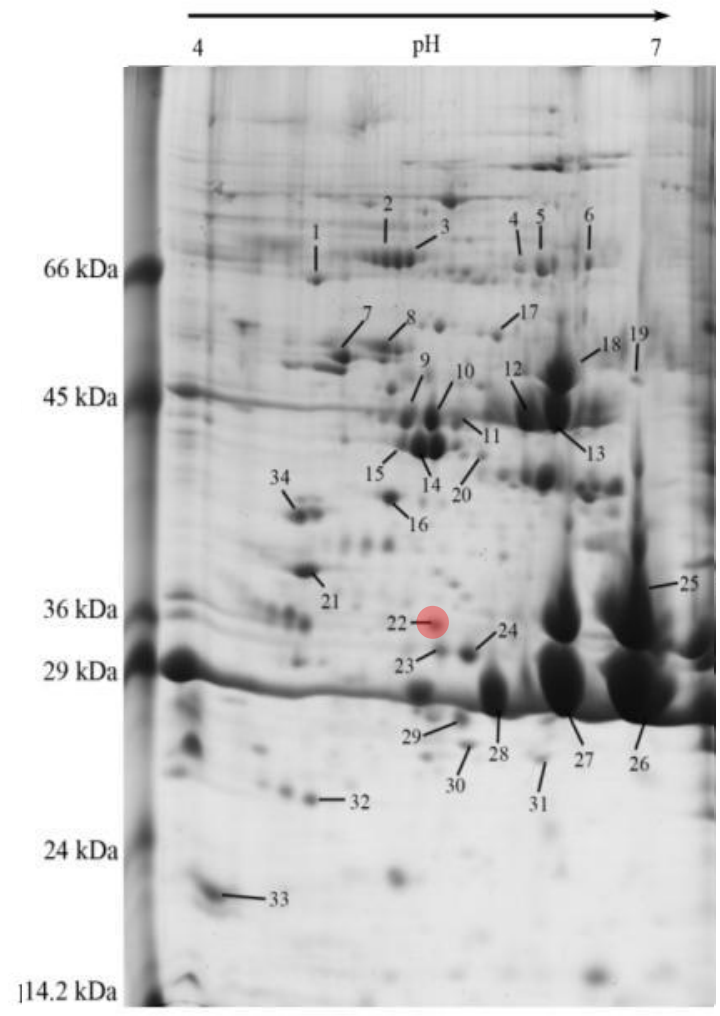

(C)

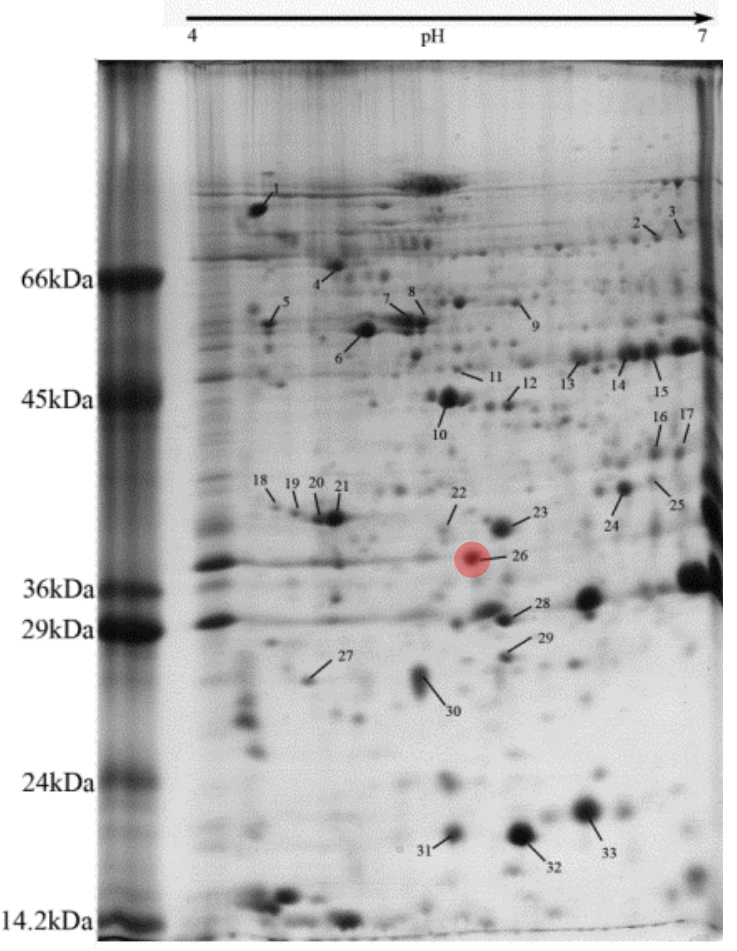

(B)

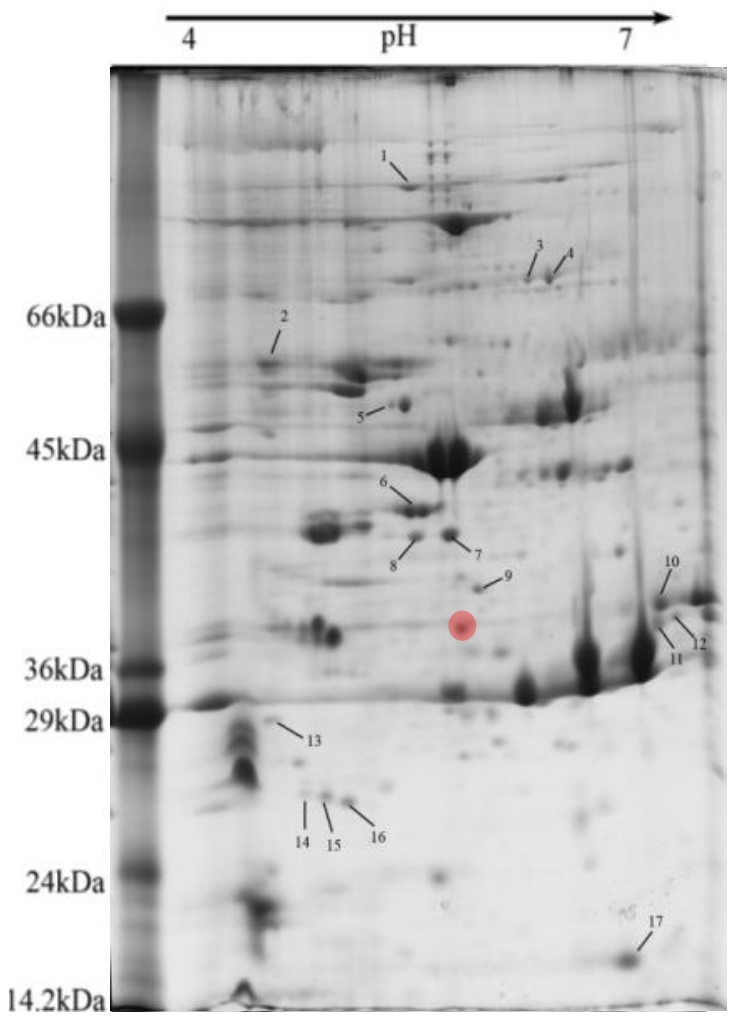

(D)

Figura 12. SDS-PAGE bidimensional mostrando modificações pós-traducionais da proteína LOC725509 no tegumento larval (L5F) (A), pupal $(\mathrm{Pw})(\mathrm{B})$ e adulto-farato $\mathrm{Pbl}(\mathrm{C})$ e $\mathrm{Pbd}(\mathrm{D})$ de abelhas operárias. Os números correspondem às proteínas que foram identificadas por espectrometria de massas. Marcadores de massa molecular são mostrados à esquerda de cada gel. Cada amostra contem 150ug de proteína. O intervalo de pH está indicado acima da figura. As marcas em vermelho mostram as diferentes massas moleculares e pIs das formas da proteína LOC725509. 
Tabela 13. Massas moleculares e pIs das formas eletroforéticas da proteína LOC725509 nos tegumentos de pupas $(\mathrm{Pw})$ e adultas-faratas $(\mathrm{Pbl}$ e $\mathrm{Pbd})$ em comparação com os valores preditos.

\begin{tabular}{l|c|c}
\hline Pw & $\begin{array}{l}\text { Massa Molecular } \\
(\mathrm{kDa})\end{array}$ & $\begin{array}{c}\text { Ponto Isoelétrico } \\
(\mathrm{pI})\end{array}$ \\
\hline Predito & 26,07 & 7,7 \\
\hline Observado & 37,57 & 5,7 \\
\hline \multicolumn{3}{|c}{} \\
\hline Pbl & $\begin{array}{c}\text { Massa Molecular } \\
(\mathrm{kDa})\end{array}$ & $\begin{array}{c}\text { Ponto Isoelétrico } \\
(\mathrm{pI})\end{array}$ \\
\hline Predito & 26,07 & 7,7 \\
\hline Observado & 32,81 & 5,4 \\
\hline \multicolumn{2}{|c}{} \\
\hline Pbd & Massa Molecular & $\begin{array}{c}\text { Ponto Isoelétrico } \\
(\mathrm{pI})\end{array}$ \\
\hline Predito & 26,07 & 7,7 \\
\hline Observado & 42 & 5,6 \\
\hline
\end{tabular}

A Figura 13 mostra que a proteína LOC100577363 com massa predita de 39,79kDa e ponto isoelétrico de 6,7 se expressa somente no tegumento de larvas (L5F) e de pupas (Pw). As massas moleculares e os pIs das diferentes formas da proteína LOC100577363 estão relacionadas na Tabela 14 . 


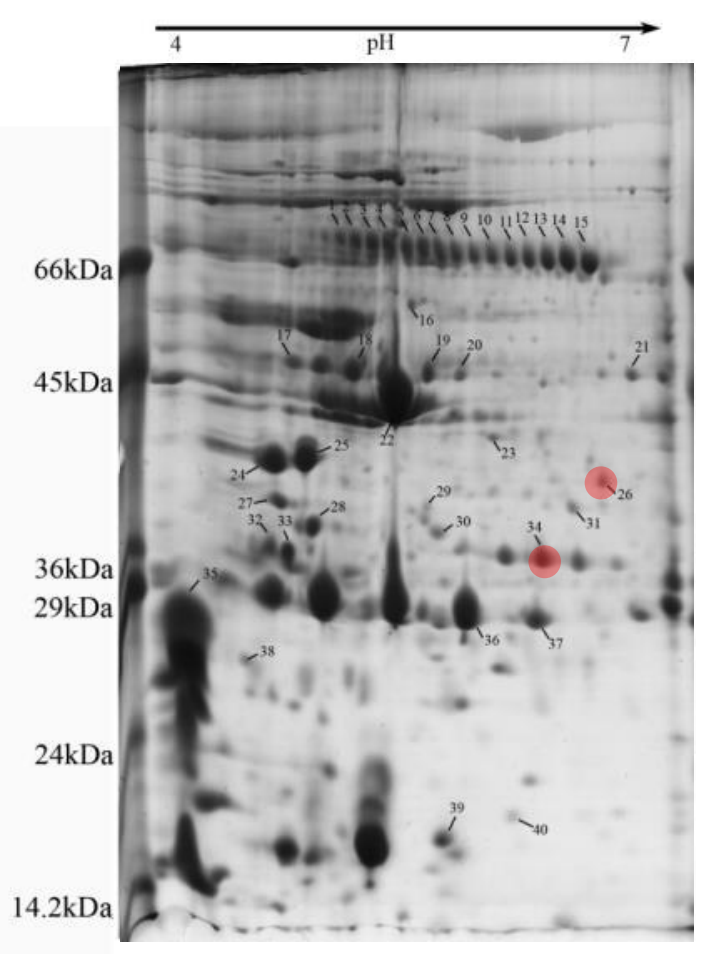

(A)

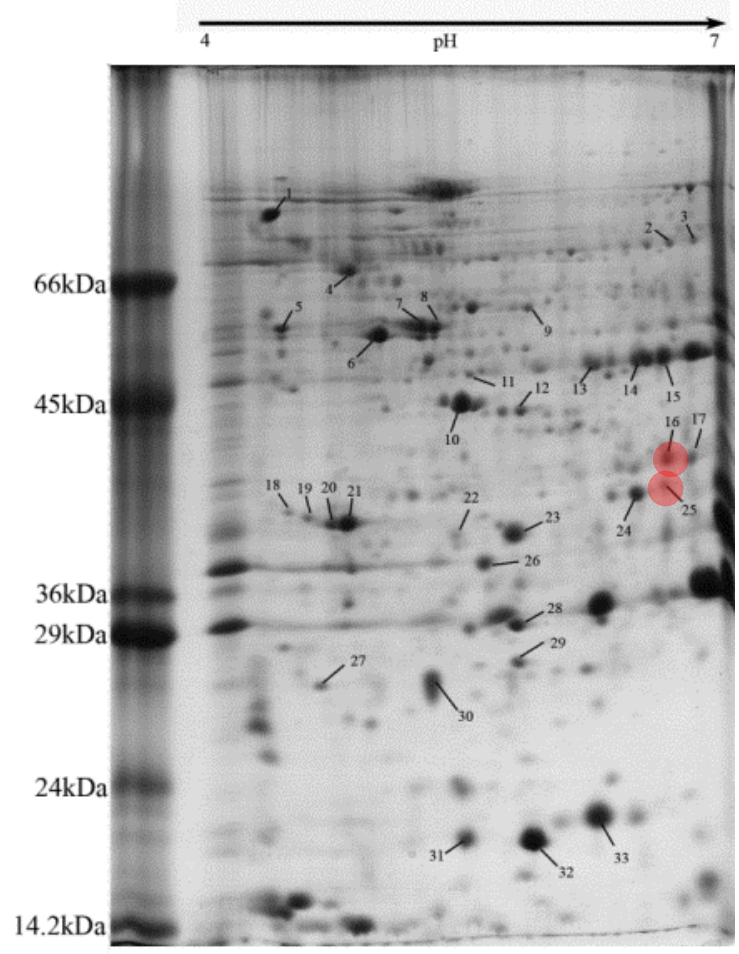

(B)

Figura 13. SDS-PAGE bidimensional mostrando modificações pós-traducionais da proteína LOC100577363 no tegumento larval (L5F) (A) e pupal (Pw) (B) de abelhas operárias. Esta proteína não foi detectada nos tegumentos de adultas-faratas $(\mathrm{Pbl}$ e $\mathrm{Pbd})$. Os números correspondem às proteínas que foram identificadas por espectrometria de massas. Marcadores de massa molecular são mostrados à esquerda de cada gel. Cada amostra contem $150 \mathrm{ug}$ de proteína. O intervalo de $\mathrm{pH}$ está indicado acima da figura. As marcas em vermelho mostram as diferentes massas moleculares e pIs das formas da proteína LOC100577363.

Tabela 14. Massas moleculares e pIs das formas eletroforéticas da proteína LOC100577363 nos tegumentos de larvas (L5F) e de pupas ( $\mathrm{Pw})$ em comparação com os valores preditos.

\begin{tabular}{l|c|c}
\hline L5F & $\begin{array}{c}\text { Massa Molecular } \\
(\mathrm{kDa})\end{array}$ & $\begin{array}{c}\text { Ponto Isoelétrico } \\
(\mathrm{pI})\end{array}$ \\
\hline Predito & 39,79 & 6,7 \\
\hline Observado & 33,43 & 6,2 \\
\hline Observado & 39,12 & 6,6 \\
\hline \multicolumn{2}{|c}{} \\
\hline Pw & $\begin{array}{c}\text { Massa Molecular } \\
(\mathrm{kDa})\end{array}$ & $\begin{array}{c}\text { Ponto Isoelétrico } \\
(\mathrm{pI})\end{array}$ \\
\hline Predito & 39,79 & 6,7 \\
\hline Observado & 39,12 & 6,6 \\
\hline Observado & 42,53 & 6,7 \\
\hline
\end{tabular}

E, finalmente, na Figura 14, observam-se as variações de massa molecular e pI encontradas para a proteína LOC409345, apresentando duas formas com grande variação de pI presentes nas fases larval (L5F), pupal ( $\mathrm{Pw}$ ) e adultas-faratas ( $\mathrm{Pbl}$ e $\mathrm{Pbd})$. As massas moleculares e o pIs das diferentes formas da proteína LOC409345 estão relacionadas na 
Tabela 15. Nos géis 2-DE de larvas L5F e adultas-faratas Pbl as isoformas de LOC 409345 foram identificadas pela posição dos respectivos spots.

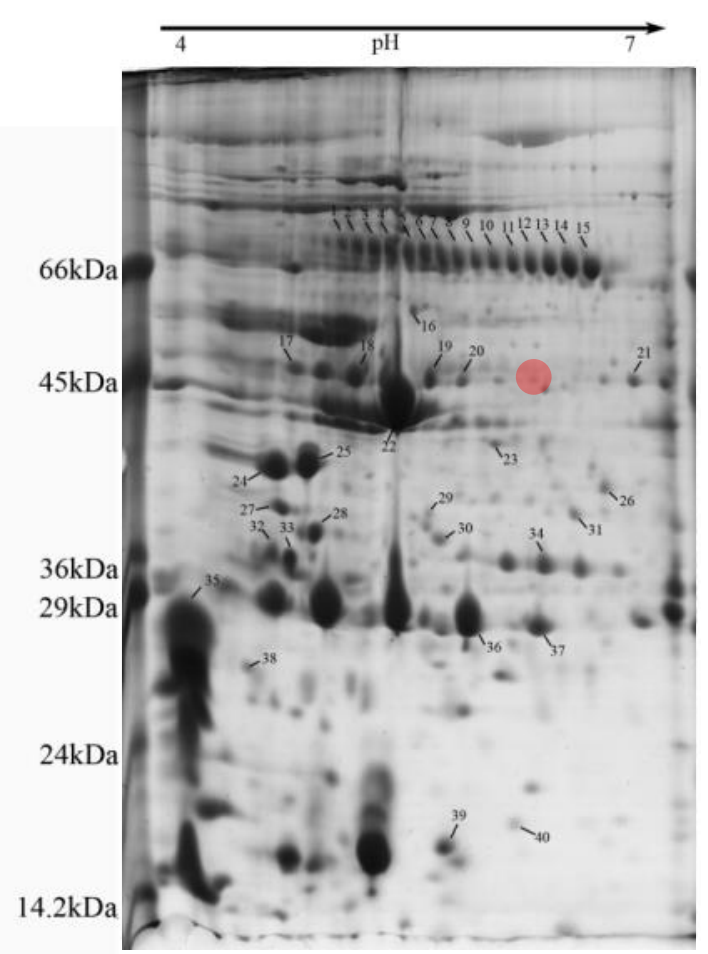

(A)



(C)

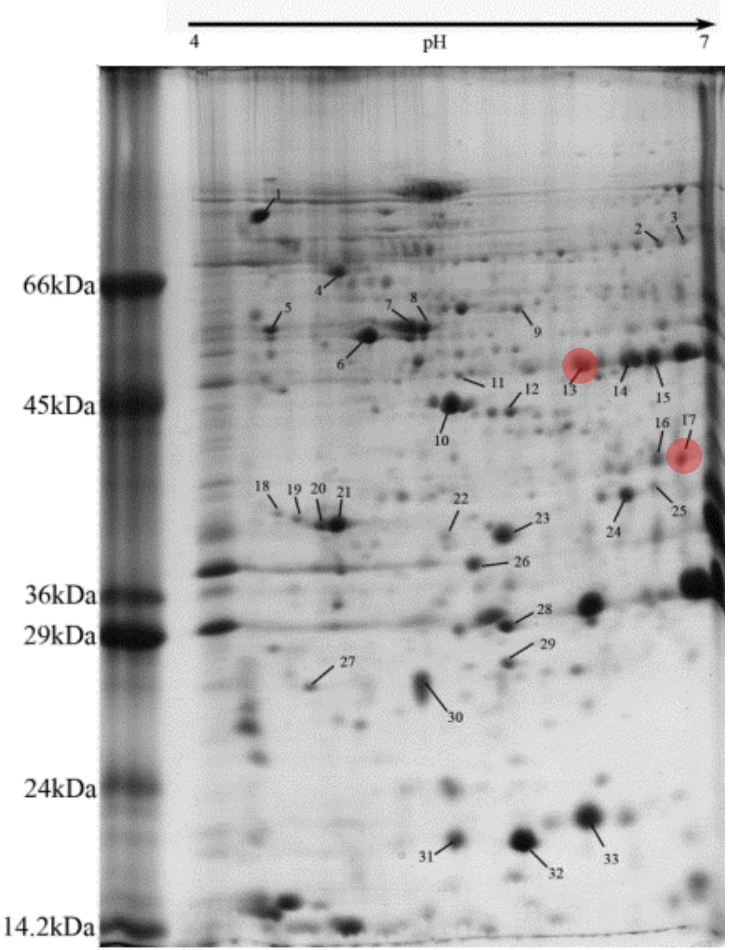

(B)

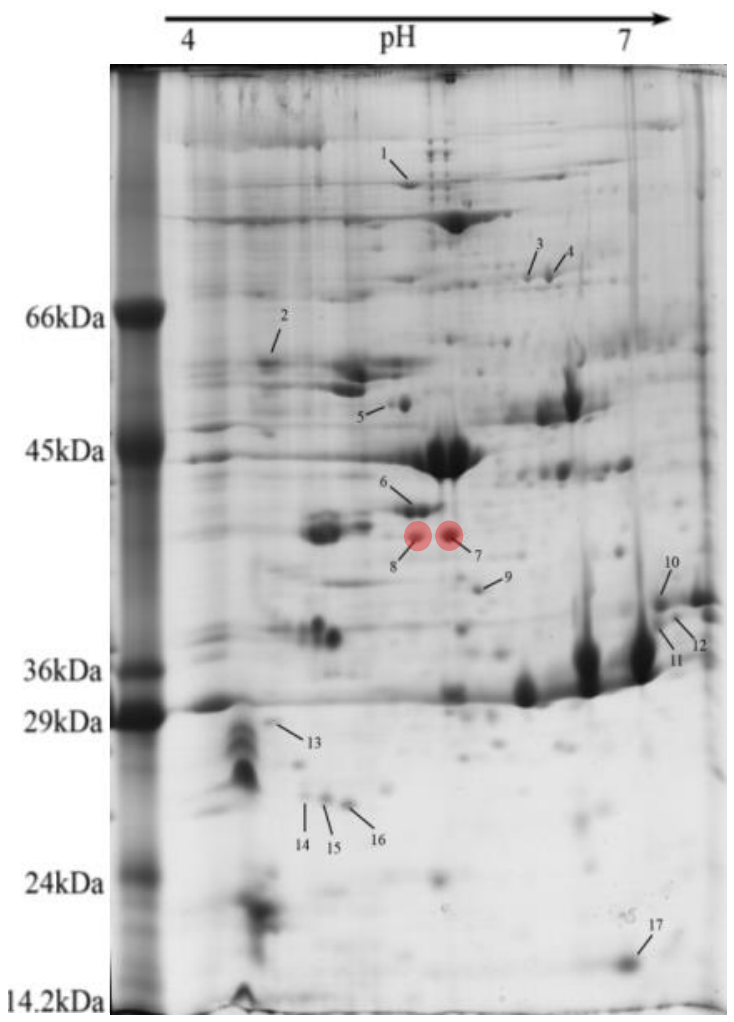

(D) 
Figura 14. SDS-PAGE bidimensional mostrando modificações pós-traducionais da proteína LOC409345 (Amel CPR3) no tegumento larval (L5F) (A), pupal (Pw) (B) e adulto-farato $\mathrm{Pbl}(\mathrm{C})$ e $\mathrm{Pbd}(\mathrm{D})$ de abelhas operárias. Os números correspondem às proteínas que foram identificadas por espectrometria de massas. Marcadores de massa molecular são mostrados à esquerda de cada gel. Cada amostra contem 150ug de proteína. O intervalo de pH está indicado acima da figura. As marcas em vermelho mostram as diferentes massas moleculares e pIs das formas da proteína LOC409345.

Tabela 15. Massas moleculares e pIs das formas eletroforéticas da proteína LOC409345 nos tegumentos de larvas (L5F), pupas ( $\mathrm{Pw}$ ) e adultas-faratas ( $\mathrm{Pbl}$ e $\mathrm{Pbd}$ ) em comparação com os valores preditos.

\begin{tabular}{l|c|c}
\hline L5F & $\begin{array}{c}\text { Massa Molecular } \\
(\mathrm{kDa})\end{array}$ & $\begin{array}{c}\text { Ponto Isoelétrico } \\
(\mathrm{pI})\end{array}$ \\
\hline Predito & 26,07 & 7,7 \\
\hline Observado & 51,92 & 6,3 \\
\hline \multicolumn{3}{|c}{} \\
\hline Pw & $\begin{array}{c}\text { Massa Molecular } \\
(\mathrm{kDa})\end{array}$ & Ponto Isoelétrico \\
\hline Predito & 26,07 & 7,7 \\
\hline Observado & 51,92 & 6,3 \\
\hline Observado & 42 & 6,8 \\
\hline \multicolumn{3}{|c}{} \\
\hline Pbl & Massa Molecular & Ponto Isoelétrico \\
& $(\mathrm{kDa})$ & 7,7 \\
\hline Predito & 26,07 & 5,4 \\
\hline Observado & 40,58 & 5,3 \\
\hline Observado & 40,53 & Ponto Isoelétrico \\
\hline \multicolumn{2}{|c}{} \\
\hline Pbd & Massa Molecular \\
& $(\mathrm{kDa})$ & 7,7 \\
\hline Predito & 26,07 & 5,4 \\
\hline Observado & 40,58 & 5,3 \\
\hline Observado & 40,53 & \\
\hline
\end{tabular}

A Figura 15 é uma compilação das proteínas cuticulares e algumas proteínas de interesse identificadas nas fases de desenvolvimento analisadas frente às variações dos títulos de ecdisteróides. 


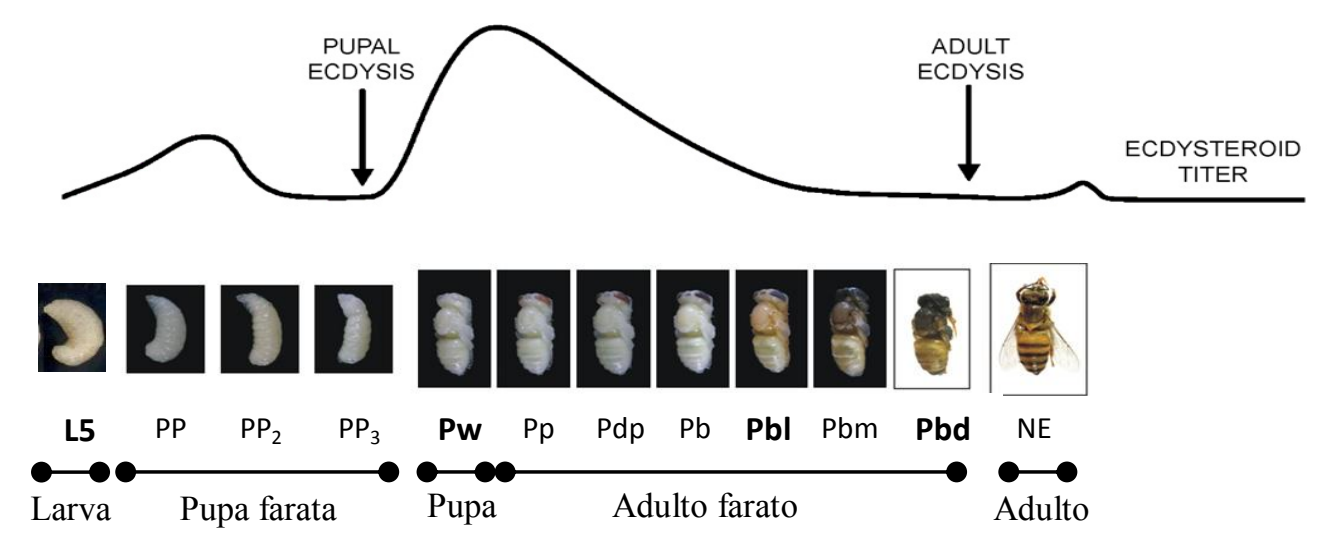

\begin{tabular}{|c|c|c|c|c|}
\hline APD 3-like & $\mathbf{x x}$ & & $\mathbf{x x x}$ & $\mathbf{x}$ \\
\hline Apidermin 2 & & & & $\mathbf{x}$ \\
\hline $\begin{array}{l}\text { Apis mellifera } \\
\text { cuticular protein } 27 \\
\text { (Amel CPR27) }\end{array}$ & & $\mathbf{x}$ & $\mathbf{x}$ & $\mathbf{x}$ \\
\hline $\begin{array}{l}\text { Cuticular protein } \\
\text { Analogous to } \\
\text { Peritrophins 3-C }\end{array}$ & $\mathbf{x x}$ & $\mathbf{x x}$ & $\mathbf{x}$ & $\mathbf{x}$ \\
\hline $\begin{array}{l}\text { Cuticular protein } \\
\text { Analogous to } \\
\text { Peritrophins 3-D }\end{array}$ & & & $\mathbf{x}$ & $\mathbf{x}$ \\
\hline $\begin{array}{l}\text { Flexible cuticle } \\
\text { protein } 12 \\
(\text { Amel CPR12) } \\
\end{array}$ & $\mathbf{x x x}$ & $\mathbf{x}$ & $\mathbf{x}$ & $\mathbf{x x}$ \\
\hline $\begin{array}{l}\text { Glycoprotein } \\
\text { SgABD-2-like }\end{array}$ & $\mathbf{x}$ & $\mathbf{x}$ & $\mathbf{x x}$ & $\mathbf{x x}$ \\
\hline LOC 100576341 & $\mathbf{x}$ & $\mathbf{x x}$ & & \\
\hline
\end{tabular}

\begin{tabular}{lllll} 
(Amel CPR16) & & & & \\
LOC 100577363 & $\mathbf{x}$ & $\mathbf{x}$ & & \\
\hline LOC 408365 & $\mathbf{x}$ & $\mathbf{x}$ & $\mathbf{x}$ & $\mathbf{x}$
\end{tabular}

(Amel CPR3)

\begin{tabular}{lllll}
\hline LOC 413679 & $\mathbf{x}$ & & & \\
\hline LOC 725454 & $\mathbf{x}$ & $\mathbf{x x}$ & & \\
\hline LOC 725838 & $\mathbf{x}$ & $\mathbf{x}$ & $\mathbf{x}$ & $\mathbf{x}$ \\
\hline Annexin-B9-like & & $\mathbf{x}$ & $\mathbf{x}$ & $\mathbf{x}$ \\
\hline LOC 100577363 & $\mathbf{x}$ & $\mathbf{x}$ & $\mathbf{x}$ & \\
\hline $\begin{array}{l}\text { Glutathione-S- } \\
\text { transferase }\end{array}$ & & & & \\
\hline $\begin{array}{l}\text { Farnesoic acid o- } \\
\text { methyltransferase }\end{array}$ & $\mathbf{x}$ & $\mathbf{x}$ & $\mathbf{x}$ & $\mathbf{x}$ \\
\hline Peroxiredoxin & & & & \\
\hline Família das SDR & $\mathbf{x}$ & & $\mathbf{x}$ & $\mathbf{x}$ \\
\hline Silk fibroin & & & $\mathbf{x}$ & $\mathbf{x}$ \\
\hline Yellow & & & \\
\hline Lipocalin & & & & \\
\hline
\end{tabular}

Figura 15. Intensidade relativa das proteínas identificadas (spots) durante o desenvolvimento em relação com a flutuação dos títulos de ecdisteróides. A curva de ecdisteróides foi baseada na quantificação efetuada por Rachinsky et al. (1990) e Pinto et al. (2002). As fases de desenvolvimento do $5^{\circ}$ instar larval (L5) para a operária adulta recém-emergida (NE) estão representadas. As fases usadas neste estudo de proteínas do tegumento estão marcadas em negrito: L5, Pw (pupa), Pbl e Pbd (adultas-faratas). x, xx e xxx = volume de spot, 
onde xx (expressão intermediária) e xxx (alta expressão) indicam um volume de duas e três vezes maior do que $\mathrm{x}$ (baixa expressão). Ausência de x significa que o spot não foi identificado no tegumento.

\subsection{Relação entre a expressão de proteínas do tegumento e dos genes que as}

\section{codificam}

\subsubsection{Operárias versus zangões}

A Figura 16 compara a densidade relativa do RNA mensageiro e a concentração da proteína análoga à peritrofina 3-C no tegumento de operárias e zangões na mesma fase do desenvolvimento adulto-farato $(\mathrm{Pbd})$. Verifica-se que tanto o mRNA quanto a proteína são mais abundantes no tegumento de zangões que no tegumento de operárias, na mesma fase de desenvolvimento $(\mathrm{Pbd})$.

\section{Quantificação relativa de mRNA Quantificação relativa proteína - 2DE}



Figura 16. Abundância relativa do mRNA e da proteína cuticular análoga à peritrofina 3-C no tegumento de operárias e zangões em fase de adulto-farato $(\mathrm{Pbd})$. A densidade de transcritos foi determinada por RT-PCR em tempo real. A abundância da proteína foi determinada através da análise de géis SDS-PAGE bidimensional pelo software ImageScanner 4.0 Amersham Biosciences. As análises foram realizadas utilizando-se 3 amostras independentes em cada comparação. A análise estatística foi efetuada pelo software SigmaStat Versão 3.5, para Windows, utilizando o teste ANOVA One Way $(\mathrm{P}<0,05)$.

Tal correlação foi também encontrada na comparação dos níveis de mRNA e da proteína glutationa S-transferase-like (Figura 17). 


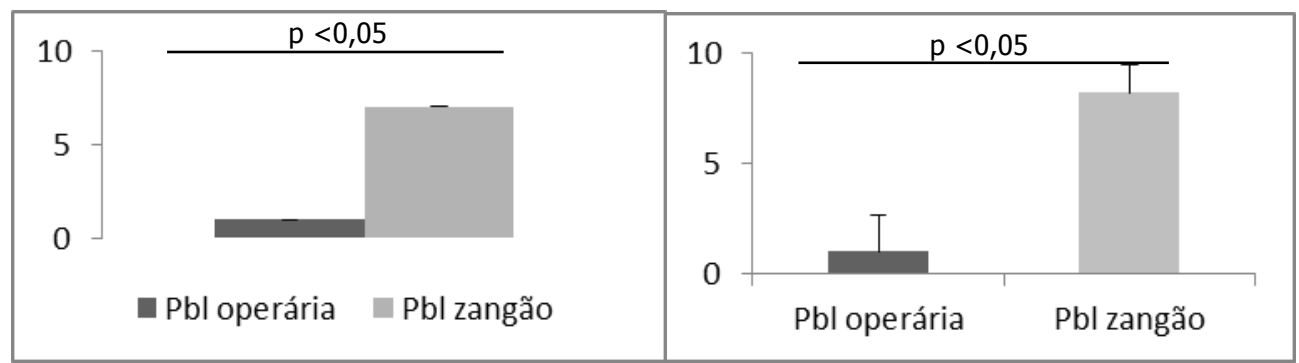

Figura 17. Abundância relativa do mRNA e da proteína cuticular glutationa S-tranferase-like no tegumento de operárias e zangões em fase de adulto-farato (Pbd). A densidade de transcritos foi determinada por RT-PCR em tempo real. A abundância da proteína foi determinada através da análise de géis SDS-PAGE bidimensional pelo software ImageScanner 4.0 Amersham Biosciences. As análises foram realizadas utilizando-se 3 amostras independentes em cada comparação. A análise estatística foi efetuada pelo software SigmaStat Versão 3.5, para Windows, utilizando o teste ANOVA One Way $(\mathrm{P}<0,05)$.

A Figura 18 compara a densidade relativa do RNA mensageiro e a concentração da proteína Yellow no tegumento de operárias e zangões na mesma fase do desenvolvimento adulto-farato $(\mathrm{Pbl})$. Verifica-se que o mRNA é mais abundante no tegumento de zangões que no tegumento de operárias, na mesma fase de desenvolvimento $(\mathrm{Pbl})$. A comparação entre as concentrações da proteína não obteve significância estatística, possivelmente por variações amostrais.

Quantificação relativa de mRNA Quantificação relativa proteína-2DE

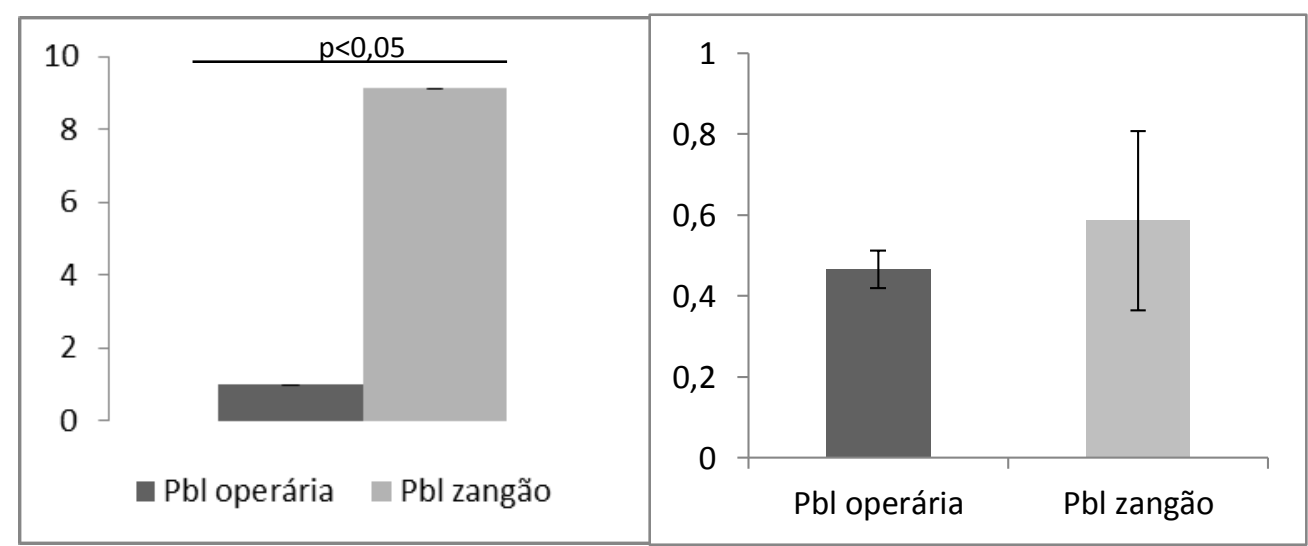

Figura 18. Comparação da abundância relativa do mRNA e da proteína Yellow-like entre operárias e zangões adultas-faratas $(\mathrm{Pbl})$. A densidade de transcritos foi determinada por RT-PCR em tempo-real. A abundância da proteína foi determinada através da análise de géis SDS-PAGE bidimensional pelo software ImageScanner 4.0 Amersham Biosciences. As análises foram realizadas utilizando-se 3 amostras independentes em cada comparação. A análise estatística foi efetuada pelo software SigmaStat Versão 3.5, para Windows, utilizando o teste ANOVA One Way $(\mathrm{P}<0,05)$.

Quando foi avaliado o perfil de expressão e tradução da proteína LOC725454 entre os morfotipos em fase larval L5F, aparentemente foi encontrada uma relação oposta, em que os níveis de mRNA do tegumento de operárias mostraram-se mais elevados do que em zangões 
enquanto que a concentração de proteína mostrou-se maior em zangões do que em operária. No entanto, estas comparações não foram estatisticamente significates (Figura 19).



Figura 19. Abundância relativa do mRNA e da proteína LOC725454 no tegumento de operárias e zangões em fase de larva (L5F). A densidade de transcritos foi determinada por RT-PCR em tempo real. A abundância da proteína foi determinada através da análise de géis SDS-PAGE bidimensional pelo software ImageScanner 4.0 Amersham Biosciences. As análises foram realizadas utilizando-se 3 amostras independentes em cada comparação. A análise estatística foi efetuada pelo software SigmaStat Versão 3.5, para Windows, utilizando o teste ANOVA One Way $(\mathrm{P}<0,05)$.

\subsubsection{Larva (L5S) versus pupa ( $\mathrm{Pw})$ versus adulta-farata $(\mathrm{Pbl})$}

As figuras seguintes comparam a abundância relativa de alguns tipos de transcritos expressos no tegumento, e das respectivas proteínas, entre as fases de desenvolvimento. Os níveis de transcritos codificadores de glutationa S-transferase-like, apresentam diferença significante entre as fases $\mathrm{Pw}$ e adultas-faratas $\mathrm{Pbl}$ e $\mathrm{Pbd}$. A análise da proteína mostrou diferença significante entre as fases Pw e Pbl (Figura 20). 
Quantificação relativa de mRNA

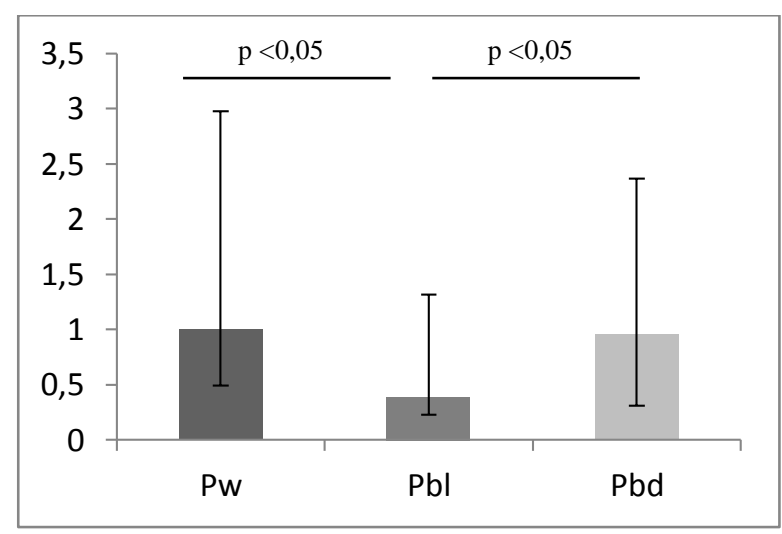

Quantificação relativa proteína - 2DE

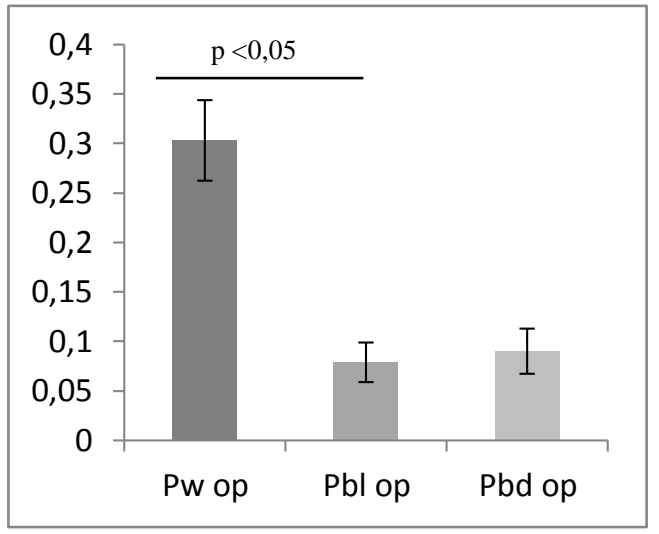

Figura 20. Abundância relativa do mRNA e da proteína cuticular glutationa S-transferase-like no tegumento de zangões em fase de pupa ( $\mathrm{Pw}$ ) e adulto-farato ( $\mathrm{Pbl}$ e $\mathrm{Pbd}$ ). A densidade de transcritos foi determinada por RTPCR em tempo real. A abundância da proteína foi determinada através da análise de géis SDS-PAGE bidimensional pelo software ImageScanner 4.0 Amersham Biosciences. As análises foram realizadas utilizandose 3 amostras independentes em cada comparação. A análise estatística foi efetuada pelo software SigmaStat Versão 3.5, para Windows, utilizando o teste de ANOVA One Way $(\mathrm{p}<0,05)$

Há diferenças significantes nos níveis da proteína Peroxiredoxina 1 nos tegumentos nas comparações entre as fases do desenvolvimento de operárias (Figura 21). Esta diferença não foi observada em zangões (Figura 22). Não houve diferença nos níveis de RNAm de Peroxiredoxina 1 entre as fases de desenvolvimento de operárias e zangões (Figuras 21 e 22). 


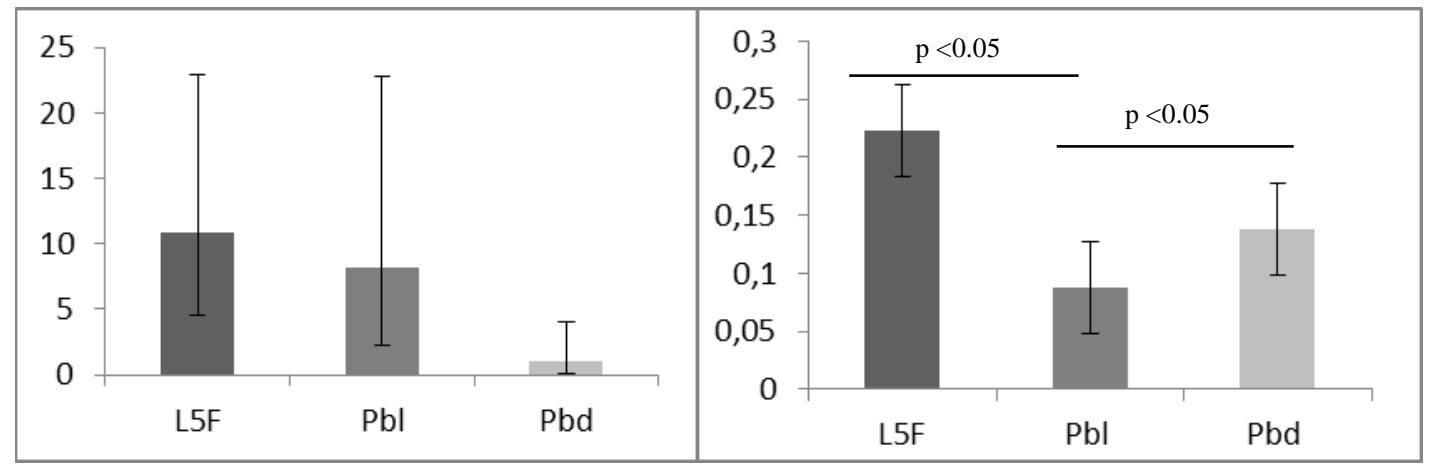

Figura 21. Abundância relativa do mRNA e da proteína cuticular Peroxiredoxina 1 no tegumento de operárias em fase larval (L5F) e de adultas-faratas ( $\mathrm{Pbl} \mathrm{e} \mathrm{Pbd).} \mathrm{A} \mathrm{densidade} \mathrm{de} \mathrm{transcritos} \mathrm{foi} \mathrm{determinada} \mathrm{por} \mathrm{RT-PCR} \mathrm{em}$ tempo real. A abundância da proteína foi determinada através da análise de géis SDS-PAGE bidimensional pelo software ImageScanner 4.0 Amersham Biosciences. As análises foram realizadas utilizando-se 3 amostras independentes em cada comparação. A análise estatística foi efetuada pelo software SigmaStat Versão 3.5, para Windows, utilizando o teste de Anova One way.

Quantificação relativa de mRNA

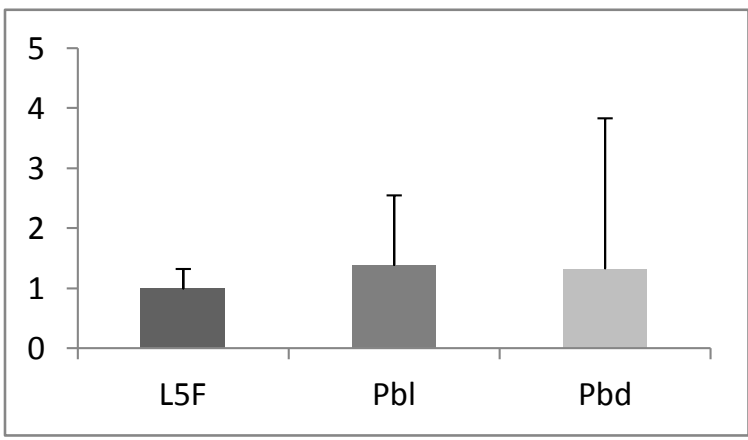

Quantificação relativa proteína - 2DE



Figura 22. Abundância relativa do mRNA e da proteína cuticular Peroxiredoxina 1 no tegumento de zangões em fases de larva (L5F) e de adultas-faratas (Pbl e Pbd). A densidade de transcritos foi determinada por RT-PCR em tempo real. A abundância da proteína foi determinada através da análise de géis SDS-PAGE bidimensional pelo software ImageScanner 4.0 Amersham Biosciences. As análises foram realizadas utilizando-se 3 amostras independentes em cada comparação. A análise estatística foi efetuada pelo software SigmaStat Versão 3.5, para Windows, utilizando o teste de Anova One way.

\section{A proteína cuticular LOC725454 (GB15046) é diferencialmente expressa na} comparação entre pupa e larva de operárias e zangões. Níveis maiores de proteína foram encontrados em pupas (Pw) em comparação com larvas (L5F) e o mesmo foi observado em relação à quantificação dos níveis de transcritos respectivos (Figuras 23 e 24). 
Quantificação relativa de mRNA

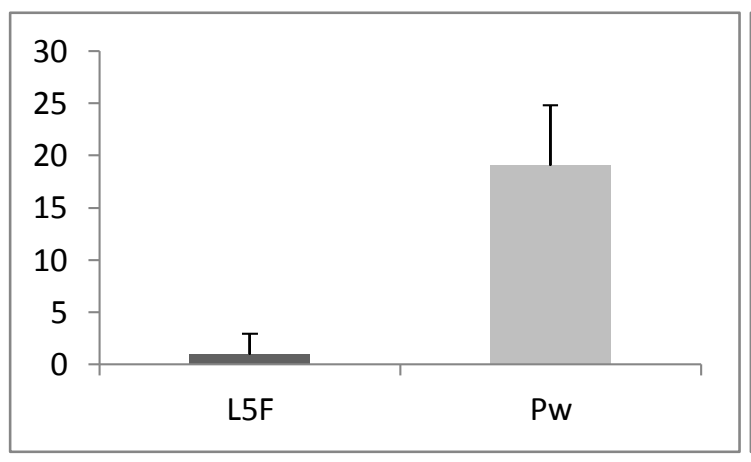

Quantificação relativa proteína - 2DE

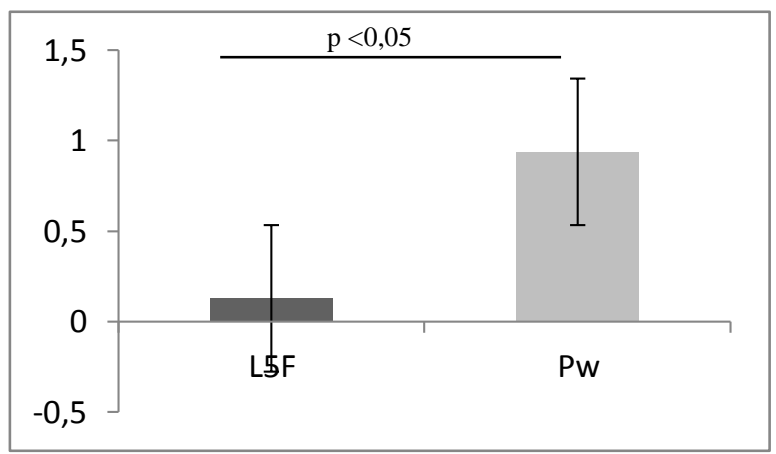

Figura 23. Abundância relativa do mRNA e da proteína LOC725454 no tegumento de operárias em fases de larva (L5F) e pupa ( $\mathrm{Pw})$. A densidade de transcritos foi determinada por RT-PCR em tempo real. A abundância da proteína foi determinada através da análise de géis SDS-PAGE bidimensional pelo software ImageScanner 4.0 Amersham Biosciences. As análises foram realizadas utilizando-se 3 amostras independentes em cada comparação. A análise estatística foi efetuada pelo software SigmaStat Versão 3.5, para Windows, utilizando o teste de Anova One way.

Quantificação relativa de mRNA

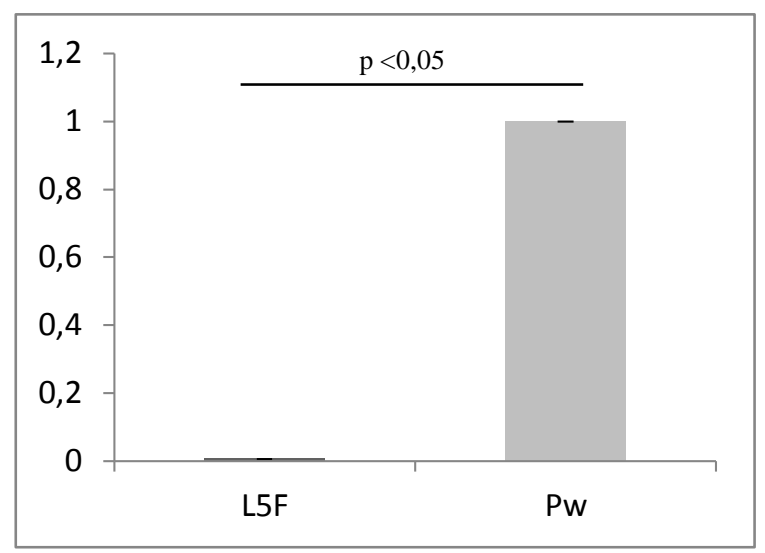

Quantificação relativa proteína - 2DE

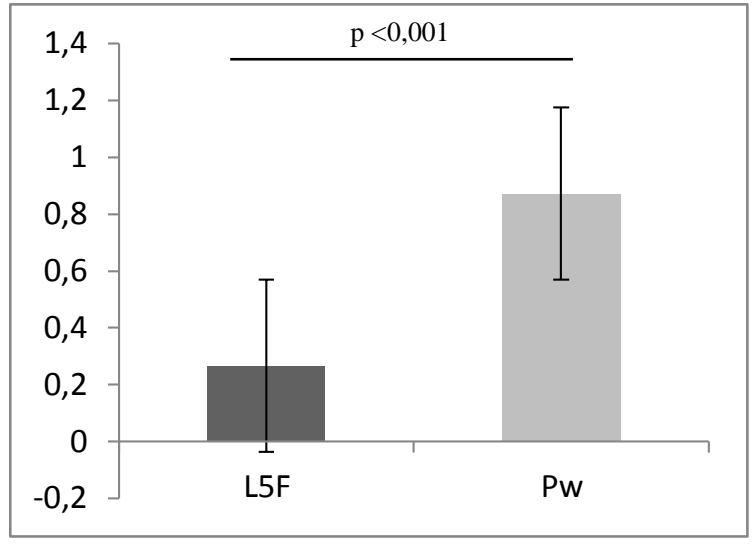

Figura 24. Abundância relativa do mRNA e da proteína LOC725454 no tegumento de zangões em fases de larva (L5F) e pupa $(\mathrm{Pw})$. A densidade de transcritos foi determinada por RT-PCR em tempo real. A abundância da proteína foi determinada através da análise de géis SDS-PAGE bidimensional pelo software ImageScanner 4.0 Amersham Biosciences. As análises foram realizadas utilizando-se 3 amostras independentes em cada comparação. A análise estatística foi efetuada pelo software SigmaStat Versão 3.5, para Windows, utilizando o teste de Anova One way.

\section{DISCUSSÃO}

O tegumento de operárias e zangões apresentou perfis eletroforéticos bidimensionais muito semelhantes. Uma exceção interessante foram os spots identificados como apidermina 3-like (APD-3-like). Genes cuticulares da família apidermina (apd-1, apd-2 e apd-3) foram 
primeiro caracterizados em A. mellifera por Kucharski et al. (2007), e podem ser típicos de Hymenoptera (Willis, 2010). As proteínas deduzidas são altamente hidrofóbicas, com alto teor de alanina. A proteína APD-3 madura é pequena $(9 \mathrm{kDa})$, conforme verificado por tradução in silico. Entretanto, APD-3-like apresentou maior massa molecular, com uma faixa de tamanho entre 24,8 a 69,7 kDa. Em himenópteros parasitas, vespas Nasonia, o gene apd-3 foi identificado e putativamente codifica uma proteína que também tem maior massa molecular (21,6 a $37 \mathrm{kDa}$ ) que a APD-3 predita de $A$. mellifera. Esta inconsistência pode ser explicada pela presença de múltiplas formas, derivadas de modificações pós-traducionais, como verificado para APD-3-like, mas esta hipótese requer investigação mais profunda.

Foram analisados por espectrometria de massas 200 spots extraídos dos géis bidimensionais, dos quais identificamos 51 proteínas, $27,4 \%$ delas portadoras de características de proteínas cuticulares, incluindo apiderminas, peritrofinas, proteínas da família CPR (Amel CPR3, Amel CPR12, Amel CPR16 e Amel CPR27), e outras, similares a proteínas cuticulares de insetos, ou contendo domínios de ligação a quitina, o principal polissacarídeo cuticular.

As proteínas da família CPR compartilham o Consenso R\&R (Rebers e Riddiford, 1988; Rebers e Willis, 2001), que as capacitam a ligarem quitina. Trinta e dois genes CPR foram preditos no genoma de A. mellifera e foram nomeados como Amel CPR1 a Amel CPR32 (Willis, 2010). Outros dois genes CPR foram recentemente identificados em análises de microarrays de cDNA de amostras de tegumento (Soares, 2012). Apenas para ressaltar, somente o gene Amel CPR14 (Soares et al., 2007), e os dois outros genes identificados nas análises de microarrays foram validados por sequenciamento dos respectivos cDNAs e por estudos de expressão utilizando amostras de tegumento. As proteínas Amel CPR3, Amel CPR12, Amel CPR16 e Amel CPR27 aqui identificadas representam a validação experimental das sequências codificadoras correspondentes, preditas do genoma sequenciado e anotado de A. mellifera.

Foi interessante constatar que a proteína SgABD-2-like, anteriormente predita como uma glicoproteína estrutural da endocutícula e aqui confirmada como uma autêntica proteína do tegumento, também possui o Consenso R\&R (tipo 1). Portanto, juntamente com as proteínas Amel CPR3, Amel CPR12, Amel CPR16 e Amel CPR27, SgAbd-2-like integra a família das proteínas CPR.

Entre estas proteínas CPR, Amel CPR3, Amel CPR12 e SgAbd-2-like foram detectadas em todas as fases de desenvolvimento analisadas, i.e., em larvas (L5F), pupas (Pw) 
e adultos-faratos ( $\mathrm{Pbl}$ e $\mathrm{Pbd}$ ). Portanto, são proteínas estruturais da cutícula de larvas, pupas e adultos. Amel CPR16 não foi detectada nas fases adultas-faratas (Pbl e Pbd), sugerindo regulação diferencial durante a formação e diferenciação da cutícula adulta. Amel CPR27 parece ser específica de cutículas pupais e de adultos.

Também foi verificado padrão variável de expressão para outras proteínas cuticulares aqui identificadas. Por exemplo, APD-3-like foi identificada em larvas e adultas-faratas, mas não em pupas. Apidermina 2 mostrou-se típica do tegumento torácico mais escuro de adultosfaratos em fase Pbd, pouco antes da ecdise para o estágio adulto. Apidermina 2 foi também detectada em análises proteômicas de carcaças abdominais (cutícula, epiderme e corpo gorduroso) de operárias A. mellifera adultas (Chan et al., 2009), indicando uma função na cutícula do estágio adulto. Entretanto, a expressão do gene apd-2 foi caracterizada inicialmente por Kucharski et al. (2007) na traqueia, esôfago e estômago, e também em embriões, sugerindo que Apidermina 2 é um componente de cutículas internas, mais flexíveis. Estes autores não detectaram expressão de apd-2 no tegumento (exoesqueleto), possivelmente devido às suas análises não terem incluído o tegumento mais escuro das adultas-faratas $(\mathrm{Pbd})$ prestes a emergir como adultas.

Em contraste, outras proteínas cuticulares, LOC100577363, LOC408365, LOC413679 e LOC725454 foram detectadas no tegumento larval, ou nos tegumentos larval e pupal, mas não no tegumento adulto em diferenciação. Estes padrões variáveis de expressão são consistentes com o que se conhece sobre a regulação de genes codificadores de proteínas cuticulares por variações do título de ecdisteróides.

Peritrofina é um dos componentes da matriz peritrófica cuticular que reveste o lúmen do intestino dos insetos. Acredita-se que ela protege os insetos da invasão por microorganismos, além de estimular a digestão do alimento (Du et al., 2006). Proteínas Peritrophin-like têm sido descritas em insetos e outros artrópodos. Genes que codificam uma família de proteínas cuticulares análogas à peritrofina 3 (CPAP3) que contém três domínios ligantes de quitina relacionados ao domínio A de peritrofinas (Chitin Binding Domain 2, ChtBD2) foram caracterizados no besouro Tribolium castaneum, onde são expressos em todas as fases de desenvolvimento em tecidos associados à cutícula, com exceção do intestino (Jasrapuria et al., 2010).

Duas formas da proteína cuticular análoga à peritrofina 3 (CPAP3-C e D) foram aqui detectadas no tegumento de A. mellifera. Como em T. castaneum, uma destas peritrofinas (CPAP3-C) está expressa em todos os estágios de desenvolvimento aqui analisados. 
Entretanto, CPAP3-D foi detectada somente em cutículas melanizadas de adultos-faratos (Pbl e $\mathrm{Pbd})$, indicando regulação temporal distinta.

Outras proteínas de interesse, além daquelas que apresentam domínios típicos de proteínas cuticulares, também integram o proteoma do tegumento. A proteína Yellow é evolutivamente relacionada com a família das Major Royal Jelly Proteins (MRJPs). Um único gene que codifica um membro ancestral da família Yellow parece ter originado as MRJPs. Em A. mellifera foram identificados 10 genes que codificam ortólogos de proteínas Yellow de $D$. melanogaster (Drapeau et al., 2006). Um deles, GB194634, codifica a proteína Yellow aqui isolada do tegumento de adultas-faratas ( $\mathrm{Pbl}$ e $\mathrm{Pbd}$ ). Em D. melanogaster, Yellow é necessária para a correta melanização da cutícula (Wittkopp et al., 2002). Merece atenção o fato de que em A. mellifera, Yellow não foi detectada no tegumento não melanizado das fases larval e pupal.

A glutationa S-transferase forma um grupo de enzimas citosólicas, mitocondriais e microssomais com a função de desintoxicação que catalisam substratos tanto endógenos como xenobióticos. Dez genes GST foram identificados em A. mellifera (Claudianos et al., 2006), e são distribuídos em seis classes: Delta (1 gene), Omega (1 gene), Sigma (4 genes), Theta (1 gene), Zeta (1 gene) e microssomal (2 genes). Essa variabilidade de GSTs tem sido considerada como adaptação dos insetos às pressões de seleção do ambiente associadas à resistência a inseticidas (Ranson et al., 2002). A região codificadora de dois genes de glutationa S-transferase em A. mellifera foi completamente sequenciada (Loterio, 2011). Os produtos putativos desses genes são GSTs da classe Sigma (GSTS1 e GSTS4). Os padrões de expressão de ambos os genes foram caracterizados durante o desenvolvimento, e em resposta aos hormônios morfogenéticos, 20-hidroxiecdisona e hormônio juvenil. Pelo menos para GSTS1, o padrão de expressão é consistente com uma função na metamorfose. A glutationa Stransferase-like (gi| 328793353) aqui identificada no estágio pupal (Pw) e em adultos-faratos ( $\mathrm{Pbl}$ e $\mathrm{Pbd})$, é 43\% idêntica à GSTS4, 45\% idêntica à GSTS1 e compartilha baixa identidade com outras GSTs de A. mellifera. Pode ser específica do tegumento, mas isto requer investigação.

Peroxiredoxina é uma enzima antioxidante que tem um papel na proteção contra radicais de oxigênio produzidos durante o metabolismo aeróbico. A atividade antioxidante da peroxiredoxina é devida à redução de hidroperóxido, com tioredoxina como um doador de hidrogênio (Chae et al., 1999). Assim como as glutationa S-transferases, peroxiredoxinas são enzimas antioxidantes que agem como peroxidases em insetos. $\mathrm{O}$ genoma de A. mellifera 
contém cinco genes codificadores de peroxiredoxinas putativas, que são homólogas às de D. melanogaster e A. gambiae. A proteína deduzida de um destes genes, AmTpx-1(GB19380) (Corona e Robinson, 2006), foi agora validada em nossa análise por 2DE e espectrometria de massas: Peroxiredoxin 1 gi|328777120. Além de ser identificada no tegumento de larvas, esta peroxiredoxina também está presente no tegumento de adultos-faratos ( $\mathrm{Pbl}$ e $\mathrm{Pbd}$ ) em processo de melanização cuticular. Atuando como peroxidases, as peroxiredoxinas podem ser importantes na via de melanização/esclerotização cuticular, assim como outras enzimas com função na oxidação de catecóis (precursores da esclerotização) em quinonas. Quinonas são precursores de melanina e interagem covalentemente com resíduos de aminoácidos de proteína cuticulares em reações que levam à esclerotização e estabilização da cutícula (Hopkins e Kramer, 1992; Andersen, 2010).

A isoforma 2 da Apoliproteína D-like (gi:328786624) tem sido associada com uma família de pequenas proteínas extracelulares ligantes de lipídios denominadas lipocalinas, a maioria delas compartilhando três domínios conservados característicos. Suas sequências de aminoácidos não são similares, embora estruturalmente elas sejam altamente conservadas e formem uma estrutura $\beta$-barrel-like consistindo de 8 fitas antiparalelas que fecham um sítio ligante interno. As funções das lipocalinas têm sido relacionadas ao transporte de pequenas moléculas hidrofóbicas incluindo hormônios esteróides, feromônios, retinóides e produtos metabólicos. Um exemplo de uma lipocalina bem conhecida é a insetocianina de lepidópteros, a qual está presente na cutícula (Flower et al., 2000; Kayser, 2005). Um tipo de lipocalina (Apolipoproteína D-like isoforma 2) foi aqui validada no tegumento de adultos-faratos ( $\mathrm{Pbl} \mathrm{e}$ $\mathrm{Pbd})$ e pode estar relacionada com o transporte de produtos para a diferenciação da cutícula.

Peroxinectina é uma enzima antioxidante que remove o peróxido de hidrogênio. Possui atividade de peroxidase (Johansson et al., 1995) e foi também relacionada ao processo de adesão celular (Johansson e Söderhäll, 1998). Em crustáceos foi associada à resposta imune mediada pela profenoloxidase (Sritunyalucksana et al., 2001), e ao sistema de defesa incluindo a adesão de hemócitos, encapsulamento (Kobayashi et al., 1990), e fagocitose (Thörnqvist et al., 1994). No lepidóptero Plodia interpunctella (Candas et al., 2002), a peroxinectina também foi estudada no contexto da defesa imune. Assim como a peroxiredoxina, a peroxinectina foi localizada no tegumento de adultas-faratas em processo de melanização, sugerindo que sua atividade peroxidásica é necessária para este processo. Considerando que a melanização também ocorre durante o encapsulamento de parasitas, um mecanismo celular de defesa caracterizado pela interação entre melanina e outras proteínas 
para formar um revestimento que envolve e provoca a morte de parasitas (Zhao et al., 1995), a peroxinectina pode também ter um papel neste processo.

Múltiplas anexinas estão presentes em eucariotos, sugerindo funções essenciais na biologia celular. As anexinas são descritas como proteínas citosólicas que interagem com os constituintes da membrana celular envolvidos na organização estrutural das células, sinalização intracelular, controle de crescimento, e podem também atuar como canais de cálcio atípicos. As anexinas compartilham um domínio formado por quatro repetições semelhantes de aproximadamente 70 aminoácidos. A. mellifera possui três anexinas (Moss e Morgan, 2004), e uma delas, Anexina-B9-like, foi aqui isolada de tegumentos de pupas (Pw) e adultos-faratos (Pbl e $\mathrm{Pbd})$.

A fibroína aqui identificada (gi|209969888) é similar a proteínas que constituem a maior fração das proteínas da seda de Bombyx mori (Sutherland et al., 2006), e foi detectada somente no estágio larval em $A$. mellifera, onde pode ser um constituinte do casulo de seda secretado pela própria larva. O casulo de seda recobre internamente cada célula do favo e no interior deste casulo, a larva se transforma em pupa. A seda é produzida pelas glândulas salivares (Silva-Zacarin et al., 2003), que são constituídas por um par de longos tubos secretores formados por um epitélio de uma única camada celular (Cruz-Landim e Mello, 1967). Seis genes relacionados à seda foram identificados em A. mellifera por meio de técnicas genômicas e proteômicas. Quatro deles codificam fibroínas e os outros dois codificam uma proteína associada à seda que atua como cola, e uma proteína com função ainda desconhecida, respectivamente (Sutherland et al., 2006). A proteína silk fibroin-3 precursor identificada nas nossas amostras do tegumento parece derivada do casulo de seda que envolve a larva.

Não foi surpreendente encontrar em nossas análises de tegumentos torácicos proteínas que fazem parte do aparelho contrátil de células musculares, considerando que as fibras musculares em diferenciação estabelecem conexão com o exoesqueleto cuticular. Actina (gi:328790806), tropomiosina-1-like (gi:66522386), tropomiosina-1-isoforma B (gi:229577296), tropomiosina-2-like (gi:48129583), tropomiosina exon 9B (gi:85165) e a cadeia pesada da miosina (isoforma muscular, gi:328790595) foram todas detectadas em nossas análises por 2-DE e espectrometria de massas.

Além de identificar proteínas do tegumento, nossos resultados mostram que (1) as proteínas do tegumento de operárias e zangões em desenvolvimento são muito similares, embora diferenças quantitativas tenham sido detectadas; (2) com exceções, as diferenças 
detectadas durante o desenvolvimento foram principalmente quantitativas, e as proteínas identificadas no tegumento larval foram também encontradas nos tegumentos de pupas e de adultos (adultos-faratos). A variação quantitativa durante o desenvolvimento é consistente com a regulação da expressão gênica no tegumento pelo título de ecdisteróides; (3) metade das proteínas cuticulares identificadas mostraram modificações pós-traducionais indicando maior variabilidade de formas proteicas na cutícula em comparação com a variabilidade de mRNAs; (4) os níveis de algumas proteínas e de seus respectivos transcritos não foram sempre positivamente correlacionados, sugerindo regulação pós-traducional. 


\section{REFERÊNCIAS BIBLIOGRÁFICAS}

Andersen, S.O. 2010. Insect cuticular sclerotization: A review. Insect Biochem. Mol. Biol. 40, 166-178.

Bradford, M.M. 1976. A rapid and sensitive method for the quantification of microgram quantities of protein utilizing the principle of protein-dye binding. Anal. Biochem. $72,248-254$.

Candas, M., Loseva O., Oppert, B., Kosaraju, P., Bulla Jr, L.A. 2002. Insect Resistance to Bacillus thuringiensis. Alterations in the indianmeal moth larval gut proteome. Mol. Cell. Proteomics 2.1,19-28.

Canhos, L.L., 2010. Caracterização de mudanças subcelulares e da expressão dos genes codificadores das enzimas tirosina hidroxilase e dopa descarboxilase no tegumento em diferenciação da abelha Apis mellifera. Monografia. Faculdade de Filosofia, Ciências e Letras de Ribeirão Preto, Universidade de São Paulo, Departamento de Biologia.

Chae, H.Z., Kang, S.W. and Rhee, S.G. 1999. Isoforms of mammalian peroxiredoxin that reduce peroxides in presence of thioredoxin. Meth. Enzymol. 300, 219-226.

Chan, Q.W.T., Foster, L. 2009. Apis mellifera Proteomics: Where will the future bee? Curr. Proteomics 6, 70-73.

Charles, J.P. 2010. The regulation of expression of insect protein genes. Insect Biochem. Mol. Biol. 40, 205-213.

Claudianos, C., Ranson H., Johnson R.M., Biswas, S., Schuler, M.A., Berenbaum, M.R., Feyereisen, R., Oakeshott, J. G. 2006. A deficit of detoxification enzymes: pesticide sensitivity and environmental response in the honeybee. Insect Mol. Biol. 15, 615-636.

Cornman, R.S., Willis, J.H. 2009. Annotation and analysis of low-complexity protein families of Anopheles gambiae that are associated with cuticle. Insect Mol. Biol. 18, 607622.

Corona M., Robinson, G.E. 2006. Genes of the antioxidant system of the honey bee. Insect Mol. Biol. 15, 687-701.

Cruz-Landim, C., Mello, M.L.S. 1967. The post-embryonic changes in Melipona quadrifasciata anthidioides Lep. (Hymenoptera, Apoidea). II. Development of the salivary glands system. J. Morphol. 123, 481-502.

Cruz-Landim, C. 2008. Abelhas: morfologia e função dos sistemas. São Paulo: Editora UNESP. 408p. 
DeAzevedo, S. V., Hartfelder, K. (2008). The insulin signaling pathway in honey bee (Apis mellifera) caste development: differential expression of insulin-like peptides and insulin receptors in queen and worker larvae. J. Insect Physiol. 54, 1064-1071.

Drapeau, M.D., Albert, S., Kucharski, R., Prusko, C., Maleszka, R. 2006.Evolution of the Yellow/Major Royal Jelly Protein family and the emergence of social behavior in honey bees.Genome Res. 16, 1385-1394.

Du, X.J., Wang, J.X., Ning L., Zhao, X.F., Li F.H., Xiang, J.H. 2006. Identification and molecular characterization of a peritrophin-like protein from fleshy prawn (Fenneropenaeus chinensis). Mol. Immunol. 43, 1633-1644.

Elias-Neto, M., Soares, M.P.M., Bitondi, M.M.G. 2009. Changes in integument structure during the imaginal molt of the honey bee. Apidologie 40, 29-39.

Elias-Neto, M., Soares, M.P.M., Simões, Z.L., Hartfelder, K., Bitondi, M.M.G., 2010. Developmental characterization, function and regulation of a Laccase 2 encoding gene in the honey bee, Apis mellifera (Hymenoptera, Apinae). Insect Biochem. Mol. Biol. 40, 241-51.

Flower, D.R., North, A.C.T., Sansom, C.E. 2000. The lipocalin protein family: structural and sequence overview. Biochim. Biophys. Acta 1482, 9-24.

Hall, B.L., Thummel, C.S. 1998. The RXR homolog ultraspiracle is an essential component of the Drosophila ecdysone receptor. Development 125, 4709-4717.

Hartfelder, K.; Engels, W. 1998. Social insect polymorphism: Hormonal regulation of plasticity in development and reproduction in the honeybee. Curr. Topics Dev. Biol. 40: 45-77.

Hasson, C., Sugumaran, M. 1987. Protein cross-linking by peroxidase - possible mechanism for sclerotization of insect cuticle. Arch. Insect Biochem. Physiol. 5, 13-28.

Haydak, M.H. 1970. Honey bee nutrition. Annu. Rev. Entomol.15: 143-156.

Hepburn, H.R. 1985. Structure of the integument. In: Compreensive Insect Physiology Biochemistry and Pharmacology. Eds: G.A. Kerkut; L.I. Gilbert. Vol 3, pp:1-58. Pergamon Press, New York, USA.

Hernández, L.G., Lu, B., da Cruz, G.C., Calábria, L.K., Martins, N.F., Togawa, R., Espindola, F.S., Yates, J.R., Cunha, R.B., de Sousa, M.V. 2012. Worker honeybee brain proteome. J. Proteome Res. 11, 1485-1493.

Herrmann, M., Trenczek, T., Fahrenhorst, H., Engels, W. 2005. Characters that differ between diploid and haploid honey bee (Apis mellifera) drones. Genet.Mol. Res. 4, 624641.

Hiruma, K., Riddiford, L. M. 2010. Developmental expression of mRNAs for epidermal and fat body proteins and hormonally regulated transcription factors in the tobacco hornworn, Manduca sexta. J. Insect Physiol. 56, 1390-1395. 
Hopkins, T.L., Kramer, K.J. 1992. Insect cuticle sclerotization. Ann. Rev. Entomol. 37, $273-$ 302.

Jasrapuria, S., Arakane, Y., Osman, G., Kramer, K.J., Beeman, R.W., Muthukrishnan, S. 2010. Genes encoding proteins with peritrophin A-type chitin-binding domains in Tribolium castaneum are grouped into three distinct families based on phylogeny, expression and function. Insect Biochem. Mol. Biol. 40, 214-227.

Jay, S.C.1963. The development of honeybee in their cells. J. Apic. Res. 2, 117-134.

Johansson, M.W., Lind, M. I., Holmblad, T., Thörnqvist, P.-O.,Söderhäll, K. 1995. Peroxinectin, a novel cell adhesion protein from crayfish blood. Biochem.Biophys. Res. Commun. 216, 1079-1087.

Johansson, M.W., Soderhall, K. 1988. Isolation and purification of a cell adhesion factor from crayfish blood cells. J. Cell Biol. 106,1795-1803.

Kamakura, M. 2011. Royalactin induces queen differentiation in honey bees. Nature 473, 478-483.

Karouzou, M.V., Spyropoulos, Y., Iconomidou, V.A., Cornman, R.S., Hamodrakas, S.J., Willis, J.H. 2007. Drosophila cuticular proteins with the R\&R Consensus: annotation and classification with a new tool for discriminating RR-1 and RR-2 sequences. Insect Biochem. Mol. Biol. 37: 754-760.

Kayser , H. 2005. Lipocalins and structurally related ligand-binding proteins. In: Gilbert, L.I., Iatrou, K., Gill, S., eds. Comprehensive Molecular Insect Science. Oxford: Elsevier. 2005, vol. 4, pp: 267-306.

Kobayashi, M., Johansson, M.W., Söderhäll, K., 1990. The 76 kDa cell adhesion factor from crayfish haemocytes promotes encapsulation in vitro. Cell Tiss. Res.260, 13-18.

Kucharski, R., Maleszka, J., Maleszka, R., 2007. Novel cuticular proteins revealed by the honey bee genome. Insect Biochem. Mol. Biol. 37, 128-134.

Kucharski, R., Maleszka, J., Foret, S., Maleszka, R. 2008.Nutritional control of reproductive status in honey bees via DNA methylation. Science 319, 1827-1830

Locke, M. 2001. The Wigglesworth Lecture: Insects for studying fundamental problems in biology. J. Insect Physiol. 47, 495-507.

Loterio, G. 2011. Os genes codificadores de glutationa S-transferase na abelha Apis mellifera: expressão, regulação e função durante e após a metamorfose. Dissertação de Mestrado. Faculdade de Medicina de Ribeirão Preto, Universidade de São Paulo. Departamento de Genética.

Lourenço, A.P., Zufelato, M.S., Bitondi, M.M.G., Simões, Z.L.P. 2005. Molecular characterization of a cDNA encoding prophenoloxidase and its expression in Apis mellifera. Insect Biochem. Mol. Biol. 35, 541-552. 
Lourenço, A.P., Mackert, A, Cristino, A.S., Simões, Z.L.P. 2008. Validation of references genes for gene expression studies in the honey bee, Apis mellifera, by quantitative real-time RT-PCR. Apidologie 39, 372-385.

Magkrioti, C.K., Spyropoulos, I.C.,Iconomidou, V.A., Willis, J.H., Hamodrakas, S.J. 2004. CuticleDB: a relational database of arthropod cuticular proteins. BMC Bioinform. $5,138-143$.

Michelette, E.R.F., Soares, A.E.E. 1993. Characterization of preimaginal developmental stages in Africanized honey bee workers (Apis mellifera L). Apidologie 24, 431440.

Moss, S.E., Morgan R.O. 2004. The annexins. Genome Biol. 5, 219- 226.

Neuhoff, V., Taube, A.N., Ehrhardt, W. 1988. Improved staining of proteins in polyacrylamide gels including isoelectric focusing gels with clear background at nanogram sensitivity using Coomassie Brilliant Blue G-250 and R-250. Electrophoresis 9, $255-262$.

Patel, A., Fondrk, M.K., Kaftanoglu, O., Emore, C., Hunt, G., Frederick, K., Amdam, G.V. 2007. The making of a queen: TOR pathway is a key player in diphenic caste development. PLos One 2(6): e509. doi:10.1371/journal.pone.0000509.

Peiren, N., Vanrobaeys, F., de Graaf, D. C., Devreeese, B., Van Beeumen, J., Jacobs, F. J. The protein composition of honeybee venom reconsidered by a proteomic approach. Biochim. Biophys. Acta - Prot. Proteom. 1752, 1-5.

Pinto, L.Z., Hartfelder, K., Bitondi, M.M.G., Simões, Z.L.P. 2002. Ecdysteroid titers in pupae of highly social bees relate to distinct modes of caste development. J. Insect Physiol 48, 783-790.

Rachinsky, A., Strambi, C., Strambi, A., Hartfelder, K. 1990. Caste and metamorphosis hemolymph titers of juvenile hormone and ecdysteroids in last instar honeybee larvae. Gen. Comp. Endocr. 79, 31-38.

Ranson, H., Claudianos, C., Ortelli, F., Abgrall, C., Hemingway, J., Sharakhova, M.V., Unger, M.F., Collins, F.H. 2002. Evolution of supergene families associated with insecticide resistance. Science 298, 179-181.

Rebers, J.E., Riddiford, L.M. 1988. Structure and expression of a Manduca sexta larval cuticle gene homologous to Drosophila cuticle genes. J. Mol. Biol. 203, 411-423.

Rebers, J.E., Willis, J.H., 2001. A conserved domain in arthropod cuticular proteins binds chitin. Insect Biochem. Mol. Biol. 31, 1083-1093.

Rembold, H., Kramer, J.P., Ulrich, G.M., 1980. Characterization of post embryonic developmental stages of the female castes of the honey bee, Apis mellifera L. Apidologie 11, 29-38. 
Riddiford, L.M., Hiruma, K., Zhou, X., Nelson, C.A. 2003. Insights into the molecular basis of the hormonal control of molting and metamorphosis from Manduca sexta and Drosophila melanogaster. Insect. Biochem. Mol. Biol. 33, 1327-1338.

Sambrook, J., Russel, D.W. 2001. Molecular Cloning: A Laboratory Manual. 3ed. Cold Spring Harbor Laboratory Press, N.Y., p. A8.40-A8.51.

Santos, A.E., Bitondi, M.M.G., Simões, Z.L.P. 2001. Hormone-dependent protein patterns in integument and cuticular pigmentation in Apis mellifera during pharate adult development. J. Insect Physiol. 47, 1275-1282.

Santos, K.S., dos Santos, L.D., Mendes M.A., de Souza, B.M., Malaspina, O., Palma, M.S. 2005. Profiling the proteome complement of the secretion from hypopharyngeal gland of Africanized nurse-honeybees (Apis mellifera L.). Insect Biochem. Mol. Biol. 35, 85-91.

Silva-Zacarin, E.C., Silva de Moraes, R.L., Taboga,S.R. 2003. Silk formation mechanisms in the larval salivary glands of Apis mellifera. J. Biosci. 28, 753-764.

Scarselli, R., Donadio, E., Giuffrida, M.G., Fortunato, D., Conti, A., Balestreri, E., Felicioli, R., Pinzauti, M., Sabatini, A.G., Felicioli, A. 2005. Towards royal jelly proteome. Proteomics 5(3), 769-776.

Silvert, D. J. 1985. Cuticular proteins during postembryonic development. In: Kerkut, G.A., Gilbert, L.I. (Eds). Comprehensive Insect Physiology Biochemistry and Pharmacology,Vol. 2, pp. 239-254, Pergamon Press, Oxford, UK.

Smolka, M.B., Martins, D., Winck, F.V., Santoro, C.E., Casteralli, R.R., Ferrari, F., Brum I.J., Galembeck, E., Della Coletta Filho, H., Machado, M.A., Marangoni, S., Novello, J.C. 2003. Proteome analysis of the plant pathogen Xylella fastidiosa reveals major cellular and extracellular proteins and a peculiar codon bias distribution. Proteomics 3, 224-237.

Snodgrass, R.E. 1956. Anatomy of the honey bee. Cornell University, Ithaca, NY, USA.

Soares M.P.M. 2012. Genes cuticulares diferencialmente expressos durante eventos da metamorphose de Apis mellifera. Tese de Doutorado. Departamento de Biologia. Faculdade de Filosofia, Ciências e Letras de Ribeirão Preto, Universidade de São Paulo.

Soares, M.P., Elias-Neto, M., Simões, Z.L., Bitondi, M.M.G. 2007. A cuticle protein gene in the honeybee: expression during development and in relation to the ecdysteroid titer. Insect Biochem. Mol. Biol. 37, 1272-1282.

Soares, M.P.M., Silva-Torres, F.A., Elias-Neto, M., Nunes, F.M.F., Simões, Z.L.P., Bitondi, M.M.G. 2011. Ecdysteroid-dependent expression of the tweedle and peroxidase genes during adult cuticle formation in the honey bee, Apis mellifera. PLoS ONE $6(5)$, e20513. 
Sritunyalucksana, K., Wongsuebsantati, K., Johansson, M.W., Soderhall, K., 2001. Peroxinectin, a cell adhesive protein associated with the proPO system from the black tiger shrimp, Penaeusmonodon. Dev. Comp. Immunol. 25, 353-363.

Tang, L., Liang, J., Zhan, Z., Xiang, Z., He, N. 2010. Identification of the chitin binding proteins from the larval proteins of silkworm, Bombyx mori. Insect Biochem. Mol. Biol. 40, 228-234.

The Honeybee Genome Sequencing Consortium 2006. Insights into social insects from the genome of the honeybee Apis mellifera. Nature 443, 931-949.

Thompson, P.R. 1978. Histological development of cuticle in the worker honeybee, Apis mellifera adansonii. J. Apic. Res. 17, 32-40.

Thörnqvist, P.-O., Johansson, M.W., Söderhäll, K., 1994. Opsonic activity of cell adhesion proteins and b-1,3-glucan binding proteins from two crustaceans. Dev. Comp. Immunol.18, 3-12.

Togawa, T.; Nakato, H.; Izumi, S. 2004. Analysis of the chitin recognition mechanism of cuticle proteins from the soft cuticle of the silkworm, Bombyx mori. Insect Biochem. Mol. Biol. 34, 1059-1067.

Tozetto, S.O., Bitondi, M.M.G., Dallacqua, R.P., Simões, Z.L.P., 2006. Protein profiles of testes, seminal vesicles and accessory glands of honeybee pupae and their relation to the ecdysteroid titer. Apidologie 38, 1-11.

Wheeler, D. E., Buck, N., Evans, J. D. 2006. Expression of insulin pathway genes during the period of caste determination in the honey bee, Apis mellifera. Insect. Mol. Biol. $15,597-602$.

Willis, J.H., Iconomidou, V.A, Smith, R.F., Hamodrakas, S.J. 2005. Cuticular proteins. In: Gilbert, L.I., Iatrou, K., Gill, S.S. (Eds). Comprehensive Molecular Insect Science, vol. 4. , pp. 79-109, Elsevier Pergamon, Australia.

Willis, J. H., 2010. Structural cuticular proteins from arthropods: annotation, nomenclature, and sequence characteristics in the genomics era. Insect Biochem. Mol. Biol. 40, 189-204.

Winston, M.L. 2003. A biologia da abelha. Editora Magister, Porto Alegre.

Wittkopp, P.J., True, J.R., Carroll, S.B. 2002a. Reciprocal functions of the Drosophila Yellow and Ebony proteins in the development and evolution of pigment patterns. Development 129, 1849-1858.

Wolschin, F., Mutti, N.S., Amdam, G. V. 2011. Insulin receptor substrate influences female caste development in honeybees. Biol. Lett. 7, 112-115.

Zhao, X., Ferdig, M.T., Li, J., Christensen, B.M, 1995. Biochemical pathway of melanotic encapsulation of Brugia malayi in the mosquito Armigeres subalbatus. Dev. Comp. Immunol. 19, 205-215. 
Zitnan, D., Adams, M.E. 2005. Neuroendocrine Regulation of Insect Ecdysis. In: Gilbert, L.I., Iatrou, K., Gill, S. (Eds). Comprehensive Molecular Insect Science. Elsevier Press., Oxford, pp 1-60.

Zufelato, M.S., Lourenço, A.P., Simões, Z.L.P., Jorge, J.A., Bitondi, M.M.G. 2004. Phenoloxidase activity in Apis mellifera honey bee pupae and ecdysteroiddependent expression of the prophenoloxidase mRNA. Insect Biochem. Mol. Biol. $34,1257-1268$. 